UNIVERSIDADE DE SÃO PAULO

ESCOLA DE ENFERMAGEM

CRENÇAS DE PROFISSIONAIS DE CENTROS DE DOR SOBRE DOR CRÔNICA

Dayse Maioli Garcia

São Paulo

2006 
DAYSE MAIOLI GARCIA

\title{
CRENÇAS DE PROFISSIONAIS DE CENTROS DE DOR SOBRE DOR CRÔNICA
}

\author{
Dissertação (Mestrado) apresentada à Escola \\ de Enfermagem da Universidade de São \\ Paulo para obtenção do título de Mestre. \\ Orientadora: Profa. Dra. Cibele Andrucioli de \\ Mattos Pimenta
}

São Paulo 
Catalogação na publicação (CIP)

\section{Biblioteca "Wanda de Aguiar Horta" da EEUSP}

Garcia, Dayse Maioli.

Crenças de profissionais de Centros de Dor sobre dor crônica. / Dayse Maioli Garcia. - São Paulo: D. M. Garcia, 2006.

$100 \mathrm{p}$.

Dissertação (Mestrado) - Escola de Enfermagem da Universidade de São Paulo.

Orientadora: Prof ${ }^{\mathrm{a}}$ Dr $^{\mathrm{a}}$ Cibele Andrucioli de Mattos Pimenta

1. Dor 2. Atitude do pessoal de saúde 3. Conhecimento

4. Profissionais da saúde 5. Conhecimentos, Atitudes e Prática em Saúde. I. Título. 
Aos meus amigos, pela generosidade...

À minha irmã Cristina, pela coragem...

Ao meu filho Lucas, com quem aprendi o verdadeiro significado da vida. 


\section{Agradecimentos}

À Prof.Dra Cibele Andrucioli de Mattos Pimenta, minha orientadora, que com sua sabedoria, compreensão e confiança tornou possível a realização desta pesquisa, todo meu respeito e a minha gratidão.

Aos meus avós, meus pais Bernardino e Ilda, meus irmãos Paulo, Rubens, Cris, Dino e Carlos, minhas cunhadas, meus sobrinhos, meus tios, tias, primos e meu filho Lucas, pelos ensinamentos da vida, pelos verdadeiros valores e por compartilharem comigo a felicidade e alegria de uma família.

À Prof. Dra Eliane Correa, minha amiga desde a graduação, pela amizade, incentivo, confiança e contribuição.

À Prof.Dra Diná de Almeida Monteiro da Cruz, pela valiosa contribuição.

À Rita Ortega, figura única, fora do comum, pelo profissionalismo e alegria, pela amizade, apoio e paciência nas buscas bibliográficas intermináveis.

À Fernanda Raquel, pela amizade e disponibilidade, pelo incansável e precioso apoio durante a realização desta pesquisa.

À Beatriz Cordenunsi, Geana Paula Kurita e Dálete Delalibera Corrêa de Faria Mota, pela amizade, disponibilidade e ajuda em momentos difíceis.

Às colegas do Grupo de Pesquisa CNPq: Dor, Controle de Sintomas e Cuidados Paliativos, pelas sugestões e apoio.

A todos profissionais de saúde dos Centros de Dor, que participaram desta pesquisa.

À Diretoria de Senhoras do Hospital Sírio Libanês por me terem dado a oportunidade de me desenvolver profissionalmente nessa instituição. 
À Ivana Lúcia C. Pimentel de Siqueira, Superintendente de Atendimento e Operações do Hospital Sírio Libanês e Audry Elizabeth dos Santos, Gerente de Enfermagem do Hospital Sírio Libanês pelo apoio, incentivo e confiança.

Ao Dr João Valverde Filho, pelos ensinamentos, colaboração e por acreditar na minha capacidade profissional. Às enfermeiras Valéria Delponte, Suely Goto, Denise Alves e minha afilhada Fabiana, pela amizade e ajuda na tradução dos textos.

A todos amigos e colaboradores do Hospital Sírio Libanês, pelo apoio, incentivo, confiança e compreensão.

À Prof. Dra Eutália Aparecida Cândido de Araujo, pela valiosa contribuição na análise estatística.

À Prof. Lígia Fornari, pelas sugestões na redação final. Às minhas irmãs de alma Ciça e Vera por estarem sempre comigo. 


\section{RESUMO}

Garcia, D.M. Crenças de profissionais de Centros de Dor sobre dor crônica. São Paulo; 2006.

Os profissionais cuidam dos doentes de acordo com seus conceitos e crenças. Buscou-se analisar as crenças sobre dor crônica não oncológica dos profissionais de saúde que atendem doentes com dor crônica em Centros de Dor da cidade de São Paulo, por meio do Inventário de Atitudes frente à Dor-profissionais. Nove $(81,8 \%)$ dos onze Centros de Dor identificados concordaram em participar. Os profissionais preencheram ficha de caracterização pessoal, profissional e o Inventário de Atitudes frente à Dor-profissionais, adaptado do Inventário de Atitudes frente à dor-versão breve (IAD-breve), utilizado para doentes. Foram entrevistados 75 profissionais $(59,5 \%)$. A média de idade foi 42,8 anos ( $D P=10,5)$, a distribuição foi semelhante entre os sexos e o tempo médio de graduação foi 16 anos (DP=9,9). A maioria dos profissionais eram médicos $58,7 \%$, seguidos pelos fisioterapeutas $(42,7 \%)$ e dentistas $(10,7 \%)$. A maioria $(42,7 \%)$ possuía especialização e $26,7 \%$, mestrado ou doutorado. Sessenta por cento dos profissionais auto-avaliaram sua experiência com doentes com dor crônica como mediana e 44,0\% relataram atender mais que 20 doentes ao mês. O IAD-versão profissional foi validado com 20 itens, a análise fatorial confirmou 6 domínios (emoção, controle, incapacidade, solicitude, cura médica e dano físico) e a confiabilidade dos domínios, avaliada por meio do alfa de Cronbach, variou entre 0,567 a 0,807, valores considerados moderados e bons. Os profissionais mostraram crenças "fortemente desejáveis" nos domínios controle $(3,1)$ e emoção $(3,7)$ e "moderadamente desejáveis" nos domínios dano físico $(1,2)$ e incapacidade $(1,5)$; crença "fortemente não desejável" foi encontrada no domínio cura médica $(3,4)$ e "moderadamente não desejável" no domínio solicitude $(2,5)$. Visando identificar se diferenças nas crenças poderiam estar relacionadas às características demográficas e profissionais, foram compostos 3 clusters: médicos/ pós-graduados; não médicos/especializados/ pouco experiente e graduados/dor crônica oncológica. A comparação entre os clusters não mostrou diferenças estatisticamente significantes. A inexistência de diferenças indicou que variáveis como profissão, sexo, idade, nível de escolaridade e de experiência não influiu nas crenças dos profissionais frente à dor crônica. As crenças "indesejáveis" manifestadas pelos profissionais de que solicitude é desejável e que se pode esperar cura para dor crônica não oncológica indicam a necessidade de incorporação de novos conceitos na prática clínica. Crenças não adequadas podem levar a equívocos na condução no tratamento como reforçar expectativas irrealistas, aumentar a incapacidade e a dependência.

Palavras chave: dor crônica, crenças, avaliação, instrumento, conhecimento, profissionais de saúde. Atitudes, atitudes do pessoal de saúde. 


\begin{abstract}
Garcia DM. Beliefs of Health Professionals in Pain Clinics regarding chronic pain. Sao Paulo; 2006.

Health professionals assist patients according to their concepts and beliefs. This study analyzed the beliefs of health professionals who assist patients with nonmalignant chronic pain, in different Pain Clinics in Sao Paulo - Brazil, using the Pain Attitude Inventory - Professionals. Nine (9) out of 11 Pain Clinics, (81.8\%) identified in Sao Paulo, agreed to participate. The professionals completed a Personal and Professional Characterization Profile and the Pain Attitude Inventory Professionals, adapted from the Survey of Pain Attitudes-Brief (SOPA-B). Seventy five (75) professionals were interviewed $(59.5 \%)$. The mean age was 42.8 years $(S D=10.5)$, the distribution regarding gender was similar, and they had a mean of 16 years $(S D=9.9)$ since graduation; the majority were physicians $(58.7 \%)$, followed by physical therapists $(42.7 \%)$ and dentists $(10.7 \%)$; many of the respondents had completed specialization courses $(42.7 \%)$, and $26.7 \%$ had a master or doctorate degree; $60 \%$ of the professionals self-assessed their experience with patients with nonmalignant chronic pain as moderate and $44.0 \%$ stated that they assist over 20 patients per month. The Pain Attitude Inventory - Professionals was validated with 20 items, the factorial analysis confirmed 6 domains (emotion, control, disability, solicitude, cure and harm), and the reliability of the domains, assessed by Chronbach's alfa, ranged from 0.567 and 0.807 , values which are considered moderate to good. The professionals showed beliefs that were "strongly desirable" in the control (3.1), and emotion (3.7) domains, and "moderately desirable" beliefs in the harm (1.2), and disability (1.5) domains; and "strongly undesirable" beliefs in the cure domain (3.4) and finally "moderately undesirable" beliefs in the solicitude domain (2.5). In order to identify if differences in beliefs could be related to demographic and professional characteristics, three (3) clusters were formed: physicians/post-graduation; non-physicians/specialization courses/ little experience; and graduates/ oncology pain. The comparison between these clusters did not show any statistically significant differences. This inexistence of differences indicated that variables such as profession, gender, age, educational level and years of professional experience did not influence the beliefs of health professionals concerning chronic pain. The "undesirable" beliefs expressed by the health professionals, that "solicitude" is desirable and that a cure for nonmalignant chronic pain is highly possible, indicate that there is a need for the incorporation of new concepts in clinical practice. Inadequate beliefs can mislead the conduction of treatment as well as reinforce unrealistic expectations, and cause increases in incapacity and dependence.
\end{abstract}

Key-words: chronic pain, beliefs, assessment, instrument, knowledge, health professionals, attitudes, attitudes of health professionals. 


\section{LISTA DE QUADRO}

Quadro 1 - Conhecimento e crenças dos profissionais sobre dor crônica não oncológica. São Paulo, 2006

\section{LISTA DE FIGURA}

Figura 1 - Percentual de respondentes por Centros de Dor. São Paulo, 2006 38

\section{LISTA DE TABELAS}

Tabela 1 - Caracterização da amostra (n=75). São Paulo, 2006. 45

Tabela 2 - Análise Fatorial, correlações entre itens e 7 domínios, do IADprofissionais pré-teste. São Paulo, 2006

Tabela 3 - Análise Fatorial, correlações entre itens e 6 domínios, do IADprofissionais. São Paulo, 2006

Tabela 4 - Proposição de domínios e itens. São Paulo, 2006 50

Tabela 5 - Análise de consistência ( $\alpha$ de Chronbach) de cada domínio do IADprofissionais. São Paulo, 2006

Tabela 6 - Análise da freqüência de respostas do Inventário de Atitudes Frente à Dor, por item e por categoria. São Paulo, 2006.

Tabela 7 - Estatística descritiva das crenças dos profissionais. São Paulo, 2006.54

Tabela 8 - Distribuição dos profissionais por grupos.São Paulo, 2006. 56

Tabela 9 - Características sócio-demográficas, de formação e de experiência dos grupos. São Paulo, 2006

Tabela 10 - Comparação das crenças (domínios) entre os clusters. São Paulo, 2006 


\section{SUMÁRIO}

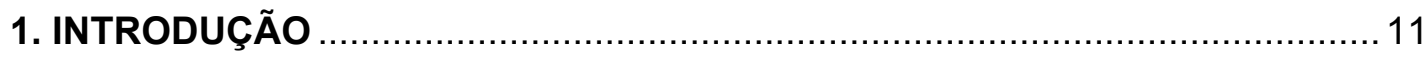

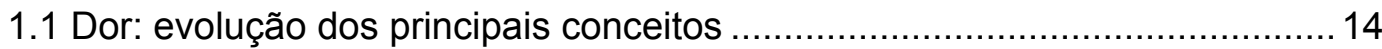

1.2 Dor Crônica: conceitos básicos e crenças dos profissionais......................... 17

1.2.1 Dor crônica oncológica ......................................................... 18

1.2.2 Dor crônica não oncológica ........................................................ 21

1.3 Instrumentos utilizados para investigação das crenças sobre dor crônica não oncológica entre profissionais da saúde.......................................... 31

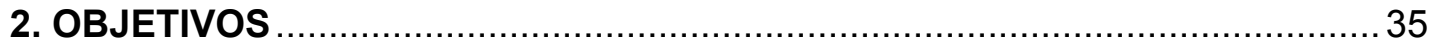

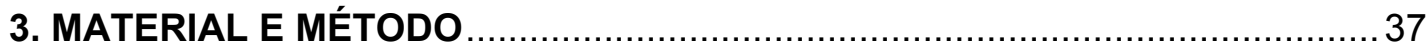

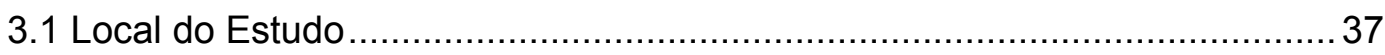

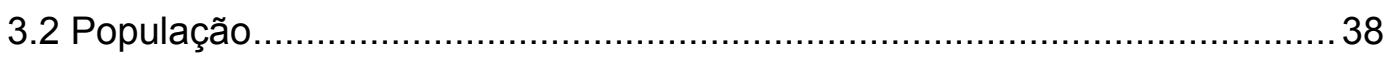

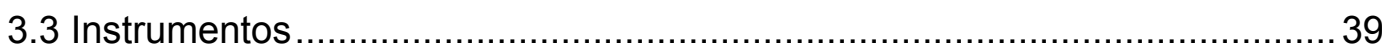

3.3.1 Adaptação do Inventário de Atitudes frente à Dor-profissionais........... 40

3.4 Procedimentos de coleta e aspectos éticos .............................................. 42

3.5 Organização e análise dos dados ........................................................... 43

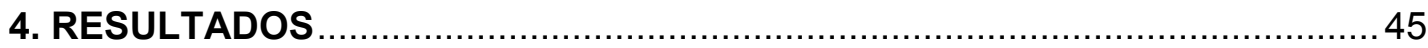

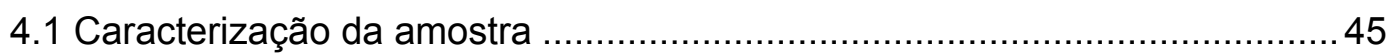

4.2 Validação do Inventário de Atitudes Frente à Dor - versão profissionais ...... 46

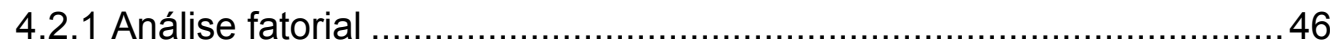

4.2.2 Análise de Consistência ............................................................. 50

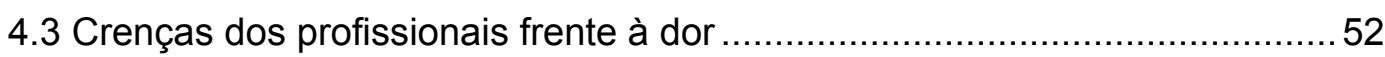

4.4 Análise de Cluster ............................................................................... 56

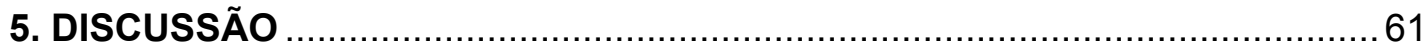

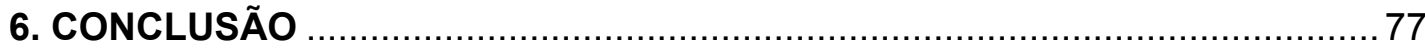

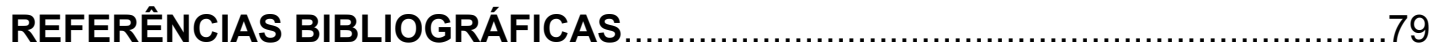

ANEXOS 
Introdução 


\section{INTRODUÇÃO}

Os profissionais da saúde cuidam dos doentes de acordo com o que conhecem e acreditam, isto é, de acordo com seus conceitos e crenças.

Vários estudos ${ }^{1-11}$ mostram que o conhecimento e as crenças dos profissionais interferem na avaliação e nos tratamentos que administram e que a discrepância entre a expectativa do profissional e o relato do doente pode ser fator de falha no adequado controle da dor. Por exemplo, o profissional espera que o doente com dor apresente lesões, alterações físicas como as de sinais vitais, choro, gemido, caretas, comportamentos que não são comuns na dor crônica. Se o doente não age como se estivesse com dor, ou se nenhuma causa física é encontrada, muitos profissionais tendem a não considerar na íntegra o relato do doente.

A experiência pessoal do profissional também pode afetar a avaliação que ele faz da pessoa com dor. Enfermeiros que já sofreram dor intensa são mais disponíveis a considerar relatos de intensidade mais alta de dor ${ }^{4}$.

A subjetividade da dor, associada a crenças inadequadas dos profissionais de saúde, pode resultar em tratamento baseado em opinião pessoal.

Em dor aguda, muitos são os estudos mostrando a deficiência na formação dos profissionais, a existência de crenças errôneas e de atitudes "negativas" no manejo da dor. Há numerosas descrições sobre o desconhecimento da fisiopatologia da dor, dos métodos de avaliação e registro das características da dor e da analgesia, dos métodos de tratamento disponíveis, da farmacologia dos analgésicos, do medo excessivo dos efeitos indesejáveis dos opióides como depressão respiratória, dependência psíquica e tolerância. Há grande número de relatos sobre os medos e a relutância dos pacientes em pedir analgésicos e sobre a 
incompleta responsabilização dos profissionais na condução do tratamento de modo a se obter adequado alívio da dor ${ }^{1,7,8,11-27}$.

Em dor oncológica, há diversos estudos que exploram o conhecimento e as crenças dos profissionais da saúde. O desconhecimento dos princípios do manejo da dor do câncer, a aceitação da dor como fato que acompanha o câncer, a dificuldade em acreditar na queixa de dor do doente, o sentimento de impotência diante da dor, o desconhecimento da escada analgésica da Organização Mundial da Saúde, o temor exagerado do desenvolvimento de "vício", a confusão entre os conceitos de dependência física, dependência psicológica e tolerância, a possibilidade de depressão respiratória, a super estimação da ação da morfina, o desconhecimento das propriedades farmacológicas dos opióides e da equivalência analgésica são algumas barreiras que parecem manter a dor e o sofrimento dos doentes com câncer ${ }^{1-9,28-61}$.

No entanto, as crenças dos profissionais de saúde sobre dor crônica não oncológica são ainda pouco conhecidas, pois vários estudos ${ }^{62-}$ ${ }^{87}$ enfatizam a questão do conhecimento e não as crenças. Não há estudo nacional sobre o tema e conhecer as crenças dos profissionais sobre dor crônica não oncológica é o objetivo desse trabalho.

Diferenciar conhecimento de crença é difícil, apesar de constituírem modos distintos de atividade mental e de apresentarem origens diferentes, são complementares e não opostos. A crença é um "entendimento" inconsciente, construído a partir de associações não verdadeiras. Conhecimento representa uma aquisição consciente, edificada por métodos exclusivamente racionais, como a experiência e a observação ${ }^{88-90}$.

Saber e crer são coisas distintas, mas não opostas. Enquanto a aquisição da menor verdade científica exige enorme labor, a posse de uma certeza baseada no "crer" não exige nenhum trabalho. A aquisição de 
conhecimento é condição necessária para a modificação de crença, mas não é condição suficiente ${ }^{88-90}$.

A crença direciona a atribuição de significado aos fatos, idéias, pessoas e à maneira de proceder ${ }^{88-90}$.

Conhecimento, nesse estudo, será definido como aquele resultante de instrução formal, adquirido na academia ou em situações correlatas (auto-instrução, congressos etc.); o que é específico do profissional e que não se espera que um leigo saiba, como por exemplo, o risco de um opióide causar dependência, as doses adequadas dos analgésicos, as síndromes dolorosas mais comuns etc. A análise do conhecimento dos profissionais sobre dor e analgesia não será objeto deste estudo.

Crença será enfocada sob o olhar da Terapia Comportamental Cognitiva e definida como concepções muito antigas, culturalmente compartilhadas; noções pré-existentes sobre a natureza da realidade que molda nossa percepção de nós mesmos, dos outros e de nosso ambiente; crenças são consideradas pelas pessoas como verdades absolutas ${ }^{90,}{ }^{91}$. As crenças "residem" na cognição e predispõem a comportamentos ${ }^{89}$.

Atitudes são disposições afetivas, relativamente estáveis, que implicam a tendência a responder a idéias (crenças), pessoas, instituições ou eventos de um certo modo, de reagir ao alvo ou objeto (crença, ideal, símbolo, frase, pessoa, instituição, idéia, qualquer coisa existente para o indivíduo) de forma positiva ou negativa. É a preparação ou prontidão para a ação. Atitudes são culturalmente aprendidas e organizadas pela experiência ${ }^{91}$.

Para a análise da literatura sobre crenças e atitudes dos profissionais de saúde frente à dor crônica não oncológica, foi realizada busca bibliográfica no MEDLINE, LILACS e BDEnf utilizando-se as palavraschaves em inglês e/ou em português, conforme descrito: 
- MEDLINE: Professional Practice OR Professional Competence OR Nursing, Team OR Health Personnel AND Beliefs OR Knowledge OR Misconception, sendo todos associados aos descritores chronic pain. A análise abrangeu o período de março de 1960 a maio de 2006.

- LILACS: Dor AND Profissional AND Crença OR Crenças OR Conhecimento, sendo todos associados ao descritor crônica, no período de janeiro de 1982 a maio de 2006.

- BDEnf: Dor AND Crença OR Crenças OR Conhecimento, sendo todos associados ao descritor crônica, no período de 1988 a maio de 2006.

Foram identificados 127 títulos e destes foram selecionados 26 artigos que avaliaram, por meio de questionário, conhecimento, crenças e atitudes de profissionais da saúde em relação à dor crônica não oncológica. Foram excluídos 77 artigos por não se relacionarem ao tema, 14 por serem artigos de atualização e 3 artigos em Norueguês.

\subsection{Dor: evolução dos principais conceitos}

A dor e o medo são sofrimentos dos mais primitivos do homem, diante dos quais ele fica muito indefeso, ao contrário do que ocorre com a fome e o frio, situação com as quais ele lida melhor ${ }^{92}$.

Aristóteles (384 a 322 aC.) dizia ser a dor e o prazer paixões da alma. Imaginava que a dor sentida no coração seria uma qualidade ou paixão do espírito, um estado de sentimento, uma experiência oposta ao prazer e a síntese do desprazer, isto é, julgava ser a dor uma emoção e não uma sensação. Essa teoria foi aceita por mais de 2000 anos e talvez tenha atrasado os estudos neurofisiológicos sobre o fenômeno doloroso. Nesse enfoque, dor seria uma vivência resultante de processos emocionais e de interesse apenas dos profissionais de saúde mental ${ }^{93,94}$. 
Em 1644, Descartes propôs a Teoria da Especificidade da Dor, que previa que para cada estímulo haveria um receptor específico, uma via de condução única e que seria interpretado em um centro de dor no sistema nervoso central. Essa teoria teve e tem grande influência no modo de os profissionais compreenderem o que é dor. Nesse modelo há que haver lesão para existir dor e o tamanho da lesão estaria diretamente relacionado à vivência de dor. A partir do século XIX, os avanços da fisiologia corroboraram com a compreensão de que dor seria uma sensação, e a opinião dos filósofos de que dor seria só emoção foi posta de lado ${ }^{93,94}$.

No século XX, em 1965, Melzack e Wall ${ }^{95}$ propuseram a Teoria da Comporta da Dor, que previa que dor seria uma sensação e uma emoção, que fatores físicos, emocionais e cognitivos participavam na gênese e modulação da sensação dolorosa, isto é, dor seria resultante da interação de todos esses fatores, que poderiam atuar como facilitadores ou inibidores da sensação dolorosa. A partir da Teoria da Comporta de Dor volta-se a considerar o componente psicológico ou reativo da sensação dolorosa, reconhecendo a emoção como fator importante na dor, agregada aos aspectos físicos e cognitivos.

A Teoria da Comporta da Dor forneceu a estrutura teórica que explicou a integração de estímulos periféricos aos fenômenos corticais e afetivos. Esse modelo teórico prevê que, no corno posterior da substância cinzenta da medula espinhal e em outras estruturas rostrais do sistema nervoso central, ocorre modulação da dor ${ }^{95,96 .}$

Assim, a informação dolorosa é transmitida da periferia ao sistema nervoso central e, ao atingir as estruturas encefálicas, interage com fatores emocionais e culturais que podem interferir e modificar a percepção da informação inicial. A experiência dolorosa resulta então da interpretação dos aspectos físico-químicos do estímulo nocivo e da sua interação com os fatores emocionais e culturais individuais que estejam de alguma forma relacionados à dor, tais como humor, crenças, experiências anteriores, 
atitudes, conhecimentos e significado simbólico atribuído à queixa dolorosa, entre outros ${ }^{95-97}$.

Considerando a dualidade alma/corpo e baseados na Teoria da Comporta da Dor, autores propuseram uma definição para dor que abrangesse os dois aspectos e que serviu como base para a definição proposta pela Associação Internacional para Estudos da Dor (IASP) em 1979: "Dor é uma experiência sensorial e emocional desagradável, associada a um dano real ou potencial dos tecidos, ou descrita em termos de tais danos. Cada indivíduo aprende a utilizar este termo através de suas experiências anteriores"2.

Por essa definição percebemos que a relação entre dor e lesão tecidual não é direta nem exclusiva, que os aspectos sensitivos, emocionais e culturais estão imbricados de modo indissociável, e que a dor é uma experiência subjetiva e pessoal ${ }^{1,2,95}$. Esses conceitos são essenciais para a compreensão do que seja dor, para a definição dos domínios que a compõem, de quais métodos devem ser utilizados na sua avaliação e quais as estratégias para o seu controle ${ }^{2}$.

Os conceitos que os profissionais têm sobre dor nem sempre são os mais precisos. A falta ou pequena educação formal sobre dor nas escolas de saúde leva a que os profissionais trabalhem com conceitos incompletos, algumas vezes ultrapassados ou mesmo errôneos, embora façam parte do senso comum.

Em estudos realizados em nosso meio com médicos, profissionais de enfermagem, profissionais de farmácia e doentes, observou-se que muitos mitos e fantasias sobre dor e os métodos para seu controle, expressos por grande número de doentes e profissionais de saúde, sugerem que esses conceitos são arraigados aos indivíduos durante a educação familiar e escolar básica e que não necessariamente se modificam com a educação intermediária e superior especializada. Muitos imaginam que a dor pode não ser controlada. Doentes e profissionais admitem que a dor é 
necessária para o diagnóstico das doenças. O tratamento da causa e não dos sintomas é prioritário para alguns. Os mecanismos da analgesia, os métodos de administração de fármacos, as vantagens de usar a medicação de forma preventiva, parecem ser desconhecidos pelos profissionais de enfermagem. Essa última é também compartilhada pelos doentes. A suposta dependência advinda do uso de analgésicos é também preocupação comum aos doentes e profissionais ${ }^{7,98}$.

\subsection{Dor Crônica: conceitos básicos e crenças dos profissionais}

Dor crônica é aquela que persiste após o tempo razoável para a cura de uma lesão ou que está associada a processos patológicos crônicos que causam dor contínua ou recorrente. Não tem mais a função de alertar o organismo sobre a agressão, sendo mal delimitada no tempo e no espaço. Geralmente não há respostas neurovegetativas associadas e a ansiedade e depressão são respostas emocionais freqüentemente associadas ao quadro $^{2}$. Dor crônica é aquela que persiste de modo contínuo ou recorrente há mais de três meses, para fins clínicos, e seis meses para fins de pesquisa $^{99}$

"Dor crônica é um quadro complexo no qual elementos biológicos, emocionais e socioculturais estão imbricados de modo indivisível na determinação, na apreciação e na expressão do fenômeno doloroso. Dor crônica é mais do que um sintoma. É a doença que persiste. É aquela que não desaparece após a cura da lesão ou que está relacionada a processos patológicos crônicos. Sua presença constante ou intermitente, e a duração prolongada em geral são muito perturbadoras para quem a sente. Acarreta alterações nas atividades físicas, no sono, na vida sexual e no humor; associa-se a baixa auto-estima, distorções cognitivas, apreciação desesperançada da vida, reações familiares conflituosas, prejuízo no trabalho e no lazer"96. 
A dor crônica, quanto a etiopatogênia, pode ser neuropática, nociceptiva ou mista. Dor neuropática ou por desaferentação ocorre quando há lesão parcial ou total das vias nervosas do sistema nervoso central ou periférico como as decorrentes de neuropatia dolorosa por diabetes, herpes zoster, acidente vascular cerebral, invasão de estruturas nervosas por tumores, entre outras. Dor nociceptiva é aquela em que há elevada síntese de substancias algiogênicas e intensa estimulação das fibras nociceptivas, tal como ocorre nas situações de doenças inflamatórias, traumáticas ou isquêmicas ${ }^{2}$. A dor crônica mista é aquela com componentes nociceptivos e neuropáticos, como a maioria das dores oncológicas, as dores articulares, entre outras ${ }^{94}$.

A dor crônica pode ser dividida em dor crônica oncológica e não oncológica, pois embora ambas sejam dores crônicas, há características diferentes.

\subsubsection{Dor crônica oncológica}

Entre as síndromes dolorosas, a dor relacionada ao câncer é uma das mais importantes. Apesar de o número total de doentes com dor relacionada ao câncer ser menor do que 3\% da população com dor aguda ou crônica, a dor do câncer tem um significado especial para o doente e sua família. A dor relacionada ao câncer afeta cerca de 9 milhões de pessoas no mundo, anualmente, e seu controle é geralmente inadequado. Como resultado, muitos doentes vivem as últimas semanas, meses e até anos de suas vidas em grande desconforto, sofrimento e incapacidade ${ }^{100}$.

"A dor relacionada ao câncer pode ser aguda ou crônica. Quando aguda geralmente resulta de ações diagnósticas ou terapêuticas. A dor crônica está relacionada ao tumor ou suas metástases em cerca de $2 / 3$ dos casos e deve-se à invasão óssea ou neural, infiltração de tecidos moles, compressão ou oclusão de vasos sanguíneos e vísceras ocas. Em aproximadamente $1 / 5$ dos casos a dor crônica resulta de terapias 
antineoplásicas, como as decorrentes de lesões actínicas". Em grande número de doentes, múltiplas causas concorrem para a ocorrência de dor. Embora as dores sejam mistas, sempre há um predomínio e nos doentes oncológicos este quase sempre é de aumento da nocicepção ${ }^{97}$.

Dentre as síndromes álgicas, as que se manifestam nos doentes com câncer são as mais incapacitantes. A dor é menos freqüente nas fases iniciais da doença, sendo observada em $20 \%$ a $50 \%$ dos casos quando do diagnóstico e em $70 \%$ a $90 \%$ dos indivíduos com doença neoplásica avançada $^{28,94,97}$.

A ocorrência de dor, no doente com câncer, depende das características da doença e do doente. Pimenta ${ }^{101}$ observou relatos de dor mais intensa em doentes com crenças de que a dor do câncer não pode ser controlada e que remédios são perigosos, entre outras. Esse estudo confirmou a hipótese de que as crenças repercutem na vivência do quadro doloroso e mostra resultados coerentes com a concepção de que aspectos psicossocioculturais, entre eles os relacionados à atitude, influenciam o modo de o doente perceber, expressar e lidar com a dor. Assim, medos infundados sobre tolerância e dependência aos analgésicos, crenças errôneas relativas à impossibilidade de alívio da dor oncológica ou crenças de que a dor é sempre sinal de piora da doença estão relacionados com queixa álgica de maior intensidade.

O alívio da dor no câncer é uma das prioridades da Organização Mundial da Saúde. Com o objetivo de estabelecer parâmetros para o controle da dor no câncer, publicou o Guia para Tratamento da Dor no Câncer, composto por três princípios: pela boca, pelo relógio e pela escada analgésica. Porém, quando esse método não é usado, milhões de doentes morrem com dor não controlada, sendo esse sofrimento na maioria das vezes desnecessário, pois mais de $90 \%$ dos casos de dor no câncer podem ser tratados efetivamente ${ }^{28,94}$. 
Em estudo realizado no Brasil com profissionais de enfermagem, farmácia e médicos, percebeu-se, pelas respostas obtidas, 0 desconhecimento sobre dor crônica oncológica. A maior parte dos profissionais de enfermagem entrevistados (58,3\%) acreditavam que o desenvolvimento de dependência psíquica, nesse tipo de doente é comum; julgavam, erroneamente, que administrar os medicamentos em regime de demanda previne tolerância e dependência psíquica; ainda 42,1\% julgavam que só se devem administrar estes fármacos a pacientes terminais. Dos médicos entrevistados, apenas uma pequena porcentagem referiu utilizar derivados morfínicos e empregar associações medicamentosas em doentes terminais. Conceitos errôneos e a falta de informação dos profissionais de enfermagem podem levá-los a adiar o início da administração desses medicamentos, espaçar os intervalos de administração e julgar que os doentes desenvolvem dependência psicológica muito acima do usual. O desconhecimento dos médicos, os mitos e fantasias; o medo da depressão respiratória, da tolerância e da dependência; a dificuldade para prescrição e aquisição de alguns desses agentes são, entre outras, as razões pelas quais muitos dos profissionais ainda relutam em prescrever esses agentes farmacológicos e quando o fazem ainda podem empregá-los em doses menores do que as necessárias ou a intervalos inadequados ${ }^{7}$.

Elliot et al. ${ }^{35}$ pesquisaram 145 médicos em Minnesota para determinar a extensão dos déficits no conhecimento no manejo da dor no câncer e as atitudes que poderiam ser barreiras para o tratamento efetivo. Médicos demonstraram déficit significativo no conhecimento em 9 das 14 áreas pesquisadas. As nove áreas eram representadas através dos seguintes conceitos: tolerância por opióides raramente é um problema; risco de adição é baixo nos doentes com câncer; tolerância para os efeitos colaterais dos opióides geralmente ocorre; dor associada ao câncer pode ser evitada; doses de opióides estão relacionadas ao nível de dor, não à tolerância; doses de opióides são relacionadas à intensidade da dor, não à gravidade da doença; adição não é igual a dependência física; a via oral é efetiva e antidepressivos são efetivos como drogas analgésicas adjuvantes. 
Os únicos problemas atitudinais identificados relacionavam-se a preocupações com relação a efeitos colaterais dos opióides e a eficácia dos tratamentos não-farmacológicos da dor. Esses resultados foram também encontrados por $\mathrm{Ger}^{51}$ e $\mathrm{Yu}^{54}$.

As crenças dos profissionais de saúde em relação à dor crônica oncológica não é objetivo dessa pesquisa.

\subsubsection{Dor crônica não oncológica}

A dor crônica não oncológica é aquela que persiste após o tempo razoável para a cura de uma lesão ou que está relacionada a processos patológicos crônicos que causam dor contínua ou recorrente ${ }^{2}$. As dores crônicas mais freqüentes são cefaléia, lombalgia, artralgias, dores em membros inferiores, dores miofasciais e dores neuropáticas, como as da neuropatia diabética e herpes zoster, entre outras. Estudos desenvolvidos no Brasil, em que se analisou população não vinculada ao serviço de saúde, observou-se dor recorrente em $28,75 \%$ das crianças. As dores mais freqüentes foram dor de cabeça $(15,96 \%)$, seguida de dor nos membros $(6,99 \%)$ e dor abdominal $(6,78 \%)^{102}$. Entre os adultos avaliados, observou-se dor crônica em $61,38 \%$ deles; dor de cabeça foi a mais prevalente $(26,36 \%)$, seguida de dor lombar $(19,4 \%)$ e em membros inferiores $(13,26 \%)^{103}$. Nos idosos investigados, dor crônica ocorreu em 51,44\%; as dores mais freqüentes foram localizadas no dorso (21,73\%), membros inferiores $(21,50 \%)$, em região cefálica $(7,09 \%)^{104}$.

No Brasil, as dores consideradas mais incapacitantes são as lombalgias, as cefaléias, as epigastralgias e a dor músculo-esquelética generalizada. Aproximadamente $85 \%$ da população apresenta dor indefinida, possivelmente músculo-esquelética e cefaléias ${ }^{94}$.

A eliminação total da sensação dolorosa é possível nos quadros de dor aguda, porém não é o principal objetivo da maioria das intervenções realizadas em dores crônicas. Estudos demonstram que o comportamento 
de alguns doentes com dor crônica está relacionado ao aprendizado baseado na experiência que tiveram com a dor aguda. $E$, de fato, nas situações de dor aguda, o comportamento envolve a imobilização da área afetada, a diminuição da atividade geral, a compreensão de que há algo errado com o organismo e a emissão de comportamentos de dor como choro, gemidos e "caretas" para obter ajuda. Ainda, comportamentos de solicitude das pessoas para com o indivíduo com dor, freqüentemente, estão presentes, visto a necessidade de restrição da área lesada e duração limitada do agravo. Mas, em inúmeros casos de dor crônica, não há mais lesão ou essa não é proporcional à queixa, a ajuda profissional na maioria dos casos já foi obtida, a restrição à movimentação é contra-indicada e a excessiva solicitude de outrem quando da manifestação da dor contribui para a incapacidade, visto que a duração do quadro é imprevisível ${ }^{63}$.

Loder, Witkower, McAlary e Huhta ${ }^{105}$, num estudo objetivando o desenvolvimento de um projeto educacional num hospital de reabilitação americano, pesquisaram as atitudes e conhecimentos dos profissionais envolvidos com controle da dor crônica. Os resultados apontam que muitos conceitos sobre o que constitui o manejo adequado da dor são derivados de modelos de dor aguda e oncológica, onde há uma forte ênfase no uso de medicações, especialmente opióides, com menor ênfase em métodos não farmacológicos, físicos e comportamentais.

Clarke, French, Bilodeau, Capasso, Edwards e Empoliti ${ }^{62}$, num estudo examinando o conhecimento, atitudes e prática clínica de 120 enfermeiras num hospital de ensino em Massachusetts, revelam que a formação educacional das enfermeiras é inadequada nas áreas de intervenções não farmacológicas para o alívio da dor, na diferença entre dor aguda e crônica e na anatomia e fisiologia da dor. As maiores barreiras relatadas pelas enfermeiras para o manejo da dor foram a relutância dos pacientes em relatar dor e tomar opióides para o alívio da dor. Esse estudo avaliou também os registros de enfermagem em relação à documentação da avaliação da dor e verificou que $76 \%$ dos prontuários tinham falhas. A 
utilização de instrumentos de auto-relato para avaliação da dor também se mostrou incompleta, apesar de as enfermeiras referirem fazer uso desses instrumentos. Foi observado também que $90 \%$ dos prontuários não registravam o uso de intervenções não-farmacológicas para alívio da dor.

Latimer, Maher, Refshauge ${ }^{81}$, em estudo explorando as atitudes e crenças dos estudantes de fisioterapia sobre lombalgia, através do HCPAIRS, identificou que as atitudes e crenças dos estudantes que não tiveram um módulo de ensino sobre lombalgia são similares às dos cuidadores não profisionais.

Tarzian e Hoffman ${ }^{82}$, explorando as barreiras para o manejo da dor em casas de repouso, identificou que médicos e enfermeiras têm falta de conhecimento sobre manejo da dor crônica e baixa aceitação do uso de tratamentos padronizados; os médicos se baseiam em atitudes pessoais para prescreverem opióides, falham no diagnóstico preciso da dor e apresentam dificuldades na escolha do analgésico correto.

Daykin e Richadson ${ }^{83}$, em estudo qualitativo com fisioterapeutas, evidenciaram que as crenças sobre dor desses profissionais podiam influenciar no tratamento que eles administravam aos doentes.

A preocupação em conhecer e mensurar as crenças e atitudes dos doentes com dor crônica iniciou-se na década de 80, pois surgiram indícios de que as atitudes poderiam influir na habilidade do doente em lidar com a dor, na adesão ao plano terapêutico, na capacidade funcional, na aceitação do quadro, no ajustamento social e nos resultados das intervenções. Passou-se a recomendar a organização de estratégias que possibilitassem conhecer as atitudes, crenças e expectativas dos doentes sobre sua dor de modo rotineiro ${ }^{106}$.

Em estudo realizado no Brasil, Pimenta ${ }^{96}$ observou as atitudes de 69 doentes utilizando o Inventário de Atitudes frente a Dor - versão breve, validado para a língua portuguesa pela autora em 1999. O inventário 
permitiu a avaliação das atitudes diante de sete domínios da experiência dolorosa crônica: dano físico, medicação, solicitude, controle, emoção, incapacidade e cura médica. Uma parcela dos doentes $(41,7 \%)$ disse acreditar na influência pessoal no controle da dor, metade considerou-se favorável à solicitude de outros durante sua manifestação de dor, $51 \%$ julgaram que a dor significa dano físico e 56,9\% reconheceram haver relação entre suas emoções e a intensidade da dor. Ainda, $57,5 \%$ relataram que a dor incapacita $63,3 \%$ acreditavam que medicamento é o melhor tratamento para o controle da dor e $73,8 \%$ acreditavam na existência de cura médica para dor crônica. Não crer na sua influência pessoal sobre a dor, julgar desejável comportamento de solicitude, crer que dor representa dano tecidual, não reconhecer a relação entre emoção e dor, julgar que dor é incapacitante, acreditar que medicamento é o melhor tratamento para dor crônica e esperar sempre cura médica para dor crônica são crenças pouco adaptativas. Essas mesmas atitudes foram avaliadas em dois momentos: logo após a admissão no serviço e entre 6 a 15 meses após o início do tratamento em serviço de dor e não se observaram diferenças estatisticamente significativas. Isso significa que as atitudes dos doentes diante da dor não se modificaram com o tempo.

O conhecimento, as crenças e as atitudes da equipe de saúde são fundamentais para o manejo adequado da dor crônica. "A equipe deve objetivar o controle dos sintomas, normalizar ou restaurar os componentes físicos, psíquicos e sociais, maximizar os potenciais remanescentes, prevenir a deterioração das condições físicas e psíquicas, desenvolver a autoconfiança e encorajar a execução de atividades. Visa-se a eliminar o medo de que novas lesões possam se instalar, corrigir os desajustamentos familiares, sociais e profissionais que contribuem para o sofrimento e para a incapacidade e promover o uso criterioso de medicamentos bem como a independência do sistema de saúde “63.

Apesar de todo o avanço no conhecimento da fisiopatologia da dor, nos métodos de tratamento e das recomendações propostas por 
organizações internacionais como American Pain Society (APS), World Health Oraganization (WHO), Agency for Health Care Policy and Research (AHCPR), entre outras, o controle da dor no mundo continua sendo insatisfatório. Apontam-se conhecimentos insatisfatórios e crenças inadequadas dos profissionais sobre dor crônica como causas desse inadequado manejo.

O Quadro 1 apresenta síntese dos estudos sobre conhecimento, crenças e atitudes dos profissionais de saúde em relação à dor crônica não oncológica. 
Quadro 1 - Conhecimento e crenças dos profissionais sobre dor crônica não oncológica. São Paulo, 2006.

\begin{tabular}{|c|c|c|c|c|c|}
\hline AUTOR & TITULO & ANO & TIPO DE ESTUDO & INSTRUMENTO & RESULTADOS \\
\hline Dixon BA. ${ }^{66}$ & $\begin{array}{l}\text { Institucional survey of nurse } \\
\text { anesthesia practice in patients } \\
\text { receiving opioids via patient- } \\
\text { controlled analgesia. }\end{array}$ & 1993 & $\begin{array}{l}\text { Retrospectivo } \\
\text { exploratório }\end{array}$ & Questionário & $\begin{array}{l}\text { Enfermeiros e anestesistas não têm } \\
\text { conhecimento adequado nem do uso da PCA, } \\
\text { nem de drogas adjuvantes para a dor crônica. }\end{array}$ \\
\hline $\begin{array}{l}\text { Glaros AG, Glass EG, } \\
\text { McLaughlin L. }\end{array}$ & $\begin{array}{l}\text { Knowledge and beliefs of dentists } \\
\text { regarding temporomandibular } \\
\text { disorders and chronic pain. }\end{array}$ & 1994 & Randomizado & Questionário & $\begin{array}{l}\text { Os dentistas gerais e especialistas } \\
\text { demonstraram conhecimento adequado em } \\
\text { relação aos quatro domínios abordados pelo } \\
\text { questionário: psico-fisiológico, doença } \\
\text { psiquiátrica, dor crônica e fisiopatologia em } \\
\text { relação à doença temporo-mandibular. }\end{array}$ \\
\hline $\begin{array}{l}\text { Turk DC, Brody MC, } \\
\text { Okifuji EA. }{ }^{68}\end{array}$ & $\begin{array}{l}\text { Physicians' attitudes and practices } \\
\text { regarding the long-term prescribing } \\
\text { of opioids for non-cancer pain. }\end{array}$ & 1994 & Randomizado & Questionário & $\begin{array}{l}\text { A prescrição varia conforme a região dos EEUU } \\
\text { e especialidade médica. }\end{array}$ \\
\hline $\begin{array}{l}\text { Brunier G, Carson MG, } \\
\text { Harrison DE. }\end{array}$ & $\begin{array}{l}\text { What do nurses know and believe } \\
\text { about patients with pain? Results } \\
\text { of a hospital survey. }\end{array}$ & 1995 & Descritivo analítico & $\begin{array}{l}\text { Nurses' } \\
\text { Knowledge and Attitudes Survey }\end{array}$ & $\begin{array}{l}\text { Falha no conhecimento e compreensão nos } \\
\text { princípios básicos do manejo da dor, uso de } \\
\text { opióides e conceito de dor aguda e dor crônica. }\end{array}$ \\
\hline $\begin{array}{l}\text { Rainville J, Bagnall D, } \\
\text { Phalen L. }\end{array}$ & $\begin{array}{l}\text { Health care providers' attitudes } \\
\text { and beliefs about functional } \\
\text { impairments and chronic back } \\
\text { pain. }\end{array}$ & 1995 & Retrospectivo analítico & $\begin{array}{l}\text { Health Care-Providers' Pain and } \\
\text { Impairment Relationship Scale } \\
\text { (HC-PAIRS) }\end{array}$ & $\begin{array}{l}\text { O estudo demonstra que as propriedades } \\
\text { psicométricas do HC-PAIRS são adequadas. }\end{array}$ \\
\hline $\begin{array}{l}\text { Clarke EB, French B, } \\
\text { Bilodeau ML, Capasso } \\
\text { VC, Edwards A, Empoliti } \\
J^{6{ }^{62}}\end{array}$ & $\begin{array}{l}\text { Pain management knowledge, } \\
\text { attitudes and clinical practice: the } \\
\text { impact of nurses' characteristics } \\
\text { and education. }\end{array}$ & 1996 & Clínico randomizado & $\begin{array}{l}\text { Nurses' } \\
\text { Knowledge and Attitudes Survey } \\
\text { e } \\
\text { Pain Audit Tool }\end{array}$ & $\begin{array}{l}\text { Déficit no conhecimento em relação a } \\
\text { intervenções não farmacológicas, diferença } \\
\text { entre dor aguda e crônica e anatomia e fisiologia } \\
\text { da dor. } \\
\text { Relatam como barreira a relutância dos } \\
\text { pacientes em relatar dor e tomar opióides. }\end{array}$ \\
\hline Closs SJ. ${ }^{69}$ & $\begin{array}{l}\text { Pain and elderly patients: a survey } \\
\text { of nurses' knowledge and } \\
\text { experiences. }\end{array}$ & 1996 & Quantitativo & Questionário & $\begin{array}{l}\text { Bom conhecimento sobre prevalência da dor no } \\
\text { idoso } \\
\text { Conceitos errôneos sobre tratamento } \\
\text { farmacológico de dor no idoso. } \\
\text { Exagero no risco de depressão respiratória por } \\
\text { opióides no idoso. }\end{array}$ \\
\hline
\end{tabular}




\begin{tabular}{|c|c|c|c|c|c|}
\hline AUTOR & TITULO & ANO & TIPO DE ESTUDO & INSTRUMENTO & RESULTADOS \\
\hline $\begin{array}{l}\text { Tornkvist L, Gardulf A, } \\
\text { Strender LE. }\end{array}$ & $\begin{array}{l}\text { The opinions of district nurses } \\
\text { regarding the knowledge, } \\
\text { management and documentation } \\
\text { of patients with chronic pain. }\end{array}$ & 1998 & Prospectivo & Questionário & $\begin{array}{l}\text { Discute o conhecimento, manejo e registro dos } \\
\text { pacientes com dor crônica antes e depois da } \\
\text { introdução de um "pain advisers". } \\
\text { Não tem avaliação individualizada do paciente, } \\
\text { os profissionais usam poucos instrumentos de } \\
\text { medida, fazem poucos registros. } \\
\text { As enfermeiras estão pouco satisfeitas com o } \\
\text { cuidado prestado }\end{array}$ \\
\hline $\begin{array}{l}\text { Greenwald BD, } \\
\text { Narcessian EJ, } \\
\text { Pomeranz BA. }\end{array}$ & $\begin{array}{l}\text { Assessment of physiatrists' } \\
\text { knowledge and perspectives on } \\
\text { the use of opioids: review of basic } \\
\text { concepts for managing chronic } \\
\text { pain. }\end{array}$ & 1999 & Randomizado & Questionário & $\begin{array}{l}\text { Os fisiátras apresentaram falhas no } \\
\text { conhecimento em relação ao uso dos opióides } \\
\text { para doentes oncológicos, no conceito de adição } \\
\text { e demonstram preocupação no uso de opióides } \\
\text { para dor crônica não oncológica., }\end{array}$ \\
\hline $\begin{array}{l}\text { Weinstein SM, Laux LF, } \\
\text { Thornby JI, Lorimor RJ, } \\
\text { Hill CS, Thorpe DM, } \\
\text { Merrill JM. }\end{array}$ & $\begin{array}{l}\text { Medical students'attitudes toward } \\
\text { pain and the use of opioid } \\
\text { analgesics: implications for } \\
\text { changing medical school } \\
\text { curriculum. }\end{array}$ & 2000 & Descritivo & Questionário & $\begin{array}{l}\text { Educação médica falha não somente na didática } \\
\text { da dor e seu controle, mas também pode } \\
\text { engendrar traços psicológicos negativos nos } \\
\text { alunos, promovendo um manejo inadequado da } \\
\text { dor. } \\
\text { Médicos em treinamento devem ser ensinados a } \\
\text { enfocar os aspectos psico-sociais complexos do } \\
\text { cuidado ao paciente. } \\
\text { A profissionalização pode reforçar atitudes } \\
\text { negativas. }\end{array}$ \\
\hline $\begin{array}{l}\text { Weinstein SM, Laux LF, } \\
\text { Thornby JI, Lorimor RJ, } \\
\text { Hill CS, Thorpe DM, } \\
\text { Merrill } \mathrm{JM}^{73}\end{array}$ & $\begin{array}{l}\text { Physicians' attitudes toward pain } \\
\text { and the use of opioid analgesics: } \\
\text { results of a survey from the Texas } \\
\text { Cancer Pain Initiative. }\end{array}$ & 2000 & Retrospectivo & Questionário & $\begin{array}{l}\text { Barreiras ao adequado manejo da dor: } \\
\text { opioidefobia, falha no conhecimento da } \\
\text { fisiopatologia da dor e do seu tratamento e visão } \\
\text { negativa do paciente com dor crônica. }\end{array}$ \\
\hline $\begin{array}{l}\text { Rainville J, Carlson N, } \\
\text { Polatin P, Gatchel RJ, } \\
\text { Indahl A. }\end{array}$ & $\begin{array}{l}\text { Exploration of physicians' } \\
\text { recommendations for activities in } \\
\text { chronic low back pain. }\end{array}$ & 2000 & Randomizado & $\begin{array}{l}\text { Health Care-Providers' Pain and } \\
\text { Impairment Relationship Scale } \\
\text { (HC-PAIRS) } \\
2 \text { vignetes }\end{array}$ & $\begin{array}{l}\text { As recomendações para realização de atividade } \\
\text { física e retorno ao trabalho variam } \\
\text { enormemente, mas geralmente são restritivas. } \\
\text { As recomendações refletem: } \\
\text { - Atitudes pessoais dos médicos assim como } \\
\text { fatores relacionados aos sintomas clínicos } \\
\text { dos pacientes. }\end{array}$ \\
\hline
\end{tabular}




\begin{tabular}{|c|c|c|c|c|c|}
\hline AUTOR & TITULO & ANO & TIPO DE ESTUDO & INSTRUMENTO & RESULTADOS \\
\hline $\begin{array}{l}\text { Potter M, Schafer S, } \\
\text { Gonzalez-Mendez E, } \\
\text { Gjeltema K, Lopez A, Wu } \\
\text { J, Pedrin R, Cozen M, } \\
\text { Wilson R, Thom D, } \\
\text { Crougham_Minihane } \\
\text { M. }^{75}\end{array}$ & $\begin{array}{l}\text { Opioids for chronic nonmalignant } \\
\text { pain. Attitudes and practices of } \\
\text { primary care physicians in the } \\
\text { UCSF/Stanford Collaborative } \\
\text { Research Network. }\end{array}$ & 2001 & & 3 vignetes & $\begin{array}{l}\text { Barreiras: } \\
\text { - Preocupação sobre dependência física, } \\
\text { tolerância e adição aos opióides; } \\
\text { - São disponíveis para prescrever opióides de } \\
\text { III escala (ex: acetaminofeno+codeína) "se } \\
\text { necessário", mas muitos não são favoráveis } \\
\text { à prescrição de opióides de II escala (ex.: } \\
\text { morfina de liberação lenta) em intervalos } \\
\text { regulares. }\end{array}$ \\
\hline Li LC, Bombardier C. ${ }^{76}$ & $\begin{array}{l}\text { Physical therapy management of } \\
\text { low back pain: an exploratory } \\
\text { survey of therapist approaches. }\end{array}$ & 2001 & Exploratório & Questionário & $\begin{array}{l}46,3 \% \text { dos fisioterapeutas concordam que os } \\
\text { protocolos são úteis para tratar lombalgia, porém } \\
\text { se sentem inseguros em relação ao valor prático } \\
\text { dos protocolos. }\end{array}$ \\
\hline Alley LG. ${ }^{77}$ & $\begin{array}{l}\text { The influence of an organizational } \\
\text { pain management policy on } \\
\text { nurses' pain management } \\
\text { practices. }\end{array}$ & 2001 & Descritivo correlacional & Questionário & $\begin{array}{l}\text { Variáveis do estudo: } \\
\text { Conhecimento dos enfermeiros sobre o cuidado } \\
\text { em saúde num sistema organizado de dor } \\
\text { crônica; sobre dor e o seu manejo e sobre a } \\
\text { administração de opióides. } \\
\text { O conhecimento dos enfermeiros sobre dor e } \\
\text { seu manejo foi percebido e relatado como } \\
\text { significativo para a organização do serviço de } \\
\text { dor. }\end{array}$ \\
\hline Weiner DK, Rudy TE. ${ }^{78}$ & $\begin{array}{l}\text { Attitudinal barriers to effective } \\
\text { treatment of persistent pain in } \\
\text { nursing home residents. }\end{array}$ & 2002 & Exploratório & Questionário & $\begin{array}{l}\text { Enfermeiros e auxiliares de enfermagem } \\
\text { queixaram-se da falta de tempo e de não serem } \\
\text { ouvidas. } \\
\text { Doentes referiram crenças como: dor crônica } \\
\text { não muda, medo da dependência e medo da } \\
\text { adição. }\end{array}$ \\
\hline $\begin{array}{l}\text { Loder E, Witkower A, } \\
\text { McAlary P, Huhta M, } \\
\text { Matarrazzo J. }\end{array}$ & $\begin{array}{l}\text { Rehabilitation hospital staff } \\
\text { knowledge and attitudes regarding } \\
\text { pain }\end{array}$ & 2003 & & & $\begin{array}{l}\text { Conceitos são derivados de modelos de dor } \\
\text { aguda e oncológica com forte ênfase no uso de } \\
\text { medicações opióides e menor ênfase no uso de } \\
\text { métodos não farmacológicos. }\end{array}$ \\
\hline
\end{tabular}




\begin{tabular}{|c|c|c|c|c|c|}
\hline AUTOR & TITULO & ANO & TIPO DE ESTUDO & INSTRUMENTO & RESULTADOS \\
\hline Moseley L. ${ }^{79}$ & $\begin{array}{l}\text { Unraveling the barriers to } \\
\text { reconceptualization of the problem } \\
\text { in chronic pain: The actual and } \\
\text { perceived ability of patients and } \\
\text { health professionals to understand } \\
\text { the neurophysiology. }\end{array}$ & 2003 & Descritivo analítico & Questionário & $\begin{array}{l}\text { Doentes e profissionais possuem pouco } \\
\text { conhecimento sobre a neurofisiologia da dor e o } \\
\text { profissional subestima a capacidade do doente } \\
\text { em entender a neurofisiologia da dor. O } \\
\text { profissional não apresenta esse conceito como } \\
\text { parte do tratamento e isso é uma barreira a } \\
\text { reconceitualização da dor pelo doente. }\end{array}$ \\
\hline $\begin{array}{l}\text { Tornkvist L, Gardulf A, } \\
\text { Strender LE. }\end{array}$ & $\begin{array}{l}\text { Effects of "pain-advisers": district } \\
\text { nurses' opinions regarding their } \\
\text { own knowledge, management and } \\
\text { documentation of patients in } \\
\text { chronic pain. }\end{array}$ & 2003 & Clínico randomizado & Questionário & $\begin{array}{l}\text { Enfermeiros referiram melhora na avaliação } \\
\text { individualizada da dor dos doentes, maior uso de } \\
\text { escalas de avaliação da dor (VAS); ficaram mais } \\
\text { satisfeitos com a documentação da dor. } \\
\text { Reconhecem que os "Pain Advisers", com } \\
\text { pequeno recurso, levou a significantes melhora. }\end{array}$ \\
\hline $\begin{array}{l}\text { Latimer J, Maher C, } \\
\text { Refshauge K. }\end{array}$ & $\begin{array}{l}\text { The attitudes and beliefs on } \\
\text { physiotherapy students to chronic } \\
\text { back pain. }\end{array}$ & 2004 & Descritivo exploratório & $\begin{array}{l}\text { Health Care-Providers' Pain and } \\
\text { Impairment Relationship Scale } \\
\text { (HC-PAIRS) }\end{array}$ & $\begin{array}{l}\text { As atitudes e crenças dos estudantes de } \\
\text { fisioterapia que não tiveram um módulo de } \\
\text { ensino sobre lombalgia são similares aos } \\
\text { cuidadores da comunidade. }\end{array}$ \\
\hline $\begin{array}{l}\text { Tarzian AJ, Hoffman } \\
\text { DE. }\end{array}$ & $\begin{array}{l}\text { Barriers to managing pain in nurse } \\
\text { home: findings from a statewide } \\
\text { survey. }\end{array}$ & 2004 & Exploratório & Questionário & $\begin{array}{l}\text { Médicos e enfermeiros demonstraram falta de } \\
\text { conhecimento sobre o manejo da dor e baixa } \\
\text { aceitação de uma padronização no tratamento } \\
\text { da dor. } \\
\text { Atitudes pessoais dos médicos em relação ao } \\
\text { tratamento de dor revelaram medo da adição e } \\
\text { da superdosagem de opióide, falha na precisão } \\
\text { do diagnóstico e tratamento da dor, dificuldade } \\
\text { em escolher o analgésico corretamente, falta de } \\
\text { pessoal para cuidar dos doentes. }\end{array}$ \\
\hline $\begin{array}{l}\text { Daykin AR, Richardson } \\
\text { B. }^{83}\end{array}$ & $\begin{array}{l}\text { Physiotherapists' pain beliefs and } \\
\text { their influence on the management } \\
\text { of patients with chronic low back } \\
\text { pain. }\end{array}$ & 2004 & Qualitativo exploratório & Entrevista semi-estruturada & $\begin{array}{l}\text { As crenças sobre dor dos fisioterapeutas podem } \\
\text { influenciar no tratamento que eles dão aos } \\
\text { pacientes. }\end{array}$ \\
\hline $\begin{array}{l}\text { Grahmann PH, Jackson } \\
\text { KC 2nd, Lipman AG. }\end{array}$ & $\begin{array}{l}\text { Clinician beliefs about opioid use } \\
\text { and barriers in chronic } \\
\text { nonmalignantpain. }\end{array}$ & 2004 & Descritivo & Questionário & $\begin{array}{l}\text { A aceitação da prescrição de opióides para dor } \\
\text { crônica está aumentando, porém ela varia de } \\
\text { acordo com a síndrome dolorosa. }\end{array}$ \\
\hline
\end{tabular}




\begin{tabular}{|c|c|c|c|c|c|}
\hline AUTOR & TITULO & ANO & TIPO DE ESTUDO & INSTRUMENTO & RESULTADOS \\
\hline $\begin{array}{l}\text { Ponte C D, PharmD, } \\
\text { Ttibino J J. }\end{array}$ & $\begin{array}{l}\text { Attitudes and knowledge about } \\
\text { pain: an assessment of West } \\
\text { Virginia family Physicians }\end{array}$ & 2005 & Descritivo & Questionário & $\begin{array}{l}\text { Para muitos médicos é difícil avaliar a dor } \\
\text { crônica não oncológica e a dor no idoso. A } \\
\text { maioria dos médicos de família de Virginia Oeste } \\
\text { relataram preocupações em prescrever opióides } \\
\text { para dor crônica não oncológica e para pessoas } \\
\text { com história de abuso de substâncias. Referiram } \\
\text { que a formação médica que receberam não foi } \\
\text { suficiente para o manejo adequado da dor. }\end{array}$ \\
\hline $\begin{array}{l}\text { Schrader S L, Nelson M } \\
\text { L, Halbriter S, Eidsness } \\
\text { L. }{ }^{\circ}\end{array}$ & $\begin{array}{l}\text { South Dakota Pain Surveys: } \\
\text { Results from } 2001\end{array}$ & 2005 & Decritivo & Questionário & $\begin{array}{l}\text { Os resultados mostram lacunas de } \\
\text { conhecimento e atitudes que impedem o } \\
\text { tratamento adequado da dor aguda e crônica. } \\
\text { Há necessidade de uma abordagem para } \\
\text { padronizar a prática do manejo da dor nos } \\
\text { serviços de saúde. }\end{array}$ \\
\hline $\begin{array}{l}\text { Brown C A, Richardson } \\
\text { C. }^{85}\end{array}$ & $\begin{array}{l}\text { Nurses' in the multi-professional } \\
\text { pain team: A study of attitudes, } \\
\text { beliefs and treatment } \\
\text { endorsements }\end{array}$ & 2006 & Descritivo & Questionário $\mathrm{BPCQ}$ & $\begin{array}{l}\text { O estudo pesquisou quais tratamentos para dor } \\
\text { crônica são aprovados pelos enfermeiros. Os } \\
\text { achados reconhecem que os enfermeiros } \\
\text { aprovam um número maior de tratamentos que } \\
\text { outros profissionais e que estão mais cientes } \\
\text { que o manejo da dor crônica deve ser feito de } \\
\text { uma maneira mais flexível e de mente aberta. }\end{array}$ \\
\hline
\end{tabular}




\subsection{Instrumentos utilizados para investigação das crenças sobre dor crônica não oncológica entre profissionais da saúde}

A preocupação em mensurar e comparar as crenças e atitudes das pessoas frente aos mais diversos objetos acentuou-se na quarta e quinta décadas do século passado, quando inúmeros estudos foram realizados nas áreas de educação, marketing, saúde, política, entre outros. Os estudos versaram sobre vários aspectos, desde compreender o processo de como as crenças e atitudes se formam, o que as compõe, quão estáveis elas são, até como poderiam ser avaliadas e mensuradas. $\mathrm{O}$ interesse em se estudar crenças e atitudes reside no fato de que são aprendidas e, portanto, podem também por aprendizado, serem modificadas ${ }^{106}$.

Da revisão bibliográfica feita, observou-se que os instrumentos que descrevem as propriedades psicométricas, utilizados para avaliar as crenças e atitudes frente à dor crônica não oncológica entre profissionais de saúde, foram o Nurses' Knowledge and Atitudes Survey (NKAS) e o Health Care Providers' Pain and Impairment Relationship Scale (HC-PAIRS).

O questionário Nurses' Knowledge and Atitudes Survey (NKAS) ${ }^{64}$, foi criado por Ferrel and Leek em 1990. Consta de 46 itens e é indicado para medir conhecimento e atitudes de enfermeiras em relação à dor. Os itens têm o mesmo peso, sendo 46 o máximo de pontos. A uma resposta certa é dado o valor 1 e a uma resposta incorreta ou em branco é dado o valor 0 . Altos escores indicam um alto número de respostas corretas relacionadas ao conhecimento e atitudes em relação a dor. O NKAS é o único instrumento que avalia o conhecimento e atitudes sobre a dor nas várias áreas clínicas. O conteúdo desse instrumento foi baseado nas recomendações para o manejo da dor, preconizadas pela American Pain Society e World Health Organization. A validade do conteúdo do questionário Nurses' Knowledge and Atitudes Survey (NKAS) foi estabelecida através de revisão por especialistas em dor. A validade discriminante, uma forma de validade de construto, foi estabelecida quando diferenças na direção esperada foram 
encontradas nos escores das enfermeiras com variados níveis de qualificação como: estudantes, recém formadas, enfermeiras oncológicas, doutorandas e especialistas em dor, isto é, os escores variaram de mais baixos em estudantes de enfermagem, até mais altos no grupo de especialistas em dor. A confiabilidade através do teste-reteste foi estabelecida $(r>0,80)$. $O$ alfa de Cronbach foi estabelecido em $0,70 \mathrm{com}$ itens refletindo os domínios de conhecimento e atitude. Esse instrumento não está disponível em Língua Portuguesa.

O instrumento Health Care Providers' Pain and Impairment Relationship Scale (HC-PAIRS) foi criado por Rainville ${ }^{65}$ em 1995 para identificar as crenças e atitudes dos profissionais de saúde em relação à expectativa funcional dos doentes com lombalgia. Este instrumento foi desenvolvido através da modificação do Pain and Impairment Relationship Scale (PAIRS) usado para avaliar atitudes e crenças de doentes com lombalgia. O HC-PAIRS consta de 15 itens que avaliam dificuldade e incapacidade causadas pela dor em doentes com dores nas costas, por meio de uma escala tipo Likert de sete pontos, ancorada por graus de concordo e não concordo. A Confiabilidade foi determinada através do alfa de Cronbach $(0,78)$. A análise fatorial foi efetuada para confirmar as dimensões das atitudes e das crenças (expectativa funcional, expectativa social, necessidade de cura e cognição projetada). A validade foi avaliada comparando-se as atitudes e as crenças dos especialistas em reabilitação às dos profissionais de saúde comunitária $(p<0,000)$. As diferenças observadas deveram-se às discordâncias da noção de que a lombalgia justifica dificuldade e incapacidade causadas pela dor.

A limitação desse instrumento refere-se ao fato de ser específico para avaliar crenças e atitudes referentes à incapacidade relacionada a lombalgia, não atendendo ao interesse deste estudo.

Como a revisão da literatura não disponibilizou nenhum instrumento que permita a avaliação de atitudes e crenças de profissionais de saúde em relação à dor crônica não oncológica de modo geral e 
dispondo-se de um instrumento validado para a língua portuguesa que avalia atitudes e crenças de doentes em relação à dor crônica não oncológica, optou-se por adaptar esse instrumento para ser usado com profissionais da saúde.

O instrumento intitulado Inventário de Atitudes frente à Dor versão breve (IAD-breve) foi validado para a língua portuguesa por Pimenta ${ }^{96}$ (1999), Pimenta e Cruz ${ }^{107}$ (2006). É a versão brasileira do Survey of Pain Attitudes-Brief (SOPA-B), um instrumento que avalia crenças sobre dor crônica em doentes, proposto por Tait e Chibnall108 em 1997. O SOPA-B é a versão reduzida do instrumento Survey of Pain Attitudes (SOPA) criado por Jensen, Karoly e Huger ${ }^{116}$ em 1987, e reformulado em 1991 e 1994. É um instrumento com utilidade clínica e propriedades psicométricas adequadas $^{108}$.

Considerando que o Inventário de Atitudes frente a Dor (IADbreve) avalia crenças de extrema importância para a definição do tratamento a ser proposto ao doente, que identifica crenças importantes para a construção de programas educativos visando a melhor prática e que está validado para a língua portuguesa, optou-se por modificá-lo para Inventário de Atitudes frente a Dor para profissionais de saúde. 
Objetivos 


\section{OBJETIVOS}

- Validar o Inventário de Atitudes frente à Dor para profissionais de saúde.

- Analisar as crenças sobre dor crônica dos profissionais de saúde que atendem doentes com dor crônica em Centros de Dor. 
Material e Método 


\section{MATERIAL E MÉTODO}

\subsection{Local do Estudo}

Trata-se de um estudo descritivo, realizado em Centros de Dor, de entidades públicas e privadas da cidade de São Paulo. Centro de Dor é um serviço que visa a tratar doentes com dor crônica, constituído por médicos de várias especialidades, enfermeiros, fisioterapeutas, dentistas, psicólogos e assistentes sociais. No presente estudo foram incluídos os Centros com pelo menos duas especialidades médicas e pelo menos dois tipos de profissionais (médicos e fisioterapeuta, médicos e enfermeiro ou médicos e psicólogo), por ser essa a configuração mínima de uma Clínica Multidisciplinar de Dor ${ }^{109}$.

$\mathrm{Na}$ cidade de São Paulo, foram identificados onze serviços que atenderam esses critérios: Clinica da Dor do Hospital Nove de Julho, Centro de Tratamento da Dor do Hospital Sírio Libanês, Central da Dor do Hospital A.C. Camargo, Ambulatório de Dor do Hospital do Servidor Público Estadual, Clínica de Dor da Irmandade Santa Casa de Misericórdia de São Paulo, Serviço de Dor do Hospital Alemão Oswaldo Cruz, Ambulatório de Dor da UNIFESP, Ambulatório de Dor e Neurologia do Hospital das Clínicas da FMUSP, Equipe de Controle de Dor Disciplina de Anestesiologia do Hospital das Clínicas da FMUSP, Ambulatório de Dor da Divisão de Ortopedia do Hospital das Clínicas da FMUSP e Unidade de Dor e Cuidados Paliativos do Instituto da Criança do HC-FMUSP.

Os Centros de Dor foram localizadas através da Sociedade Brasileira para Estudo da Dor - Seção São Paulo, do livro Tratamento da Dor no Brasil ${ }^{109}$ e por indicação dos próprios participantes da pesquisa. 


\subsection{População}

Compuseram a amostra profissionais de saúde que atuam em Centros de Dor da cidade de São Paulo. Dos onze serviços localizados, um não permitiu a coleta de dados (Ambulatório de Dor da UNIFESP) e em um não foi possível coletar por não se ter obtido a aprovação em tempo hábil (Ambulatório de Dor da Divisão de Ortopedia do Hospital das Clínicas da FMUSP). Foram entrevistados profissionais de nove Centros de Dor entre agosto de 2005 e março de 2006. O número de profissionais atuando nesses serviços foi de 126 sujeitos. Alguns profissionais (17) faziam parte de mais de um Centro de Dor, porém respondeu o questionário uma única vez. Assim a amostra foi composta por 75 respondentes, o que equivaleu a $59,5 \%$ dos profissionais.

A figura 1 mostra em porcentagem a participação dos profissionais de cada um dos Centros de Dor.

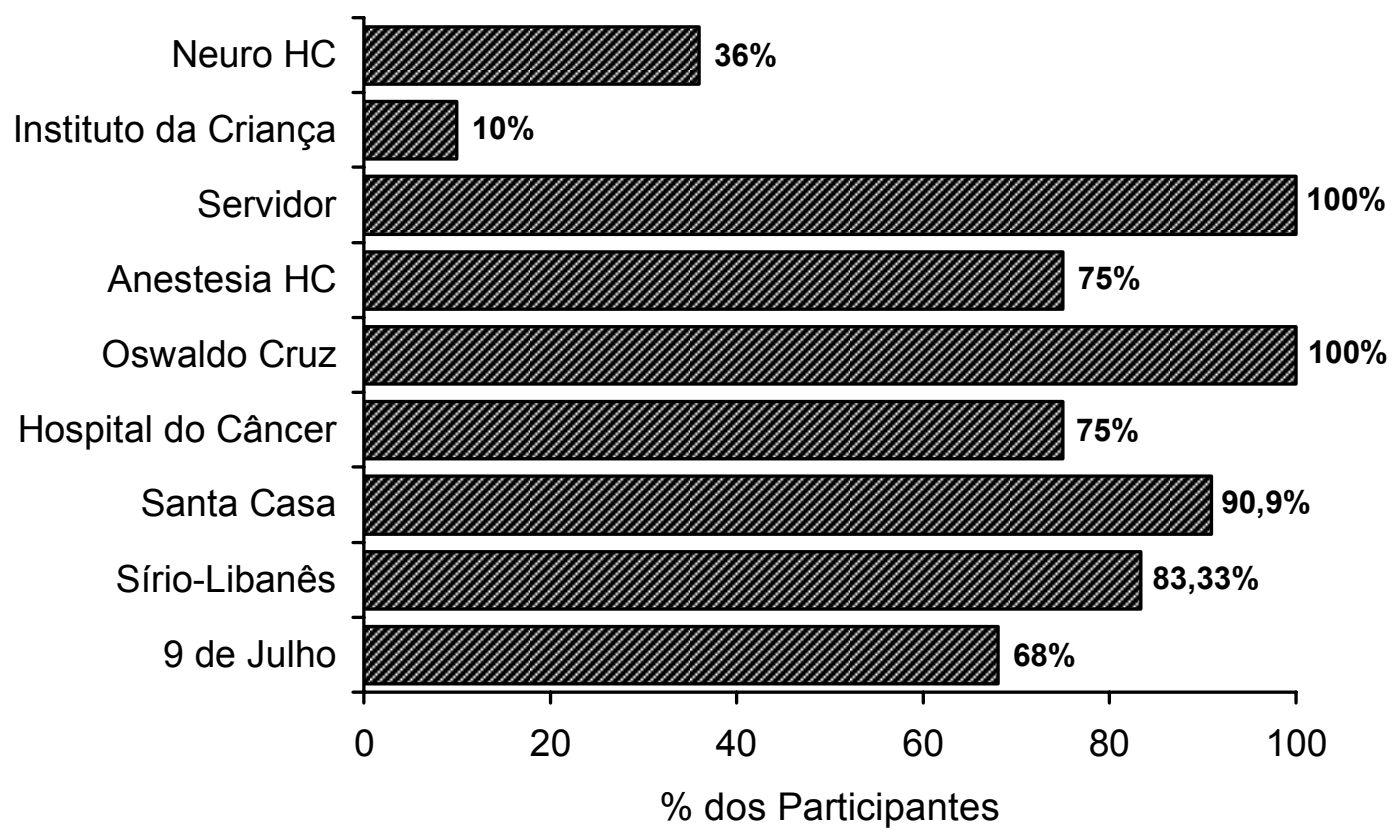

Figura 1 - Percentual de respondentes por Centros de Dor. São Paulo, 2006. 


\subsection{Instrumentos}

Os dados foram coletados por meio de dois instrumentos. $\mathrm{O}$ primeiro, denominado Identificação Pessoal (Anexo 2), visou a caracterizar o profissional quanto aos dados sócio-demográficos e experiência profissional no cuidado (avaliação e tratamento) a doentes com dor crônica não oncológica.

O segundo instrumento foi o Inventário de Atitudes frente a Dorprofissionais pré-teste (Anexo 3), utilizado para identificar crenças/atitudes dos profissionais frente à dor crônica não oncológica. Este instrumento foi adaptado a partir do Inventário de Atitudes frente a Dor-versão breve (IADbreve), construído para uso em doentes ${ }^{117}$.

O IAD-breve (doentes) é um inventário auto-aplicado, com 30 itens, que avalia sete domínios de crenças/atitudes de pacientes com dor crônica frente à dor: controle, emoção, incapacidade, dano físico, medicação, solicitude e cura médica.

O domínio de controle refere-se a quanto o doente acredita que pode controlar sua dor; emoção refere-se a quanto o doente acredita que suas emoções influem na sua experiência dolorosa; incapacidade refere-se a quanto o doente acredita que está incapacitado pela dor; dano físico refere-se a quanto o doente acredita que a dor significa que ele está machucando a si mesmo e que deveria evitar exercícios físicos; medicação refere-se a quanto o doente acredita que medicamento é o melhor tratamento para dor crônica; solicitude refere-se a quanto o doente acredita que outros, especialmente os familiares, devem ser mais solícitos quando ele sente dor; cura médica refere-se a quanto o doente acredita na cura pela medicina para a sua dor.

O instrumento é auto-aplicado, e os respondentes indicam a concordância com cada uma das assertivas, em escala tipo Likert de cinco 
pontos, que varia de 0 a $4(0=$ totalmente falso, $1=$ falso, $2=$ nem verdadeiro, nem falso, 3 = quase verdadeiro, 4 = totalmente verdadeiro).

A análise do inventário é feita por domínio. O escore de cada domínio é calculado pela soma dos pontos das respostas de cada item, dividido pelo número de itens respondidos. O escore final médio de cada escala poderá variar entre 0 e 4 . Há itens invertidos $(4,8,11,23,24,26,27$, $28,29)$ que devem ter os seus escores revertidos antes da soma. A reversão do escore é feita subtraindo-se de 4 o escore escolhido pelo respondente (4 menos o escore escolhido).

Não há pontos de corte, resposta certa ou errada, e os escores dos sete domínios ou escalas não são somados. Há orientações de respostas mais "desejáveis" por serem consideradas pelo autor do inventário como hipoteticamente mais adaptativas.

A orientação desejável dos escores para cada escala, depois do ajuste dos escores dos itens invertidos é: controle $=4$, emoção $=4$, incapacidade $=0$, dano físico $=0$, medicação $=0$, solicitude $=0$ e cura médica $=0$.

\subsubsection{Adaptação do Inventário de Atitudes frente a Dor-profissionais}

O IAD-breve (doentes) foi modificado para investigar as atitudes e crenças de profissionais de saúde frente à dor, e foi denominado IADprofissionais pré-teste (Anexo 3).

A adaptação inicial do IAD-breve doentes para IADprofissionais pré-teste foi realizada pelas autoras através da mudança das frases na primeira pessoa do singular (eu/ meu) para a expressão "no doente" em vinte e nove assertivas, com exceção da assertiva 13, que não faz referência à primeira pessoa do singular. Por exemplo: "muitas vezes eu consigo influenciar a intensidade da dor que sinto" para "muitas vezes o doente consegue influenciar a intensidade da dor". 
Com essa modificação as autoras assumiram que as respostas para cada assertiva refletiriam as atitudes/crenças dos profissionais de saúde frente à dor crônica não-oncológica.

O instrumento foi submetido aos pesquisadores do grupo Dor, Controle de Sintomas e Cuidados Paliativos. Inicialmente, as cinco pesquisadoras responderiam ao questionário IAD-profissionais pré-teste e anotariam as dificuldades percebidas. A seguir, julgariam se cada uma das assertivas mantinha paralelo com a original e se permitiria ao profissional expressar uma crença, porém, ao responderem o IAD-profissionais pré-teste, as pesquisadoras perceberam que estavam expressando uma crença em relação ao doente e não sua própria crença em relação à dor crônica nãooncológica. Sugeriram, então, que a referência "ao doente" fosse retirada das assertivas. As decisões foram tomadas por consenso e os ajustes no instrumento foram feitos.

A proposição inicial foi de que o IAD-profissionais pré-teste manteria os mesmos domínios (7), número de assertivas (30), de categorias (escala tipo Likert com 5 categorias, de 0 a 4), os mesmos itens invertidos e mesmo método de obtenção do escore do IAD-breve doentes.

Assim, o domínio controle refere-se a quanto o profissional da saúde acredita que a dor pode ser controlada por quem a sente (a influência pessoal no controle da dor) e está representado pelas questões 1, 12, 17, 20, e 22. O domínio emoção refere-se a quanto o profissional acredita que as emoções influem na experiência dolorosa (relação entre emoção e intensidade da dor), e está representado pelos itens $6,10,15$, e 25 . O domínio incapacidade refere-se a quanto o profissional acredita que a incapacidade advém da dor (dor como incapacitante) e está representado pelas questões 23, 26 e 30 do inventário. O domínio dano físico refere-se a quanto o profissional acredita que dor significa lesão e que os exercícios físicos devem ser evitados (dor como indicativo de dano tecidual), e está representado pelos itens 11, 16, 19, 27 e 28. O domínio medicação refere-se a quanto o profissional acredita que medicamentos são o melhor tratamento 
para dor crônica e está representado pelas questões 2, 5 e 13 do instrumento. O domínio solicitude refere-se a quanto o profissional acredita que outros, principalmente os familiares, devem ser mais solícitos quando a pessoa sente dor (solicitude de outros frente à pessoa com dor), e está representado pelos itens $3,7,9,14$ e 18. O domínio cura médica refere-se a quanto o profissional da saúde acredita na cura pela medicina para a dor crônica (cura por meios médicos) e está representada pelas questões 4,8 , 21,24 , e 29.

Após essa fase, o inventário foi aplicado aos profissionais de saúde para análise das propriedades psicométricas e os dados estão apresentados no capítulo RESULTADOS.

\subsection{Procedimentos de coleta e aspectos éticos}

O estudo foi avaliado pelo Comitê de Ética e Pesquisa de cada uma das Instituições envolvidas (Comitê de Ética em Pesquisa da Escola de Enfermagem da USP, Comitê de Ética em Pesquisa do Hospital Alemão Oswaldo Cruz, Comitê de Ética em Pesquisa do Hospital Sírio Libanês, Comitê de Ética e Pesquisa Departamento de Neurologia da FMUSP, Comitê de Pesquisa e Ética Departamento de Pediatria da FMUSP, Comissão de Ética em Pesquisa do Hospital A.C. Camargo, Comitê de Ética em Pesquisa da Irmandade Santa Casa de São Paulo, Comitê de Ética em Pesquisa do Hospital do Servidor Público Estadual) e os profissionais da saúde foram convidados a participar. Após assinarem o Termo de Consentimento Pós-esclarecido (Anexo 1) responderam ao questionário de identificação pessoal (Anexo 2) e ao Inventário de Atitudes frente a Dor para profissionais da Saúde, IAD- profissionais pré-teste (Anexo 3).

Previamente à aplicação do IAD-profissionais pré-teste foi explicado aos profissionais, sucintamente, o objetivo do inventário e o modo de respondê-lo. 
A pesquisadora entregou os questionários a todos que concordaram em participar, no local de trabalho dos profissionais e, na maioria das vezes, aguardou o preenchimento, permanecendo à disposição para esclarecimentos. Em alguns serviços, os questionários foram deixados para serem respondidos, sendo depois recolhidos pela autora. Em algumas situações, a pesquisadora permaneceu ao lado, lendo junto com o profissional as assertivas. Após o preenchimento, foi verificado se todos os itens estavam respondidos ou se havia resposta dupla; se necessário, foi solicitado aos profissionais que revisassem e confirmassem suas resposta.

\subsection{Organização e análise dos dados}

Os dados foram lançados em base de dados para 0 processamento das analises descritivas e por inferências. Os resultados foram organizados em tabelas e figuras e as freqüências em números absolutos e relativos. Para todos os testes estatísticos utilizados o nível de significância foi determinado em $5 \%$.

Para a confirmação dos fatores foi feita a análise fatorial e a confiabilidade foi estimada por meio do alfa de Cronbach.

Para a identificação de diferenças na expressão de crenças entre os profissionais foi feita a análise de cluster, considerando-se as variáveis idade, sexo, profissão, titulação, tipo de doente que o profissional mais atende (dor aguda, crônica, oncológica), número de doentes atendidos por mês e auto-avaliação da experiência com dor. Os grupos foram compostos utilizando-se o método do K-Médias. A comparação entre os grupos foi feita pelo Qui-quadrado e para confirmação do resultado foi aplicado o teste Monte Carlo. 
Resultados 


\section{RESULTADOS}

Os dados estão apresentados na seguinte ordem: caracterização da amostra, validação do Inventário de Atitudes frente à Dor-profissionais e crenças dos profissionais.

\subsection{Caracterização da amostra}

$\mathrm{Na}$ Tabela 1 estão apresentadas as características sóciodemográficas da amostra.

Tabela 1 - Caracterização da amostra (n=75). São Paulo, 2006.

\begin{tabular}{|c|c|c|c|c|c|}
\hline Características & $\mathbf{n}$ & $\%$ & Média (dp) & Mediana & Variação \\
\hline \multicolumn{6}{|l|}{ Sexo } \\
\hline Feminino & 38 & 50,7 & & & \\
\hline Masculino & 37 & 49,3 & & & \\
\hline Idade & 75 & & $42,8(10,5)$ & 40,0 & 24 a 67 \\
\hline Tempo de formado & 75 & & $17,8(9,9)$ & 16 & 1 a 39 \\
\hline \multicolumn{6}{|l|}{ Profissão } \\
\hline Médico & 44 & 58,7 & & & \\
\hline Enfermeiro & 5 & 6,7 & & & \\
\hline Fisioterapêuta & 11 & 14,7 & & & \\
\hline Psicólogo & 6 & 8,0 & & & \\
\hline Dentista & 8 & 10,7 & & & \\
\hline Assistente Social & 1 & 1,3 & & & \\
\hline \multicolumn{6}{|l|}{ Titulação } \\
\hline Graduação & 22 & 29,3 & & & \\
\hline Especialização & 32 & 42,7 & & & \\
\hline Mestrado & 11 & 14,7 & & & \\
\hline Doutorado & 9 & 12,0 & & & \\
\hline Pós-doutorado & 1 & 1,3 & & & \\
\hline \multicolumn{6}{|c|}{ Auto-avaliação da experiência com dor crônica } \\
\hline Pequena & 12 & 16,0 & & & \\
\hline Média & 45 & 60,0 & & & \\
\hline Grande & 18 & 24,0 & & & \\
\hline \multicolumn{6}{|c|}{$\begin{array}{l}\text { Número de doentes com dor crônica não oncológica } \\
\text { atendidos por mês }\end{array}$} \\
\hline entre 1 e 5 doentes & 11 & 14,7 & & & \\
\hline entre 6 e 10 & 12 & 16,0 & & & \\
\hline entre 11 e 20 & 19 & 25,3 & & & \\
\hline 21 ou mais & 33 & 44,0 & & & \\
\hline
\end{tabular}


A Tabela 1 mostra que a distribuição entre os sexos foi semelhante. A idade média dos entrevistados foi de 42,8 e a mediana foi de 40,0 anos. Os profissionais haviam se graduado em média há 17,8 anos (mediana de 16 anos). Os médicos representaram a maioria da amostra $(58,7 \%)$, seguidos pelos fisioterapeutas $(14,7 \%)$ e dentistas $(10,7 \%)$. Dos respondentes, a maioria possuía especialização $(42,7 \%)$ e $26,7 \%$ mestrado ou doutorado. A maioria (60\%) auto-avaliou-se como medianamente experiente no cuidado ao doente com dor crônica não oncológica e 44,0\% disseram atender, ao mês, acima de vinte doentes com dor crônica não oncológica.

Em relação à forma como foi adquirido o conhecimento em dor, $78,6 \%$ respondeu ter sido através de eventos científicos, 76\% através de cursos de dor, $85,3 \%$ através de leitura e $42,6 \%$ através de estágios em serviços de dor, Internet, etc. Observa-se que 62,7\% dos profissionais associaram eventos científicos, cursos de dor e leitura.

\subsection{Validação do Inventário de Atitudes Frente à Dor-versão profissionais}

A validade do inventário foi testada por meio da análise fatorial e a confiabilidade, pelo alfa de Cronbach.

\subsubsection{Análise fatorial}

A análise fatorial teve como finalidade verificar se a estrutura dos fatores mantinha-se semelhante à original após a versão do IAD-breve doentes para profissionais

Inicialmente foi feita uma análise com os 7 fatores e os 30 itens originais, através do método de rotação Varimax. Observou-se que vários itens não carregavam no domínio original com carga fatorial adequada, que 
foi definida como acima de $0,3^{110}$. Nessa primeira versão, a variância total explicada foi de $57,7 \%$ (Tabela 2 ).

Tabela 2 - Análise Fatorial, correlações entre itens e 7 domínios, do IAD-profissionais préteste. São Paulo, 2006.

\begin{tabular}{|c|c|c|c|c|c|c|c|}
\hline & \multicolumn{7}{|c|}{ DOMÍNIOS } \\
\hline & 1 & 2 & 3 & 4 & 5 & 6 & 7 \\
\hline Q1 & 0,360 & 0,205 & 0,422 & $-0,165$ & $-0,122$ & $-0,061$ & 0,008 \\
\hline Q2 & 0,157 & $-0,058$ & 0,361 & 0,173 & $-0,049$ & $-0,048$ & $-0,561$ \\
\hline Q3 & $-0,076$ & $-0,020$ & 0,056 & 0,768 & 0,094 & $-0,044$ & $-0,167$ \\
\hline Q4 (inv) & $-0,215$ & 0,156 & $-0,100$ & 0,402 & $-0,474$ & 0,015 & 0,067 \\
\hline Q5 & 0,094 & 0,068 & 0,103 & 0,087 & 0,611 & $-0,062$ & $-0,061$ \\
\hline Q6 & 0,804 & $-0,004$ & 0,250 & 0,079 & 0,066 & 0,054 & $-0,079$ \\
\hline Q7 & 0,196 & 0,097 & 0,053 & 0,716 & 0,357 & $-0,021$ & 0,126 \\
\hline Q8 (inv) & $-0,021$ & $-0,159$ & 0,020 & $-0,046$ & $-0,199$ & $-0,655$ & 0,199 \\
\hline Q9 & $-0,040$ & $-0,064$ & 0,461 & 0,448 & 0,279 & $-0,052$ & 0,079 \\
\hline Q10 & 0,867 & 0,007 & 0,196 & 0,084 & 0,102 & $-0,017$ & $-0,068$ \\
\hline Q11 (inv) & $-0,055$ & 0,652 & $-0,106$ & 0,260 & $-0,290$ & 0,028 & 0,095 \\
\hline Q12 & 0,156 & $-0,238$ & 0,707 & $-0,045$ & $-0,065$ & 0,256 & $-0,113$ \\
\hline Q13 & 0,002 & 0,178 & 0,622 & 0,111 & 0,156 & 0,148 & 0,281 \\
\hline Q14 & 0,263 & 0,048 & 0,666 & 0,158 & 0,082 & $-0,209$ & 0,048 \\
\hline Q15 & 0,647 & $-0,168$ & 0,074 & $-0,072$ & 0,240 & $-0,057$ & $-0,055$ \\
\hline Q16 & 0,024 & 0,635 & 0,141 & $-0,057$ & $-0,066$ & 0,129 & $-0,140$ \\
\hline Q17 & 0,257 & $-0,281$ & 0,342 & $-0,122$ & $-0,077$ & 0,460 & $-0,114$ \\
\hline Q18 & $-0,008$ & 0,078 & 0,046 & 0,761 & $-0,194$ & 0,104 & 0,035 \\
\hline Q19 & $-0,037$ & 0,356 & 0,068 & 0,096 & 0,174 & $-0,438$ & $-0,445$ \\
\hline Q20 & 0,203 & $-0,027$ & 0,104 & $-0,114$ & $-0,266$ & 0,602 & $-0,204$ \\
\hline Q21 & $-0,144$ & 0,034 & 0,047 & 0,168 & 0,070 & 0,659 & 0,219 \\
\hline Q22 & 0,271 & $-0,345$ & 0,486 & $-0,063$ & $-0,253$ & 0,225 & $-0,136$ \\
\hline Q23 (inv) & $-0,097$ & 0,749 & 0,023 & 0,043 & 0,225 & $-0,087$ & 0,105 \\
\hline Q24 (inv) & 0,065 & 0,195 & 0,121 & 0,172 & $-0,066$ & $-0,020$ & 0,751 \\
\hline Q25 & 0,785 & $-0,140$ & $-0,059$ & $-0,104$ & $-0,163$ & 0,196 & 0,235 \\
\hline Q26 (inv) & $-0,148$ & 0,640 & 0,094 & $-0,158$ & 0,332 & 0,060 & 0,199 \\
\hline Q27 (inv) & 0,053 & 0,479 & $-0,291$ & $-0,036$ & $-0,049$ & $-0,200$ & 0,104 \\
\hline Q28 (inv) & $-0,092$ & 0,543 & $-0,123$ & 0,348 & $-0,129$ & 0,090 & $-0,130$ \\
\hline Q29 (inv) & 0,012 & $-0,064$ & 0,170 & $-0,067$ & $-0,178$ & $-0,289$ & 0,669 \\
\hline Q30 & 0,000 & $-0,005$ & $-0,133$ & 0,082 & 0,808 & 0,117 & $-0,121$ \\
\hline
\end{tabular}

Domínios iniciais: 1: emoção, 2: dano físico, 3: controle, 4: solicitude, 5: incapacidade, 6: medicação, 7: cura médica.

Inv:= item invertido 
Algumas vezes os itens apresentaram carga fatorial mais alta em domínios com os quais não tinham coerência teórica. Visando a ajustar o modelo, analisaram-se as cargas dos itens nos domínios e foram feitos ajustes de modo que os itens fossem alocados nos domínios originais desde que apresentassem carga fatorial mínima de 0,3. Se o item carregava com o maior valor no domínio a que originalmente pertencia, foi mantido nesse domínio; se o item carregava no domínio original com carga mínima de 0,3, foi mantido nesse domínio, mesmo que a carga fatorial tivesse sido maior em outro domínio. A última situação foi quando o item não carregou no domínio original com carga maior que 0,3 e, nesse caso, ele foi excluído, mesmo que ele tivesse carregado com carga alta em outro domínio. Assim, foram excluídos os itens $2,4,5,8,13,14,20$ e 21 e o domínio medicação deixou de existir. Nessa versão ficaram 22 itens e 6 domínios.

Novas rotações (4) foram realizadas com 6 domínios e 22 itens e a que apresentou melhor solução foi a Equamax, que explicou $63,739 \%$ da variância total. $\mathrm{O}$ item 19 precisou ser retirado, pois não atendeu ao critério "apresentar carga fatorial maior que 0,3 no domínio original" e o item 30 foi retirado, pois na análise de confiabilidade observou-se que sua retirada melhorava o alfa de Cronbach do domínio. A versão final ficou com 6 domínios e 20 itens (Anexo 4). A Análise Fatorial com esses domínios e itens é apresentada na Tabela 3 e a análise de confiabilidade desses domínios, na Tabela 5. A adequação da amostra foi testada pelo KaiserMeyer-Olken (KMO) que foi igual a 0,67 e pelo Bartlett que foi igual a 0,000. 
Tabela 3 - Análise Fatorial, correlações entre itens e 6 domínios, do IAD-profissionais. São Paulo, 2006.

\begin{tabular}{lcccccc}
\hline \multicolumn{7}{c}{} \\
& $\mathbf{1}$ & $\mathbf{2}$ & $\mathbf{3}$ & $\mathbf{4}$ & $\mathbf{5}$ & $\mathbf{6}$ \\
\hline q6 & $\mathbf{0 , 8 0 6}$ & 0,114 & 0,290 & $-0,038$ & 0,076 & 0,002 \\
q10 & $\mathbf{0 , 8 7 7}$ & 0,121 & 0,192 & $-0,017$ & 0,033 & $-0,024$ \\
q15 & $\mathbf{0 , 6 9 2}$ & 0,010 & 0,014 & 0,229 & $-0,052$ & $-0,120$ \\
q25 & $\mathbf{0 , 7 3 6}$ & $-0,173$ & 0,143 & 0,062 & $-0,258$ & 0,231 \\
q11_inv & $-0,082$ & 0,094 & $-0,140$ & $\mathbf{0 , 7 6 2}$ & 0,157 & 0,149 \\
q16 & 0,044 & $-0,072$ & 0,113 & $\mathbf{0 , 4 7 5}$ & 0,474 & 0,189 \\
q27_inv & 0,070 & $-0,111$ & $-0,398$ & $\mathbf{0 , 4 3 8}$ & 0,149 & 0,044 \\
q28_inv & $-0,134$ & 0,219 & $-0,095$ & $\mathbf{0 , 6 8 3}$ & 0,132 & $-0,061$ \\
q1 & 0,367 & $-0,116$ & $\mathbf{0 , 3 4 2}$ & 0,024 & 0,359 & 0,091 \\
q12 & 0,126 & 0,103 & $\mathbf{0 , 3 4 2}$ & $-0,180$ & 0,056 & 0,051 \\
q17 & 0,182 & $-0,043$ & $\mathbf{0 , 6 4 0}$ & $-0,156$ & $-0,111$ & $-0,005$ \\
q22 & 0,202 & $-0,071$ & $\mathbf{0 , 7 2 0}$ & 0,060 & 0,338 & 0,022 \\
q3 & $-0,088$ & $\mathbf{0 , 8 0 7}$ & 0,023 & 0,089 & 0,069 & 0,131 \\
q7 & 0,229 & $\mathbf{0 , 7 7 3}$ & 0,113 & 0,049 & 0,094 & 0,097 \\
q9 & 0,010 & $\mathbf{0 , 6 1 7}$ & 0,281 & $-0,261$ & 0,300 & 0,090 \\
q18 & $-0,052$ & $\mathbf{0 , 6 8 5}$ & 0,025 & 0,348 & $-0,191$ & 0,078 \\
q23_inv & $-0,065$ & 0,152 & 0,226 & 0,290 & $\mathbf{0 , 7 3 7}$ & 0,084 \\
q26_inv & $-0,067$ & $-0,057$ & $-0,157$ & 0,101 & $\mathbf{0 , 7 7 8}$ & 0,120 \\
q24_inv & 0,054 & 0,115 & $-0,059$ & 0,175 & 0,088 & $\mathbf{0 , 8 2 7}$ \\
q29_inv & $-0,049$ & $-0,066$ & 0,020 & $-0,136$ & 0,026 & $\mathbf{0 , 8 4 7}$ \\
\hline
\end{tabular}

Domínios 1: emoção 2: solicitude 3: controle 4: dano físico 5: incapacidade 6: cura médica. Inv:= item invertido

Considerando-se a coerência teórica entre domínio e item e carga fatorial do item no domínio e os valores da análise de confiabilidade (Tabela 5), foram compostos os domínios expressos na Tabela 4. Para a nova composição dos domínios foram excluídos dez itens $(2,4,5,8,13,14,19$, 20, 21 e 30) e um domínio (medicação). O domínio emoção permaneceu igual à versão original (IAD-breve doente). O domínio controle teve o item 20 excluído e o dano físico teve o item 19 excluído; no domínio solicitude foi excluído o item 14; no domínio incapacidade foi excluído o item 30 e no domínio cura médica foram excluídos os itens 4, 8 e 21 . Todos os itens do domínio medicação foram excluídos $(2,5$, e 13) e esse domínio desapareceu do IAD-profissionais 
Tabela 4 - Proposição de domínios e itens. São Paulo, 2006.

\begin{tabular}{lcc}
\hline \multicolumn{1}{c}{ Domínios } & Itens do IAD - profissionais & $\begin{array}{c}\text { Itens do IAD-breve doentes } \\
\text { (original) }\end{array}$ \\
\hline Emoção & $6,10,15,25$ & $6,10,15,25$ \\
Dano Físico & $11,16,27,28$ & $11,16,19,27,28$ \\
Controle & $1,12,17,22$ & $1,12,17,20,22$ \\
Solicitude & $3,7,9,18$ & $3,7,9,14,18$ \\
Incapacidade & 23,26 & $23,26,30$ \\
Cura Médica & 24,29 & $4,8,21,24,29$ \\
Medicação & - & $2,5,13$ \\
\hline
\end{tabular}

\subsubsection{Análise de Consistência}

A análise de consistência interna de um instrumento é uma das técnicas para estimar a confiabilidade. O coeficiente alfa de Chronbach é o caso mais geral desse tipo de análise. Com essa técnica verifica-se a congruência que cada item do instrumento tem com o restante dos itens. $O$ coeficiente obtido, que pode variar de 0 a 1, reflete o grau de covariância dos itens entre si, servindo de indicador da consistência interna do domínio/ instrumento.

No IAD, as somas dos escores dos itens componentes de cada domínio representam escores de atitudes/crenças no domínio a que se referem. Para verificar a contribuição de cada item na consistência interna do domínio, considerou-se, principalmente, o efeito da retirada de cada item na confiabilidade. A análise de consistência interna foi realizada separadamente para cada domínio e a versão final está apresentada na Tabela 5. 
Tabela 5 - Análise de consistência ( $\alpha$ de Chronbach) de cada domínio do IAD- profissionais. São Paulo, 2006.

\begin{tabular}{|c|c|c|}
\hline Domínio & $\begin{array}{l}\text { Correlação do item com a } \\
\text { correlação total }\end{array}$ & $\alpha$ (se item deletado) \\
\hline \multicolumn{3}{|l|}{ Controle $\alpha=0,643$} \\
\hline Q1 & 0,225 & 0,704 \\
\hline Q12 & 0,611 & 0,452 \\
\hline Q17 & 0,430 & 0,571 \\
\hline Q22 & 0,469 & 0,541 \\
\hline \multicolumn{3}{|l|}{ Emoção $\alpha=0,807$} \\
\hline Q6 & 0,699 & 0,722 \\
\hline Q10 & 0,789 & 0,685 \\
\hline Q15 & 0,490 & 0,834 \\
\hline Q25 & 0,562 & 0,786 \\
\hline \multicolumn{3}{|c|}{ Incapacidade $\alpha=0,688$} \\
\hline Q23 & 0,525 & não se aplica \\
\hline Q26 & 0,525 & não se aplica \\
\hline \multicolumn{3}{|l|}{ Dano Físico $\alpha=0,567$} \\
\hline Q11 & 0,542 & 0,345 \\
\hline Q16 & 0,261 & 0,598 \\
\hline Q27 & 0,281 & 0,552 \\
\hline Q28 & 0,391 & 0,482 \\
\hline \multicolumn{3}{|l|}{ Solicitude $\alpha=0,720$} \\
\hline Q3 & 0,597 & 0,603 \\
\hline Q7 & 0,573 & 0,618 \\
\hline Q9 & 0,375 & 0,729 \\
\hline Q18 & 0,500 & 0,664 \\
\hline \multicolumn{3}{|c|}{ Cura Médica $\alpha=0,595$} \\
\hline Q24 & 0,457 & \\
\hline Q29 & 0,457 & \\
\hline
\end{tabular}

Pela Tabela 5, observa-se que o valor do alfa de Cronbach obtido para o domínio controle foi moderado $(0,643)$, uma vez que o valor máximo que se pode obter para alfa é 1. Para o domínio emoção, o valor do alfa de Cronbach foi bom $(0,807)$, mostrando que o domínio é bastante consistente; a exclusão do item Q15 poderia aumentar mais o valor de alfa, porém como o valor com os quatro itens já está elevado, optou-se por não excluí-lo. No 
domínio incapacidade, o valor do alfa de Cronbach foi considerado moderado $(0,688)$. Para o domínio dano físico, o valor do alfa de Cronbach também foi moderado $(0,567)$. No domínio solicitude, o valor do alfa de Cronbach foi bom $(0,720)$ e no domínio cura médica, o alfa de Cronbach foi moderado $(0,595)^{111}$.

\subsection{Crenças dos profissionais frente à dor}

A seguir, estão apresentadas as crenças dos profissionais frente à dor, avaliadas pelo IAD-profissionais. Serão apresentados os resultados das crenças relativas aos 6 domínios e 20 itens, que foi o modelo confirmado.

Tabela 6 - Análise da freqüência de respostas do Inventário de Atitudes Frente a Dor, por item e por categoria. São Paulo, 2006.

\begin{tabular}{|c|c|c|c|c|c|c|}
\hline Item & Domínio/Assertiva & $\begin{array}{l}\text { Totalmente } \\
\text { falso }\end{array}$ & $\begin{array}{l}\text { Quase } \\
\text { falso }\end{array}$ & $\begin{array}{l}\text { Nem verdadeiro } \\
\text { nem falso }\end{array}$ & $\begin{array}{c}\text { Quase } \\
\text { verdadeiro }\end{array}$ & $\begin{array}{l}\text { Totalmente } \\
\text { verdadeiro }\end{array}$ \\
\hline & Controle & & & & & \\
\hline 1 & $\begin{array}{l}\text { Muitas vezes o doente } \\
\text { consegue influenciar na } \\
\text { intensidade da dor. }\end{array}$ & & $5,3 \%$ & $14,7 \%$ & $37,3 \%$ & $42,7 \%$ \\
\hline 12 & $\begin{array}{l}\text { Consegue-se diminuir a dor } \\
\text { através da concentração ou } \\
\text { relaxamento. }\end{array}$ & - & $2,7 \%$ & $12,0 \%$ & $34,7 \%$ & $50,7 \%$ \\
\hline 17 & $\begin{array}{l}\text { Pode-se controlar a dor } \\
\text { mudando-se os pensamentos. }\end{array}$ & $2,7 \%$ & $4,0 \%$ & $25,3 \%$ & $41,3 \%$ & $26,7 \%$ \\
\hline \multirow[t]{2}{*}{22} & $\begin{array}{l}\text { Pode-se, com certeza, aprender } \\
\text { a lidar com a dor. }\end{array}$ & $1,3 \%$ & $4,0 \%$ & $13,3 \%$ & $41,3 \%$ & $40,0 \% \%$ \\
\hline & Emoção & & & & & \\
\hline 6 & A ansiedade aumenta a dor. & - & - & $5,3 \%$ & $12,0 \%$ & $82,7 \%$ \\
\hline 10 & O estresse aumenta a dor. & - & - & $5,3 \%$ & $6,7 \%$ & $88,0 \%$ \\
\hline 15 & A depressão aumenta a dor. & - & $2,7 \%$ & $1,3 \%$ & $18,7 \%$ & $77,3 \%$ \\
\hline \multirow[t]{2}{*}{25} & $\begin{array}{l}\text { Há uma forte ligação entre as } \\
\text { emoções e a intensidade da } \\
\text { dor. }\end{array}$ & - & $1,3 \%$ & $1,3 \%$ & $16,0 \%$ & $81,3 \%$ \\
\hline & Incapacidade & & & & & \\
\hline 23 & $\begin{array}{l}\text { A dor não impede de se levar } \\
\text { uma vida fisicamente ativa }\end{array}$ & $5,3 \%$ & $8,0 \%$ & $24,0 \%$ & $34,7 \%$ & $28,0 \%$ \\
\hline 26 & $\begin{array}{l}\text { A pessoa com dor pode fazer } \\
\text { quase tudo que fazia antes de } \\
\text { ter dor. }\end{array}$ & $12,0 \%$ & $14,7 \%$ & $26,7 \%$ & $34,7 \%$ & $12,0 \%$ \\
\hline
\end{tabular}




\begin{tabular}{|c|c|c|c|c|c|c|}
\hline Item & Domínio/Assertiva & $\begin{array}{l}\text { Totalmente } \\
\text { falso }\end{array}$ & $\begin{array}{l}\text { Quase } \\
\text { falso }\end{array}$ & $\begin{array}{l}\text { Nem verdadeiro } \\
\text { nem falso }\end{array}$ & $\begin{array}{c}\text { Quase } \\
\text { verdadeiro }\end{array}$ & $\begin{array}{l}\text { Totalmente } \\
\text { verdadeiro }\end{array}$ \\
\hline & \multicolumn{6}{|l|}{ Solicitude } \\
\hline 3 & $\begin{array}{l}\text { Sempre que alguém sente dor a } \\
\text { família deve tratá-lo melhor. }\end{array}$ & $14,7 \%$ & $14,7 \%$ & $45,3 \%$ & $12,0 \%$ & $13,3 \%$ \\
\hline 7 & $\begin{array}{l}\text { Sempre que alguém sente dor } \\
\text { as pessoas devem tratá-lo com } \\
\text { cuidado e preocupação. }\end{array}$ & $9,3 \%$ & $10,7 \%$ & $24,0 \%$ & $25,3 \%$ & $30,7 \%$ \\
\hline 9 & $\begin{array}{l}\text { É responsabilidade dos que } \\
\text { amam o doente, ajudarem-no } \\
\text { quando ele sente dor. }\end{array}$ & $2,7 \%$ & $4,0 \%$ & $20,0 \%$ & $25,3 \%$ & $48,0 \%$ \\
\hline \multirow[t]{2}{*}{18} & $\begin{array}{l}\text { Muitas vezes, quando se está } \\
\text { com dor, precisa-se receber } \\
\text { mais carinho que se está } \\
\text { recebendo. }\end{array}$ & $8,0 \%$ & $9,3 \%$ & $37,3 \%$ & $33,3 \%$ & $12,0 \%$ \\
\hline & \multicolumn{6}{|l|}{ Cura } \\
\hline 24 & A dor física nunca será curada. & $45,3 \%$ & $28,0 \%$ & $18,7 \%$ & $6,7 \%$ & $1,3 \%$ \\
\hline \multirow[t]{2}{*}{29} & $\begin{array}{l}\text { Não há procedimento médico } \\
\text { que ajude na dor. }\end{array}$ & $88,0 \%$ & $6,7 \%$ & $2,7 \%$ & $1,3 \%$ & $1,3 \%$ \\
\hline & \multicolumn{6}{|l|}{ Dano Físico } \\
\hline 11 & $\begin{array}{l}\text { Exercício e movimento são } \\
\text { bons para o doente com dor. }\end{array}$ & $1,3 \%$ & $2,7 \%$ & $20,0 \%$ & $33,3 \%$ & $42,7 \%$ \\
\hline 16 & $\begin{array}{l}\text { O exercício pode piorar ainda } \\
\text { mais a dor. }\end{array}$ & $14,7 \%$ & $21,3 \%$ & $36,0 \%$ & $14,7 \%$ & $13,3 \%$ \\
\hline 27 & $\begin{array}{l}\text { Se a pessoa com dor não fizer } \\
\text { exercícios regularmente a dor } \\
\text { continuará a piorar. }\end{array}$ & $4,0 \%$ & $8,0 \%$ & $36,0 \%$ & $32,0 \%$ & $20,0 \%$ \\
\hline 28 & $\begin{array}{l}\text { A prática de exercícios pode } \\
\text { diminuir a intensidade da dor. }\end{array}$ & $1,3 \%$ & - & $10,7 \%$ & $44,0 \%$ & $44,0 \%$ \\
\hline
\end{tabular}

Na Tabela 6 nota-se que no domínio controle (itens 1, 12, 17 e 22) $78 \%$ das respostas foram ser "totalmente ou quase verdadeira" a crença de que é possível ter influência pessoal sobre a dor.

No domínio emoção (itens 6, 10, 15 e 25) um percentual elevado de respostas (cerca de 96\%) referiu ser "quase verdadeiro" ou "totalmente verdadeiro" que as emoções influem na experiência dolorosa.

No domínio incapacidade (itens 23 e 26), em $55 \%$ das respostas há o reconhecimento, mesmo que em graus variáveis, de que a dor não é causa de incapacidade; $20 \%$ das respostas indicaram claramente a crença de que a dor é causa de incapacidade e, $25 \%$ das respostas situaram-se no ponto neutro (nem verdadeiro e nem falso). 
Em relação ao domínio dano físico (itens 11, 16, 27, 28), em cerca de $63 \%$ das respostas há o reconhecimento de que a dor não está relacionada à um "dano físico"; observa-se que em 3 das 4 questões, cerca de 1/3 das respostas indicaram não haver opinião consolidada (nem verdadeiro e nem falso); na questão 16 , cerca de $28 \%$ indicam a crença de que há algum problema físico, "machucado" na dor crônica e que o exercício pode piorar a dor.

Em relação ao domínio solicitude (itens 3, 7, 9 e 18) nota-se que a maioria das respostas indicaram crença de que a solicitude é desejável $(50 \%$ dos profissionais responderam acreditar que é responsabilidade de outros ajudar e ou cuidar das pessoas com dor crônica); há um índice importante de "sem opinião formada" ( $32 \%$ mantiveram-se no ponto neutro) e apenas $18 \%$ indicaram não serem favorável à crença de solicitude.

No domínio cura médica (itens 24 e 29), em torno de $84 \%$ das respostas explicitaram a crença na cura para a dor crônica, $11 \%$ mantiveram-se no ponto neutro e apenas cerca de $5 \%$ das respostas indicaram não acreditar na cura para a dor crônica.

A seguir, apresenta-se a estatística descritiva sobre as crenças dos profissionais.

Tabela 7 - Estatística descritiva das crenças dos profissionais. São Paulo, 2006.

\begin{tabular}{lcccccc}
\hline & N & Média & Mediana & $\begin{array}{l}\text { Desvio } \\
\text { Padrão }\end{array}$ & Mínimo & Máximo \\
\hline Controle & 75 & 3,1 & 3,2 & 0,6 & 1,0 & 4,0 \\
Emoção & 75 & 3,7 & 4,0 & 0,4 & 1,75 & 4,0 \\
Incapacidade & 75 & 1,5 & 1,5 & 1,0 & 0,0 & 4,0 \\
Dano Físico & 75 & 1,2 & 1,2 & 0,65 & 0,0 & 3,25 \\
Solicitude & 75 & 2,5 & 2,5 & 0,84 & 0,5 & 4,0 \\
Cura Médica & 75 & 3,4 & 3,5 & 0,7 & 0,0 & 4,0 \\
\hline
\end{tabular}


A Tabela 7 apresenta as médias e medianas das crenças dos profissionais em relação à dor crônica não oncológica. Considerando-se que o escore "desejável" para os domínios controle e emoção é 4, para os domínios incapacidade, dano físico, solicitude e cura médica é 0 e que o escore 2 representa o ponto de mudança de atitude, ponto "neutro" (nem verdadeiro nem falso), observamos que a orientação foi desejável, embora em graus diferentes, nos domínios controle, emoção, incapacidade e dano físico e não foi desejável para os domínios solicitude e cura médica.

No domínio controle, a média e a mediana estão acima do valor 3 , sugerindo orientação da crença fortemente no sentido "desejável".

No domínio emoção, a média e a mediana estão muito próximas do valor 4 , o que indica também orientação no sentido fortemente "desejável".

No domínio incapacidade, a crença está orientada para o sentido "desejável"; os valores da média e da mediana $(1,5)$ indicam que os profissionais acreditam, moderadamente, que a dor não é causa de incapacidade.

No domínio dano físico, o sentido também foi "desejável"; os valores da média e da mediana $(1,2)$ indicam que os profissionais acreditam, moderadamente, que a dor não é indicativa de dano tecidual.

No domínio solicitude, a crença não foi desejável; a média e a mediana $(2,5)$ indicam que os profissionais crêem, moderadamente, que manifestações de solicitude são desejáveis quando o doente expressa dor.

No domínio cura médica, a crença não foi desejável; os valores da média e da mediana acima de 3 demonstram que os profissionais acreditam, fortemente, na cura da dor crônica. 


\subsection{Análise de Cluster}

Havia a hipótese de que algumas características dos profissionais poderiam influir na crença. Como não se queria comparar variável por variável (crença versus sexo, idade, tempo de formado, profissão, titulação, auto-avaliação da experiência e número de doentes atendidos por mês) optou-se por fazer uma análise que envolvia o conjunto das variáveis. A análise de cluster possibilitou a formação de agrupamentos dos indivíduos, a partir das variáveis sócio-demográficas, de formação e experiência profissional. Os grupos foram compostos utilizando-se o método do KMédias. A comparação entre os grupos foi feita pelo Qui-quadrado e para confirmação do resultado foi aplicado o teste Monte Carlo.

Foram formados 3 clusters e a Tabela 8 mostra o tamanho dos grupos.

Tabela 8 - Distribuição dos profissionais por grupos.São Paulo, 2006.

\begin{tabular}{lcc}
\hline Grupo & N & $\%$ \\
\hline Grupo 1 & 19 & 25,3 \\
Grupo 2 & 26 & 34,7 \\
Grupo 3 & 30 & 40,0 \\
\hline Total & $\mathbf{7 5}$ & $\mathbf{1 0 0 , 0}$ \\
\hline
\end{tabular}

A seguir estão apresentadas as características que se destacaram para cada um dos grupos encontrados. As características que se destacam em cada grupo foram marcadas em negrito (Tabela 9). 
Tabela 9 - Características sócio-demográficas, de formação e de experiência dos grupos. São Paulo, 2006.

\begin{tabular}{|c|c|c|c|c|c|c|c|}
\hline & & \multicolumn{6}{|c|}{ Cluster (Grupos) } \\
\hline & & \multicolumn{2}{|c|}{1} & \multicolumn{2}{|c|}{2} & \multicolumn{2}{|c|}{3} \\
\hline & & $\mathbf{N}$ & $\%$ & $\mathbf{N}$ & $\%$ & $\mathbf{N}$ & $\%$ \\
\hline \multirow{3}{*}{ Idade } & Até 37 anos & 6 & 31,6 & 10 & 38,5 & 10 & 33,3 \\
\hline & Acima de 37 a 45 anos & 7 & 36,8 & 9 & 34,6 & 8 & 26,7 \\
\hline & Acima de 45 anos & 6 & 31,6 & 7 & 26,9 & 12 & 40,0 \\
\hline Sexo & $\begin{array}{l}M \\
F\end{array}$ & $\begin{array}{c}13 \\
6\end{array}$ & $\begin{array}{l}\mathbf{6 8 , 4} \\
31,6\end{array}$ & $\begin{array}{c}7 \\
19\end{array}$ & $\begin{array}{l}26,9 \\
73,1\end{array}$ & $\begin{array}{l}17 \\
13\end{array}$ & $\begin{array}{l}56,7 \\
43,3\end{array}$ \\
\hline \multirow{6}{*}{ Profissão } & Médico & 17 & 89,5 & 1 & 3,8 & 26 & 86,7 \\
\hline & Enfermeiro & 1 & 5,3 & 0 & & 4 & 13,3 \\
\hline & Fisioterapeuta & & & 11 & 42,3 & & \\
\hline & Psicólogo & & & 6 & 23,1 & & \\
\hline & Dentista & 1 & 5,3 & 7 & 26,9 & & \\
\hline & Assistente Social & & & 1 & 3,8 & & \\
\hline \multirow{5}{*}{ Titulação } & Graduação & 1 & 5,3 & 4 & 15,4 & 17 & 56,7 \\
\hline & Especialização & & & 19 & 73,1 & 13 & 43,3 \\
\hline & Mestrado & 8 & $42,1 \%$ & 3 & 11,5 & & \\
\hline & Doutorado & 9 & $47,4 \%$ & & & & \\
\hline & Pós-doutorado & 1 & $5,3 \%$ & & & & \\
\hline \multirow[t]{2}{*}{ Dor Aguda } & Pouco/Moderado & 13 & 68,4 & 17 & 65,4 & 23 & 76,7 \\
\hline & Maioria & 6 & 31,6 & 9 & 34,6 & 7 & 23,3 \\
\hline Dor Crônica & Pouco/Moderado & 17 & 89,5 & 23 & 88,5 & 22 & 73,3 \\
\hline Oncológica & Maioria & 2 & 10,5 & 3 & 11,7 & 8 & 26,7 \\
\hline \multirow{2}{*}{$\begin{array}{l}\text { Dor Crônica Não } \\
\text { Oncológica }\end{array}$} & Pouco/Moderado & 8 & 42,1 & 12 & 46,2 & 13 & $43,3 \%$ \\
\hline & Maioria & 11 & 57,9 & 14 & 53,8 & 17 & 56,7 \\
\hline \multirow{3}{*}{$\begin{array}{l}\text { número doentes com } \\
\text { dor crônica não } \\
\text { oncológica atendidos } \\
\text { ao mês }\end{array}$} & entre 1 e 10 & 3 & 15,8 & 15 & 57,7 & 5 & 16,7 \\
\hline & entre 11 e 20 & 6 & 31,6 & 8 & 30,8 & 5 & 16,7 \\
\hline & + de 21 & 10 & 52,6 & 3 & 11,5 & 20 & 66,7 \\
\hline \multirow{3}{*}{$\begin{array}{l}\text { Auto- avaliação da } \\
\text { experiência com dor } \\
\text { crônica }\end{array}$} & Pouco experiente & 3 & 15,8 & 2 & 23,1 & 3 & 10,0 \\
\hline & Mediano experiente & 11 & $57,9 \%$ & 15 & 57,7 & 19 & 63,3 \\
\hline & Muito experiente & 5 & $26,3 \%$ & 5 & $19,2 \%$ & 8 & 26,7 \\
\hline
\end{tabular}

A Tabela 9 demonstra a composição de cada um dos grupos. $O$ Cluster 1 foi formado por homens, médicos e mais graduados e foi denominado médicos/pós-graduados. O Cluster 2 foi formado por mulheres, profissionais não médicos, com especialização e pouco experiente no cuidado ao doente com dor cônica não oncológica e foi denominado não 
médicos/especializados/pouco experientes. O Cluster 3 representa os profissionais com graduação e que atendem doentes com dor crônica oncológica e foi denominado graduados/dor crônica oncológica.

Na Tabela 10 está apresentada a estatística descritiva dos domínios para cada um dos Clusters formados e o resultado da comparação dos valores de cada domínio entre os grupos

Tabela 10 - Comparação das crenças (domínios) entre os clusters. São Paulo, 2006.

\begin{tabular}{|c|c|c|c|c|c|}
\hline & & \multicolumn{3}{|c|}{ Cluster (Grupos) } & \multirow{2}{*}{$p$-valor } \\
\hline & & 1 & 2 & 3 & \\
\hline \multirow{6}{*}{ Emoção } & $\mathrm{N}$ & 19 & 26 & 30 & \multirow{6}{*}{0,329} \\
\hline & Média & 3,62 & 3,88 & 3,78 & \\
\hline & Mediana & 4,00 & 4,00 & 4,00 & \\
\hline & Desvio Padrão & 0,56 & 0,25 & 0,47 & \\
\hline & Mínimo & 2,50 & 3,00 & 1,75 & \\
\hline & Máximo & 4,00 & 4,00 & 4,00 & \\
\hline \multirow{6}{*}{ Dano Físico } & $\mathrm{N}$ & 19 & 26 & 30 & \multirow{6}{*}{0,114} \\
\hline & Média & 1,46 & 1,09 & 1,21 & \\
\hline & Mediana & 1,50 & 0,75 & 1,25 & \\
\hline & Desvio Padrão & 0,58 & 0,76 & 0,58 & \\
\hline & Mínimo & 0,50 & 1,00 & 0,00 & \\
\hline & Máximo & 2,50 & 3,25 & 2,75 & \\
\hline \multirow{6}{*}{ Controle } & $N$ & 19 & 26 & 30 & \multirow{6}{*}{0,591} \\
\hline & Média & 3,05 & 3,13 & 3,17 & \\
\hline & Mediana & 3,00 & 3,00 & 3,25 & \\
\hline & Desvio Padrão & 0,54 & 0,59 & 0,68 & \\
\hline & Mínimo & 2,00 & 2,00 & 1,00 & \\
\hline & Máximo & 4,00 & 4,00 & 4,00 & \\
\hline \multirow{6}{*}{ Solicitude } & $\mathrm{N}$ & 19 & 26 & 30 & \multirow{6}{*}{0,398} \\
\hline & Média & 2,24 & 2,47 & 2,67 & \\
\hline & Mediana & 2,00 & 2,63 & 2,63 & \\
\hline & Desvio Padrão & 0,72 & 1,01 & 0,75 & \\
\hline & Mínimo & 1,00 & 0,50 & 1,00 & \\
\hline & Máximo & 3,50 & 4,00 & 4,00 & \\
\hline \multirow{6}{*}{ Cura } & $\mathrm{N}$ & 19 & 26 & 30 & \multirow{6}{*}{0,625} \\
\hline & Média & 3,50 & 3,29 & 3,53 & \\
\hline & Mediana & 3,50 & 3,50 & 4,00 & \\
\hline & Desvio Padrão & 0,55 & 0,87 & 0,69 & \\
\hline & Mínimo & 2,00 & 0,00 & 1,00 & \\
\hline & Máximo & 4,00 & 4,00 & 4,00 & \\
\hline \multirow{6}{*}{ Incapacidade } & $\mathrm{N}$ & 19 & 26 & 30 & \multirow{6}{*}{0,284} \\
\hline & Média & 1,80 & 1,65 & 1,44 & \\
\hline & Mediana & 1,00 & 1,50 & 1,33 & \\
\hline & Desvio Padrão & 0,75 & 0,94 & 0,87 & \\
\hline & Mínimo & 0,00 & 0,33 & 0,00 & \\
\hline & Máximo & 2,67 & 3,67 & 2,67 & \\
\hline
\end{tabular}


Pela Tabela 10 observa-se que não houve diferença estatisticamente significante entre os domínios e os clusters. 
Discussão 


\section{DISCUSSÃO}

O conhecimento e as crenças dos profissionais de saúde interferem no diagnóstico que fazem e no tratamento que administram ${ }^{1-11,62 \text {, }}$ $82-86,98,105,112$. O comportamento do profissional frente a um determinado problema sofre influência de suas experiências prévias, das crenças e das expectativas construídas ao longo da vida as quais, se inadequadas, podem resultar em proposições terapêuticas equivocadas ${ }^{96,113}$.

Dor crônica é um fenômeno cuja percepção, apreciação e expressão resultam de inúmeras interações entre elementos biológicos, cognitivos e socioculturais, que influenciam no modo de o indivíduo perceber e expressar a dor e lidar com ela ${ }^{96}$. Essa concepção de dor exige estratégias de avaliação e tratamento que considerem essa multidimensionalidade. No entanto, os estudos e a observação da prática clínica mostram que nem todos os profissionais atuam em concordância com esse conceito, sugerindo déficits de conhecimento e crenças inadequadas sobre dor crônica, que persistem há mais de 30 anos 15-18, 20-22, 25, 27, 62, 70, 77-82, 85-87, 112, 113 .

$\mathrm{Na}$ literatura científica e na observação da prática clínica diária, nota-se que, mesmo após módulos educacionais, protocolos de avaliação sistematizada da dor, organização de serviços de dor e divulgação do tema dentro da instituição, nem sempre houve mudança nas atitudes dos profissionais, médicos de diversas especialidades, enfermeiros ou fisioterapeutas, quanto à importância de se considerar o relato de dor do doente, avaliar e propor tratamentos para os aspectos cognitivos e psicocomportamentais da dor. Tais fatos e a escassa literatura sobre o tema despertaram o desejo de realizar o presente estudo, que objetivou analisar as crenças dos profissionais sobre dor crônica. Pela inexistência de instrumento para avaliar as crenças de profissionais frente à dor crônica, optou-se por adaptar um instrumento que avalia crenças dos doentes para profissionais. 
Setenta e cinco profissionais, que representaram $59,5 \%$ dos que atuavam em Centros de Dor da cidade de São Paulo foram avaliados.

A distribuição frente ao sexo foi semelhante. A idade média dos profissionais foi de 42 anos e o tempo de formado foi, em média, 16 anos; a maioria foi de médicos $(58,7 \%)$, seguidos pelos fisioterapeutas $(14,7 \%)$; a maior parte possuía especialização em diversas áreas, e 26,7\% mestrado ou doutorado. Os profissionais auto-avaliaram sua experiência com doentes com dor crônica como moderada (44\% atendiam mais de 20 doentes com dores crônicas ao mês), conforme Tabela 1.

Significativa parcela dos profissionais possuía elevada formação acadêmica, e a especialização em diversas áreas explica-se, possivelmente, pela falta do título de especialista em dor em nosso meio.

Observou-se pequena parcela de assistentes sociais $(1,3 \%)$, enfermeiros $(6,7 \%)$, psicólogos (8\%), dentistas $(10,7 \%)$ e fisioterapeutas $(14,7 \%)$ nas equipes e isso chamou a atenção, pois, pela etiopatogenia, a avaliação e o tratamento da dor incluem várias modalidades e procedimentos além dos realizados por médicos. A carência desses profissionais pode afetar os resultados terapêuticos.

Encontraram-se enfermeiros apenas em cinco dos nove serviços analisados e isso pode comprometer a qualidade do atendimento. $\mathrm{Na}$ dor aguda os enfermeiros são fundamentais para a vigilância e ajuste rápido da terapêutica; na dor crônica, os enfermeiros desenvolvem ações de educação e suporte emocional aos doentes e familiares, implementam estratégias terapêuticas não farmacológicas, padronizam modelos de avaliação e de registro, estabelecem fluxo de comunicação entre os profissionais, atuam para maximizar a adesão ao tratamento, investigam a ocorrência de efeitos colaterais e propõem ações que os evitem ou minimizem.

Para a identificação das crenças dos profissionais de saúde sobre dor crônica foi utilizado o Inventário de Atitudes Frente à Dor-profissionais 
pré-teste (Anexo 3). Após sua aplicação nos profissionais, procedeu-se à análise das propriedades psicométricas.

Após análise fatorial e análise da confiabilidade interna, por meio do alfa de Cronbach, o instrumento que originalmente possuía 7 domínios e 30 itens, foi validado com 6 domínios e 20 itens (Tabela 4). Foram excluídos todos itens que não apresentaram carga fatorial acima de 0,3 em seu domínio original (Tabela 2, 3, 4, 5) e, desse modo, 10 itens e um domínio (medicação) deixaram de existir na versão final do inventário (Anexo 4). Nenhum dos itens do domínio medicação apresentou carga fatorial adequada no domínio original, como se não houvesse correlação entre eles.

Os itens 2, 4, 5, 8, 13, 14, 19, 20, 21 foram excluídos por não apresentaram carga fatorial adequada no domínio original e o item 30 foi excluído pois sua retirada melhorava o alfa de Cronbach (de 0,529 para 0,688). O alfa de Cronbach dos seis domínios variou de moderado a bom $(0,567$ a 0,807$)$, o que é considerado suficiente para a mensuração de conceitos subjetivos $^{111}$.

A possibilidade de se manterem seis domínios com confiabilidade adequada indicou que a transposição para profissionais do modelo de crenças frente à dor de doentes foi possível, o que sugere coerência desse modelo de crenças frente à dor. Por outro lado, a necessidade de exclusão de 10 itens, do domínio medicação e os valores moderados do Alfa de Cronbach nos domínios dano físico e cura médica $(0,567$ e 0,595 respectivamente) sugerem que o modelo de crenças frente à dor dos doentes para os profissionais talvez possa ser aperfeiçoado. Indaga-se se o problema deveu-se ao ajuste da linguagem ou se os conceitos e crenças dos profissionais sobre dor crônica seriam diferentes dos dos doentes. $O$ ocorrido com o item 14 do domínio solicitude é um bom exemplo.

O item 14 não teve carga fatorial adequada em solicitude, mas teve carga fatorial adequada em controle. Esse item parece não ter mantido o mesmo significado ao ser adaptado para o IAD-profissionais. "A família 
precisa aprender a lidar melhor com o doente quando ele está com dor", pressupunha uma resposta tendendo ao totalmente falso, visto querer significar que a família não devia manifestar excesso de solicitude toda vez que o doente sentisse dor e sim estimular o autocuidado, a independência e a movimentação. Porém "aprender a lidar melhor com o doente" parece que foi entendido que a família deveria ser educada para aprender a lidar com o doente, o que Ihe possibilitaria exercer melhor controle sobre a situação.

É interessante notar que alfa de Cronbach moderado foi observado nos domínios dano físico e cura médica, e que o domínio excluído foi o de medicação. As crenças representadas nesses domínios diferem das do senso comum de dor e de doença. No modelo clássico de dor e de doença, sempre há um dano físico que se espera curar e a cura geralmente se dá por meio de medicamentos e cirurgias. Na dor crônica, o dano físico (existência de uma lesão observável) e a cura no sentido clássico (algo que vai embora e nunca mais volta) nem sempre são possíveis e os remédios nem sempre são bons tratamentos para controlar/curar a dor. Talvez isso tenha trazido dificuldades que influíram na consistência desses domínios.

Para a análise das crenças dos profissionais foram consideradas somente as respostas dadas aos itens e domínios mantidos no inventário final, isto é, confirmados pela análise fatorial e de confiabilidade.

Considerando-se que havia grande número de profissionais com doutorado, mestrado, especialização e todos atuavam em clínicas de dor, poder-se-ia supor que as crenças sobre dor fossem totalmente adequadas, 0 que nem sempre ocorreu.

A definição de quais são as orientações "desejáveis" para as atitudes frente à dor crônica (crenças desejáveis) talvez tenha que ser dinâmica, devido à imaturidade teórica dos domínios do IAD, à perspectiva da Teoria Comportamental Cognitiva que esteia esse inventário e às diversas articulações teóricas que estão sendo feitas ${ }^{96}$. Porém, frente ao 
conhecimento disponível, é possível considerar a proposta de Jensen (informação pessoal) apud Pimenta ${ }^{96}$ sobre as orientações "desejáveis" das atitudes frente à dor como eixo norteador das discussões. Jensen propôs que as crenças mais desejáveis são as seguintes: a emoção influi na dor, é possível a interferência pessoal para o controle da dor crônica, dor não é causa de incapacidade, a piora da dor não se deve ao agravamento da lesão, solicitude não é desejável frente à manifestação de dor e não se pode esperar cura médica para a dor crônica.

Entre as respostas dos 75 entrevistados, 96\% referem ser "quase ou totalmente verdadeiro" que as emoções influem na experiência dolorosa, $78 \%$ indicaram ser "totalmente ou quase verdadeira" a crença de que é possível influência pessoal sobre a dor, $63 \%$ referem que a piora da dor não indica piora da lesão e 55\% mostraram que a dor crônica não incapacita e essas crenças foram "desejáveis". No entanto, $50 \%$ das respostas indicaram a crença de que a manifestação de solicitude é desejável e 84\% explicitaram a crença na cura da dor crônica, e essas crenças são consideradas "indesejáveis". Desejável e indesejável significa lidar melhor com o quadro álgico, ser mais ou menos funcional, auxiliar ou não na recuperação. Crenças menos funcionais parecem contribuir para a incapacidade e, algumas vezes, para expectativas não realistas (Tabela 6).

Relembrando que a direção desejável era 4 para os domínios emoção e controle e 0 para os domínios incapacidade, dano físico, solicitude e cura médica, observaram-se crenças fortemente desejáveis nos domínios controle $(3,1)$ e emoção $(3,7)$. As crenças foram moderadamente favoráveis nos domínios dano físico $(1,2)$ e incapacidade $(1,5)$. No domínio solicitude $(2,5)$ as crenças foram moderadamente não desejáveis e na cura médica $(3,4)$ foi fortemente indesejável, conforme Tabela 7.

As crenças dos profissionais e as médias de intensidade nos seis domínios de atitudes frente à dor estão a seguir analisadas.

*Mark P. Jensen, correspondência pessoal (e-mail), 1999. 
No domínio Controle (Tabela 6), apesar de 78\% das respostas serem na direção desejável (é possível haver controle pessoal sobre a dor) e a média do domínio ser 3,1 (Tabela 7), em torno de $39 \%$ das respostas graduaram-se como "quase verdadeiro", o que mostra que ainda há dúvidas sobre essa crença. Reforça essa idéia o fato de que no item 17, que avalia a crença de que o pensamento influi na dor, apenas $26,7 \%$ das respostas foram totalmente favoráveis a ela. No entanto, a Teoria da Comporta da Dor, proposta por Melzack e Wall ${ }^{95}$, enfatiza o mecanismo neurofisiológico a que dor é uma sensação e uma emoção, resultante e modulada pela interação do estímulo nocivo com fatores cognitivos e emocionais individuais relacionados à dor, tais como humor, crenças, expectativas, experiências anteriores, atitudes, conhecimentos e significado simbólico atribuído à queixa.

Trinta e nove por cento das respostas indicaram dúvidas a respeito da habilidade pessoal em controlar a dor (quase verdadeiro), 17\% indicaram opinião não formada e 5\% referiram-se à crença de não ser possível a interferência pessoal para o controle da dor.

Sabe-se que os doentes precisam ser educados para controlar a dor, utilizando diversas intervenções analgésicas (farmacológicas, fisioterápicas, educacionais e de relaxamento, entre outras) que reduzem a oferta de substâncias álgicas na periferia, interferem nos processos de transmissão e interpretação da dor e estimulam o sistema de modulação da dor ${ }^{2}$. Sabe-se também ser preciso aumentar o senso de controle e autoeficácia dos doentes para melhorar o bem-estar e os resultados do tratamento. Não crer que se seja capaz de controlar a dor pode levar os profissionais a não utilizarem estratégias de autocuidado, a aumentarem o sentimento de impotência e incapacidade dos doentes. O mais importante nesse domínio é que o doente perceba-se com possibilidades internas para atuar e sentir-se responsável pelo controle da sua dor. Educar o doente para utilizar uma ou diversas dessas estratégias é conseqüência desse processo $^{79,114}$. 
No domínio emoção (Tabela 6), cerca de 96\% das respostas indicaram ser "quase verdadeiro" ou "totalmente verdadeiro" que as emoções influem na experiência dolorosa e a média do domínio foi 3,7. Apenas $1 \%$ dos profissionais negaram a influência da emoção na experiência dolorosa e 3\% mantiveram-se no ponto neutro. O percentual de resposta "totalmente verdadeiro" foi o dobro $(82 \%$ x $39 \%)$ do observado no domínio controle, que avaliou a influência pessoal e a dos processos cognitivos sobre a dor e isso causou estranheza. Considerando-se que a emoção é também um processo cognitivo, esperava-se que as respostas fossem semelhantes.

Os profissionais responderam com muita convicção que a ansiedade, a depressão e o estresse aumentam a dor, mas um menor número de respostas expressou que o pensamento influi na dor. Pode ser que a maior aceitação da relação dor e emoção esteja relacionada à maior verbalização do doente sobre esse fato ("quando fico nervoso a dor piora") ou a uma maneira de responsabilizar o doente pelo insucesso terapêutico. É comum observar-se, por parte dos profissionais, a explicitação de que os "problemas emocionais" são os responsáveis pela exacerbação da dor, como se essas alterações emocionais não compusessem o quadro e só dependessem da vontade do doente. Inúmeras publicações demonstraram que o medo, a depressão, a ansiedade, o estresse, a intensidade e a duração da dor interferem no mecanismo final de percepção do fenômeno doloroso, tornando-o extremamente complexo e variável; que é intrínseca à vivência dolorosa a confluência entre os aspectos biológicos e emocionais com os relacionados à cognição; que a dor crônica é um processo psicológico com componentes afetivos, cognitivos, motivacionais, interpretativos e somáticos" ${ }^{\prime 15}$. Ansiedade, medo, depressão e estresse no doente com dor devem ser entendidos pelos profissionais como fatores que advêm e intensificam a percepção dolorosa. O medo de sentir dor é o responsável, na maior parte dos casos, por comportamentos tais como evitar atividades ou situações relacionadas à dor, o que resulta na manutenção da incapacidade. As queixas exacerbadas de dor, as dores desproporcionais à 
lesão, que não melhoram com terapias analgésicas, podem levar os profissionais a rotularem os doentes de "psicados" e a "abandoná-los", quando o esperado seria que o tratamento emocional fosse acrescido ao tratamento médico convencional ${ }^{96,112,114,115}$. Observando-se os respondentes, percebe-se que o número de enfermeiros e psicólogos, que poderiam dar maior apoio nesse sentido, é pequeno, o que leva a uma reflexão sobre o conhecimento e valorização desses aspectos pelos profissionais e sobre a disponibilidade e uso de intervenções psicossociais para o tratamento da dor nos serviços.

No domínio incapacidade (Tabela 6), em 55\% das respostas há o reconhecimento, mesmo que em graus variáveis, de que a dor não é causa de incapacidade. Vinte por cento (20\%) das respostas indicaram claramente a crença de que a dor é causa de incapacidade e $25 \%$ das respostas situaram-se no ponto neutro (nem verdadeiro e nem falso), mostrando que esse conceito precisa ser mais bem firmado. A média nesse domínio foi de 1,5. Essa crença pode estar relacionada ao excessivo afastamento do trabalho, à dependência familiar e ao retraimento do doente, com grande impacto físico, emocional e social.

"Incapacidade é conceito muito importante para a compreensão dos doentes com dor crônica. Não há relação direta entre patologia, dor e incapacidade. A avaliação da incapacidade pode ser vista exclusivamente sob a óptica do modelo biomédico tradicional, ou acrescida de aspectos psicossociais. De acordo com o referencial teórico que se possui, os instrumentos e os métodos de avaliação são elaborados e selecionados. Há quatro grupos de modelos de instrumento de avaliação de incapacidade. $O$ modelo biomédico tradicional prevalente na atualidade está centrado nas questões físicas (exercer atividades, deambulação, função dos membros) e nas necessidades de reabilitação física. Esse modelo transformou a incapacidade em preocupação médica mais que social ou moral. Os modelos de desconforto subjetivo (gradação do sofrimento e da insatisfação com a limitação), o modelo comparativo (o indivíduo consigo mesmo e o 
indivíduo comparado a outras pessoas) e o modelo de independência (necessidade de auxílio de pessoas e máquinas) devem ser complementares ao primeiro" ${ }^{96}$. O conteúdo dos itens do domínio incapacidade do IAD, aproxima-se do modelo comparativo.

A crença do quanto de incapacidade pode advir da dor varia entre os doentes e também entre os profissionais e parece que educação adequada pode ajustar crenças disfuncionais. Em estudo ${ }^{65}$ em que se compararam atitudes e crenças dos profissionais de saúde pública às dos profissionais de reabilitação sobre os prejuízos advindos da lombalgia crônica, observou-se que os profissionais de reabilitação julgaram a incapacidade decorrente da lombalgia com menor magnitude que os profissionais de saúde pública. Latimer, Maher, Refshauge ${ }^{81}$, em estudo explorando as atitudes e crenças dos estudantes de fisioterapia sobre lombalgia, identificaram que as atitudes e crenças dos estudantes que não tiveram um módulo de ensino sobre lombalgia são similares às dos cuidadores não profissionais.

A queixa de incapacidade varia muito entre os indivíduos e parece se tratar, também, de atitudes e comportamento culturalmente aprendidos. A incapacidade pode ser inadvertidamente reforçada pelos amigos, familiares, colegas de trabalho e profissionais de saúde. Daykin e Richadson ${ }^{83}$, em estudo qualitativo com fisioterapeutas evidenciaram que as crenças desses profissionais sobre dor podiam influenciar no tratamento que eles administravam aos doentes.

É importante que os profissionais tenham crenças adequadas em relação à incapacidade para que os doentes possam ser orientados de forma a aderirem aos programas de reabilitação. As atividades físicas de flexibilidade, de fortalecimento muscular e de condicionamento cardiovascular são fundamentais para a manutenção do bem-estar e para a prevenção de recorrências ou de agravamento da dor. O programa de atividade física visa à restauração da função, da força e do trofismo muscular, ao relaxamento da musculatura, ao desenvolvimento de 
movimentos coordenados, eficientes e uniformes, à restauração da flexibilidade e à prevenção da síndrome do desuso ${ }^{63}$.

É importante ressaltar que os programas de reabilitação são dispendiosos, tanto para o doente quanto para os seguros de saúde, e demandam tempo, sendo algumas vezes mais "vantajoso" para ambos optarem por tratamentos invasivos, na tentativa de melhorar a incapacidade e reduzir o tempo de doença. Esses procedimentos, entretanto, pode acentuar frustrações, piorar a incapacidade, exacerbar a busca por outros profissionais que prometam tratamentos "mágicos", expondo o doente a situações cada vez mais devastadoras. Acredita-se que, quando o profissional de saúde possui crenças e conhecimento adequados sobre controle e não cura, sobre disfunção, mas não necessariamente lesão, sobre dor e não necessariamente incapacidade, ele pode orientar os doentes a aderirem a programas educativos e de reabilitação. $O$ controle da dor e a restauração da função são objetivos alcançáveis ${ }^{112}$.

Em relação ao domínio dano físico (Tabela 6) em cerca de 63\% das respostas há o reconhecimento de que a dor não está relacionada a um "dano físico" e a média desse domínio foi de 1,2. Observa-se que $26 \%$ das respostas indicaram não haver opinião consolidada (nem verdadeiro e nem falso) e $11 \%$ referem-se à crença de que o exercício piora a dor, pois piora a lesão.

A crença de que a dor crônica advém de lesão tecidual, da existência de dano físico, é muitas vezes compartilhada por doentes e profissionais, apesar dos avanços teóricos que enfatizam a baixa correlação entre dor crônica e lesão 1, 2, 8, 34, 45, 62, 64, 73, 86, 105, 113 .

O modelo biomédico tradicional que focaliza o tratamento da dor crônica na descoberta e no alívio das lesões físicas, em que é preciso haver lesão visível responsável pela dor para que seja real e tratável, é ainda o mais compreendido e aceito pelos profissionais. Quando a causa da dor permanece desconhecida, a lesão não é identificada e o doente continua a 
se queixar, muitas vezes, este é estigmatizado como difícil e não cooperativo. Gradualmente, profissionais e doentes começam a lidar com o tratamento de modo suspeitoso. O profissional não acredita que o doente esteja sendo "preciso" e o doente tenta contar a sua historia de modo cada vez mais exacerbado, de modo a ser considerado ${ }^{96,112,113 .}$

Independentemente de haver lesão pode haver dor. Há inúmeros fatores que provocam a modificação de sistemas neurofisiológicos, como a própria dor e a experiência psicossocial. Os profissionais que não compreendem esse modelo tenderão a tratar o doente no modelo anatômico e biomédico, que busca a identificação e cura das lesões, freqüentemente por meio medicamentoso ou cirúrgico. No modelo biopsicossocial, o tratamento da dor crônica requer a compreensão de como os fatores físicos, psicológicos e sociais afetam a neurofisiologia da nocicepção, da percepção da dor, da modulação da dor, do sofrimento e do comportamento de dor ${ }^{1,79 \text {, }}$ 112,113

Acredita-se que módulos educacionais são necessários para que os profissionais de saúde compreendam os modelos de dor, os conceitos de dor aguda e dor crônica, para que o conhecimento científico disponível em pesquisas possa ser utilizado na prática clínica diária, favorecendo a mudança de atitudes e a adoção de comportamentos visando a melhor prática. Parece evidente que doentes com dor crônica e dor aguda são avaliados e tratados de forma equivocada devido à falta de atualização do conhecimento e à manutenção de crenças baseadas em pressupostos considerados falsos na atualidade.

Em relação ao domínio solicitude (Tabela 6 ) nota-se que a maioria das respostas indicaram crença de que a solicitude é desejável (50\% dos profissionais responderam acreditar que é responsabilidade de outros ajudar e ou cuidar das pessoas com dor crônica) e a média nesse domínio foi de 2,5. Há um índice importante de "sem opinião formada" (32\% mantiveram-se no ponto neutro) e apenas $18 \%$ indicaram não ser favorável à crença de solicitude. 
"Solicitude pode ser definida como atenção, atenção inquieta, cuidado constante, dedicação, consideração, zelo em prestar qualquer espécie de assistência"96.

Comportamentos de dor (aquilo que uma pessoa faz ou não, diz ou não para que outrem perceba que ela tem dor) para expressar o desconforto e receber ajuda dos familiares e dos profissionais é da natureza humana e varia de acordo com a cultura.

"Atenção e encorajamento são quase universalmente aceitos como tendo efeitos positivos sobre o sofrimento, adaptação à incapacidade e melhora da reabilitação de doentes crônicos. No entanto, na perspectiva cognitivo-comportamental, considera-se que a resposta de solicitude frente a comportamentos de dor funciona como reforço, o que poderá resultar em manutenção ou maior ocorrência na emissão dos comportamentos, maior incapacidade e dificuldade de ajustamento" ${ }^{96}$.

Comportamentos de solicitude fazem parte das relações humanas. Acolhem e reconfortam o outro em sofrimento. Procurar e oferecer acolhimento são comportamentos, até certo ponto, saudáveis. Talvez o mais importante seja perceber quando a solicitude passa a acarretar mais desajustes do que benefícios, a estimular a dependência e a manter a incapacidade. Na dor aguda, a solicitude é aceitável, considerando-se a curta duração do agravo, a necessidade de repouso e o imobilismo devido à presença de lesão. No caso de dor crônica, a excessiva solicitude acentua o grau de dependência, a incapacidade e o desajustamento social. Profissionais que julgam ser a solicitude altamente desejável podem estimular maior dependência e incapacidade. Estabelecer relação positiva de equilíbrio de poder com os profissionais de saúde, baseada no apoio mas não na dependência, na continência mas não na incapacidade, é muito importante para a funcionalidade dos doentes ${ }^{113}$.

No domínio cura médica (Tabela 6), em torno de $84 \%$ das respostas explicitaram a crença na cura para a dor crônica e a média foi de 
3,4. Mantiveram-se no ponto neutro $11 \%$ e apenas cerca de $5 \%$ das respostas indicaram não acreditar na cura para a dor crônica.

A crença na cura para a dor crônica chama bastante atenção. Segundo Gallangher ${ }^{112}$, "o fracasso na cura da dor crônica é um fracasso de conceituação que conduz a objetivos clínicos impossíveis e fora de alcance. Dor crônica não pode ser considerada como uma entidade causada por uma patologia que pode ser curada através de injeções, cirurgias, remédios, mas deve ser encarada como um processo neurofisiológico resultante de uma complexa interação de múltiplos sistemas, os quais, quando falham como um todo, levam a um controle deficitário da dor e à incapacidade funcional. O controle da dor e a restauração da função são objetivos alcançáveis que são seguramente medidos. A eliminação da dor por meio da cura do gerador original da dor raramente é alcançada, embora freqüentemente prometida".

Acreditar fortemente na cura para a dor crônica pode levar os profissionais de saúde a dar aos doentes falsas esperanças, expectativas irrealistas, dependência do sistema de saúde, tratamentos agressivos, cirurgias repetidas e até a fazê-los perder a oportunidade de continuar vivendo as suas vidas, apesar da dor. O modelo de tratamento da dor crônica deve ser de encorajar o doente a aceitar ter responsabilidade por sua dor e procurar reduzir comportamentos que a provocam ao invés de ficar à procura de cura.

Parece premente que os profissionais de saúde atualizem o conhecimento em relação à dor crônica para que possam orientar os doentes a não desperdiçarem suas vidas na busca desenfreada da cura.

Das seis crenças avaliadas entre os profissionais, quatro (emoção, controle, incapacidade e dano físico) foram "desejáveis", mas apenas duas (emoção e controle) foram fortemente desejáveis. As crenças solicitude e cura média foram indesejáveis. Os profissionais possuem conceitos corretos sobre algumas crenças, mas há outras que precisam ser ajustadas. 
Achava-se que algumas características dos entrevistados como profissão, nível de educação, idade e experiência com dor crônica, entre outras, poderiam ser associadas a conhecimento e crenças diversos, o que não ocorreu.

Para a identificação de diferenças na expressão de crenças entre os profissionais, foi feita a análise de cluster, considerando-se as variáveis idade, sexo, profissão, titulação, tipo de doente que o profissional mais atende (dor aguda, crônica, oncológica), número de doentes com dor crônica atendidos por mês e auto-avaliação da experiência com dor.

A análise de cluster (Tabela 9 e 10) não identificou diferenças nas crenças considerando-se os 3 agrupamentos (clusters) de profissionais, o que causou estranheza.

Poder-se-ia esperar que psicólogos e enfermeiros, mais afeitos às questões psicossociais, compreendessem melhor os benefícios e malefícios da solicitude, o que não ocorreu. Poder-se-ia também esperar que os médicos, mais preparados com relação ao conceito do que seja cura e mais familiarizados as respostas dos doentes com dor crônica ao tratamento, manifestassem menor crença na cura, o que também não ocorreu. Parece que os profissionais estão numa fase homogênea do conhecimento e ter maior ou menor educação assim como maior ou menor experiência em atender doentes com dor crônica não foi suficiente para atualizar conhecimento e modificar crenças que não estão de acordo com o conhecimento científico disponível. A literatura corrobora com esse achado e há diversos estudos que apontam que o conhecimento e atitudes dos profissionais de saúde ainda não estão em acordo com o conhecimento científico atual 1,13-14, 17, 22, 24, 27, 28, 62, 65, 70, 73-75, 79, 80, 82, 83, 105, 112, 115 .

É possível que cultura/ tradição/ jargão dos profissionais e das instituições "definam" e "mantenham" parte do modo de pensar e das crenças dos profissionais, o que talvez justifique a discrepância entre 0 
conhecimento construído por meio de pesquisas e a transferência dessas informações para a prática clínica. 
Conclusão 


\section{CONCLUSÃO}

Foi possível adaptar o modelo de crenças frente à dor crônica de doentes para profissionais. O Inventário de Atitudes frente à dor versão profissional foi validado com 20 itens, a análise fatorial confirmou 6 domínios (emoção, controle, incapacidade, solicitude, cura médica e dano físico) e a confiabilidade dos domínios, avaliada por meio do alfa de Cronbach, variou de 0,567 a 0,807, valores considerados moderados e bons. Disponibilizar instrumento para aferir crenças de profissionais sobre dor pode auxiliar na organização e avaliação de programas educativos.

Os profissionais mostraram crenças "fortemente desejáveis" nos domínios controle $(3,1)$ e emoção $(3,7)$ e "moderadamente desejáveis" nos domínios dano físico $(1,2)$ e incapacidade $(1,5)$; crença "fortemente não desejável" foi encontrada no domínio cura médica $(3,4)$ e "moderadamente não desejável” no domínio solicitude $(2,5)$. Há necessidade de se compreender o que determina as crenças indesejáveis, para que intervenções educativas e estratégias de re-conceituação de crenças sejam implementadas.

A comparação entre os clusters (médicos/pós-graduados, não médicos/ especializados/pouco experiente e graduados/ dor crõnica oncológica) não mostrou diferenças estatisticamente significantes, indicando que variáveis como profissão, sexo, idade, nível de escolaridade e de experiência, estranhamente, não influíram nas crenças dos profissionais frente à dor crônica. É possível que a "cultura/ jargões profissionais" sejam os responsáveis por essa semelhança.

Estudos que refinem o modelo de mensuração das crenças de profissionais de saúde frente à dor crônica e ampliem a compressão dos elementos que as determinam e mantêm são desejáveis. 
Referências Bibliográficas 


\section{REFERÊNCIAS BIBLIOGRÁFICAS}

1. McCaffery M, Pasero C. Assessment underlying complexities, misconception and pratical tools. In: . Pain clinical manual. $2^{\mathrm{a}}$ ed. St. Louis: Mosby, 1999. p.35-102.

2. Pimenta CAM. Dor: manual clínico de enfermagem. São Paulo: [s.n.]; 2000.

3. Pimenta CAM, Koizumi MS. Analgesia em câncer: crenças e atualização. Rev. Esc. Enf. USP. 1993;27:309-14.

4. Paice JA. Pain. In: McGuire DB, Yarbro $\mathrm{CH}$. Cancer pain management. $2^{\mathrm{a}}$ ed. Boston: Jones and Bartlett; 1995. p.100-25.

5. McCaffery M. Pain control: barries to the use of available information. Cancer. 1992;70:1438-49.

6. Ferrell BR, McGuirre DB, Donovan MI. Knowledge and beliefs regarding pain in a sample of nursing faculty. J Prof Nurs. 1993;9:79-88.

7. Teixeira MJ, ed. Dor no Brasil: estado atual e perspectivas. São Paulo: Limay; 1995. 195p.

8. Hamilton J, Edgar L. A survey examining nurses' knowledge of pain control. J Pain Symptom Manage. 1992;7:18-26.

9. Ferrel BR, McCaffery M, Rhiner M. Pain and addiction: an urgent need for change in nursing education. J Pain Symptom Manage. 1992;7:117-24.

10. Lee KF, Ray JB, Dunn GP. Chronic pain management and the surgeon: barries and opportunities. J Am Coll Surg. 2001;193:689-702.

11. Sinatra RS. Acute pain management and acute pain services. In: Cousins MJ; Bridenbaugh PO, eds. Neural blockade: in clinical anesthesia and management of pain. $3^{\text {a }}$ ed. Philadelphia: Raven Press; 1998. p.793-835

12. Kustaborder MJ, Degenhart ML. Workshop helps nurses develop pain management techniques. Health Prog 1984; 65:50-3.

13. Lander J. Fallacies and phobias about addiction and pain. Br J Addict 1990; 85:803-9.

14. Farre M, Badenas JM, Lamas X, Ugena B, Cami J. Tratamiento del dolor agudo en un hospital general: opiniones de medicos y enfermeras. Rev Clin Esp 1992; 190:152-6. 
15. Lavies N, Hart L, Rounsefell B, Runciman W. Identification of patient, medical and nursing staff attitudes to postoperative opioid analgesia: stage 1 of a longitudinal study of postoperative analgesia. Pain 1992; 48:313-9.

16. Brockopp DY, Warden S, Colclough G, Brockopp GW. Nursing knowledge: acute postoperative pain management in the elderly. J Gerontol Nurs 1993; 19:31-7.

17. Hiscock M. Complex reactions requiring empathy and knowledge. Psychological aspects of acute pain. Prof Nurse. 1993; 9:158-60.

18. Gould TH, Upton PM, Collins P. A survey of the intended management of acute postoperative pain by newly qualified doctors in the south west region of England in August 1992. Anaesthesia 1994; 49:807-10.

19. Dols C, Forker J, Lumm M, Huff I, Johnson M, Morrell C, Prunty N, Riehl K, Sabey M, Vail M. Enhancing nurses' reliance on patients' perceptions of pain during pain assessment: a comparison of two educational methods. $J$ Contin Educ Nurs. 1995; 26:209-13.

20. Knowles R. Standardization of pain management in the postanesthesia care unit.J Perianesth Nurs. 1996; 11:390-8.

21. Lebovits $A H$, Florence I, Bathina R, Hunko V, Fox MT, Bramble CY. Pain knowledge and attitudes of healthcare providers: practice characteristic differences. Clin J Pain. 1997; 13:237-43.

22. Heath DL. Nurses' knowledge and attitudes concerning pain management in an Australian hospital. Aust J Adv Nurs 1999; 16:15-8.

23. Fanurik D, Koh JL, Schmitz ML, Harrison RD, Roberson PK, Killebrew P. Pain assessment and treatment in children with cognitive impairment: a survey of nurses' and physicians' beliefs. Clin J Pain. 1999; 15:304-12.

24. Sjostrom B, Dahlgren LO, Haljamae H. Strategies in postoperative pain assessment: validation study. Intensive Crit Care Nurs 1999; 15:247-58.

25. Coyne ML, Reinert B, Cater K, Dubuisson W, Smith JF, Parker MM, Chatham C. Nurses' knowledge of pain assessment, pharmacologic and nonpharmacologic interventions. Clin Nurs Res 1999; 8:153-65.

26. Teixeira MJ, Fonoff ET, Lepski G, Marcon RM, Rocha RO. Dor noa tendiemnto em pronto socorro: avaliação do conhecimento da equipe de saúde sobre dor, analgesia e procedimentos prescritos para o controle. Rev Med (São Paulo) 1999; 78:359-63.

27. Mackintosh C, Bowles S. The effect of an acute pain service on nurses' knowledge and beliefs about post-operative pain. J Clin Nurs. 2000; 9:11926.

28. Pargeon $\mathrm{KL}$, Hailey BJ. Barriers to effective cancer pain management: a review of the literature. J Pain Symptom Manage. 1999; 18:358-68. 
29. Pritchard AP. Management of pain and nursing attitudes. Cancer Nurs 1988; 11:203-9.

30. Vainio A. Treatment of terminal cancer pain in Finland: a second look. Acta Anaesthesiol Scand. 1992; 36:89-95.

31. Ramos $\mathrm{CMH}$. Manejo da dor no câncer: conhecimentos do enfermeiro. [Dissertação]. Salvador: Escola de Enfermagem da Universidade Federal da Bahia; 1994.

32. Elliott TE, Murray DM, Oken MM, Johnson KM, Elliott BA, Post-White J. The Minnesota Cancer Pain Project: design, methods, and education strategies. J Cancer Educ 1995; 10:102-12.

33. von Gunten CF, von Roenn JH, Weitzman S. Housestaff training in cancer pain education. J Cancer Educ 1995; 9:230-4.

34. McCaffery M, Ferrell BR. Nurses' knowledge of pain assessment and management: how much progress have we made? J Pain Symptom Manage. $1997 ; 14: 175-88$.

35. Elliott TE, Murray DM, Elliott BA, Braun B, Oken MM, Johnson KM, PostWhite J, Lichtblau L. Physician knowledge and attitudes about cancer pain management: a survey from the Minnesota cancer pain project. J Pain Symptom Manage. 1995; 10:494-504.

36. Dalton JA, Blau W, Carlson J, Mann JD, Bernard S, Toomey T, Pierce S, Germino B. Changing the relationship among nurses' knowledge, selfreported behavior, and documented behavior in pain management: does education make a difference? J Pain Symptom Manage. 1996; 12:308-19.

37. Elliott TE, Murray DM, Oken MM, Johnson KM, Braun BL, Elliott BA, PostWhite J. Improving cancer pain management in communities: main results from a randomized controlled trial. J Pain Symptom Manage. 1997; 13:191203.

38. Ferrell BR, McCaffery M. Nurses' knowledge about equianalgesia and opioid dosing. Cancer Nurs. 1997; 20:201-12.

39. Mortimer JE, Bartlett NL. Assessment of knowledge about cancer pain management by physicians in training. J Pain Symptom Manage. 1997; $14: 21-8$.

40. de Schepper AM, Francke AL, Abu-Saad HH. Feelings of powerlessness in relation to pain: ascribed causes and reported strategies. A qualitative study among Dutch community nurses caring for cancer patients with pain. Cancer Nurs 1997; 20:422-9.

41. Mystakidou K, Liossi C, Fragiadakis K, Georgaki S, Papadimitriou J. What do Greek physicians know about managing cancer pain? J Cancer Educ 1998; 13:39-42. 
42. Dalton JA, Carlson J, Mann JD, Blau W, Bernard S, Youngblood R. An examination of nursing attitudes and pain management practices. Cancer Pract. 1998; 6:115-24.

43. Furstenberg CT, Ahles TA, Whedon MB, Pierce KL, Dolan M, Roberts L, Silberfarb PM. Knowledge and attitudes of health-care providers toward cancer pain management: a comparison of physicians, nurses, and pharmacists in the state of New Hampshire. J Pain Symptom Manage 1998; 15:335-49.

44. Hines C, Bingham J, Muirden N, Beavis M. Cancer pain management. Improving knowledge and patient care. Aust Fam Physician 1998; 27 Suppl 2:S66-9.

45. Sapir R, Catane R, Strauss-Liviatan N, Cherny NI. Cancer pain: knowledge and attitudes of physicians in Israel. J Pain Symptom Manage 1999; 17:26676.

46. Devulder J. Persisting misconceptions of Belgian physicians and nurses about cancer pain treatment. Acta Clin Belg 1999; 54:346-50.

47. Balneaves LG, Hershon L, Allen K. Nursing challenges in cancer pain assessment and management: setting an agenda for the CANO Pain Initiative. Can Oncol Nurs J 1999; 9:121-3, 126-31.

48. Hovi SL, Lauri S. Patients' and nurses' assessment of cancer pain. Eur J Cancer Care (Engl) 1999; 8:213-9.

49. Howell D, Butler L, Vincent L, Watt-Watson J, Stearns N. Influencing nurses' knowledge, attitudes, and practice in cancer pain management. Cancer Nurs 2000; 23:55-63.

50. McMillan SC, Tittle M, Hagan S, Laughlin J, Tabler RE. Knowledge and attitudes of nurses in veterans hospitals about pain management in patients with cancer. Oncol Nurs Forum 2000; 27:1415-23.

51. Ger LP, Ho ST, Wang JJ. Physicians' knowledge and attitudes toward the use of analgesics for cancer pain management: a survey of two medical centers in Taiwan. J Pain Symptom Manage 2000; 20:335-44.

52. McCaughan E, Parahoo K. Medical and surgical nurses' perceptions of their level of competence and educational needs in caring for patients with cancer. J Clin Nurs 2000; 9:420-8.

53. Manworren RC. Pediatric nurses' knowledge and attitudes survey regarding pain. Pediatr Nurs. 2000; 26:610-4.

54. Yu S, Wang XS, Cheng Y, Yang J, Cleeland CS. Special aspects of cancer pain management in a Chinese general hospital. Eur J Pain 2001;5 Suppl $\mathrm{A}: 15-20$. 
55. Wells $M$, Dryden $H$, Guild $P$, Levack $P$, Farrer K, Mowat $P$. The knowledge and attitudes of surgical staff towards the use of opioids in cancer pain management: can the Hospital Palliative Care Team make a difference? Eur J Cancer Care (Engl) 2001; 10:201-11.

56. Lasch K, Greenhill A, Wilkes G, Carr D, Lee M, Blanchard R. Why study pain? A qualitative analysis of medical and nursing faculty and students' knowledge of and attitudes to cancer pain management. J Palliat Med 2002; 5:57-71.

57. Barclay S, Todd C, Grande G, Lipscombe J. Controlling cancer pain in primary care: the prescribing habits and knowledge base of general practitioners. J Pain Symptom Manage. 2002; 23:383-92.

58. Meraviglia MG, McGuire C, Chesley DA. Nurses' needs for education on cancer and end-of-life care. J Contin Educ Nurs. 2003; 34:122-7.

59. Lai YH, Chen ML, Tsai LY, Lo LH, Wei LL, Hong MY, Hsiu LN, et al. Are nurses prepared to manage cancer pain? A national survey of nurses' knowledge about pain control in Taiwan. J Pain Symptom Manage. 2003; 26:1016-25.

60. Ger LP, Lee MC, Wong CS, Chao SS, Wang JJ, Ho ST. The effect of education and clinical practice on knowledge enlightenment to and attitudes toward the use of analgesics for cancer pain among physicians and medical students. Acta Anaesthesiol Sin. 2003; 41:105-14.

61. Vallerand AH, Riley-Doucet C, Hasenau SM, Templin T. Improving cancer pain management by homecare nurses. Oncol Nurs Forum 2004; 31:809-16.

62. Clarke EB, French B, Bilodeau ML, Capasso VC, Edwards A, Empoliti J. Pain management knowledge, attitudes and clinical practice: the impact of nurses' characteristics and education. J Pain Symptom Manage. 1996;11:18-31. 
63. Yeng LT, Teixeira MJ, Stump P, Kaziyama HHS, Barboza HFG. Medicina física e reabilitação em doentes com dor crônica. In: Teixeira MJ, Figueiró JAB. Dor: epidemiologia, fisiopatologia, avaliação, síndromes dolorosas e tratamento. São Paulo: Moreira Jr; 2001. p. 131-40.

64. Brunier G, Carson MG, Harrison DE. What do the nurses know and believe about patients with pain? Results of a hospital survey. J Pain Symptom Manage. 1995;10:436-45.

65. Rainville J, Bagnall D, Phalen L. Health care providers' attitudes and beliefs about functional impairments and chronic back pain. Clin J Pain. 1995;11:287-95.

66. Dixon BA. Institutional survey of nurse anesthesia practice in patients receiving opioids via patient-controlled analgesia. Nurse Anesth 1993; 4:1127.

67. Glaros AG, Glass EG, McLaughlin L. Knowledge and beliefs of dentists regarding temporomandibular disorders and chronic pain. J Orofac Pain 1994; 8:216-22.

68. Turk DC, Brody MC, Okifuji EA. Physicians' attitudes and practices regarding the long-term prescribing of opioids for non-cancer pain. Pain. 1994; 59:2018.

69. Closs SJ. Pain and elderly patients: a survey of nurses' knowledge and experiences. J Adv Nurs 1996; 23:237-42.

70. Tornkvist L, Gardulf A, Strender LE. The opinions of district nurses regarding the knowledge, management and documentation of patients with chronic pain. Scand J Caring Sci 1998; 12:146-53.

71. Greenwald BD, Narcessian EJ, Pomeranz BA. Assessment of physiatrists' knowledge and perspectives on the use of opioids: review of basic concepts for managing chronic pain. Am J Phys Med Rehabil 1999; 78:408-15.

72. Weinstein SM, Laux LF, Thornby JI, Lorimor RJ, Hill CS Jr, Thorpe DM, Merrill JM. Medical students' attitudes toward pain and the use of opioid analgesics: implications for changing medical school curriculum. South Med J 2000; 93:472-8.

73. Weinstein SM, Laux LF, Thornby JI, Lorimor RJ, Hill CS Jr, Thorpe DM, Merrill JM. Physicians' attitudes toward pain and the use of opioid analgesics: results of a survey from the Texas Cancer Pain Initiative. South Med J 2000; 93:479-87.

74. Rainville J, Carlson N, Polatin P, Gatchel RJ, Indahl A. Exploration of physicians' recommendations for activities in chronic low back pain. Spine 2000; 25:2210-20. 
75. Potter M, Schafer S, Gonzalez-Mendez E, Gjeltema K, Lopez A, Wu J, Pedrin $\mathrm{R}$, et al. Opioids for chronic nonmalignant pain. Attitudes and practices of primary care physicians in the UCSF/Stanford Collaborative Research Network. University of California, San Francisco. J Fam Pract 2001; 50:14551.

76. Li LC, Bombardier C. Physical therapy management of low back pain: an exploratory survey of therapist approaches. Phys Ther. 2001; 81:1018-28.

77. Alley LG. The influence of an organizational pain management policy on nurses' pain management practices. Oncol Nurs Forum. 2001; 28:867-74.

78. Weiner DK, Rudy TE. Attitudinal barriers to effective treatment of persistent pain in nursing home residents. J Am Geriatr Soc 2002; 50:2035-40.

79. Moseley L. Unraveling the barriers to reconceptualization of the problem in chronic pain: the actual and perceived ability of patients and health professionals to understand the neurophysiology. J Pain 2003; 4:184-9.

80. Tornkvist L, Gardulf A, Strender LE. Effects of 'pain-advisers': district nurses' opinions regarding their own knowledge, management and documentation of patients in chronic pain. Scand J Caring Sci 2003; 17:332-8.

81. Latimer J, Maher C, Refshauge K. The attitudes and beliefs of physiotherapy students to chronic back pain. Clin J Pain. 2004; 20:45-50.

82. Tarzian AJ, Hoffmann DE. Barriers to managing pain in the nursing home: findings from a statewide survey. J Am Med Dir Assoc. 2004; 5:82-8.

83. Daykin AR, Richardson B. Physiotherapists' pain beliefs and their influence on the management of patients with chronic low back pain. Spine 2004; 29:783-95.

84. Grahmann PH, Jackson KC 2nd, Lipman AG. Clinician beliefs about opioid use and barriers in chronic nonmalignant pain. J Pain Palliat Care Pharmacother. 2004; 18:7-28.

85. Brown CA, Richardson C. Nurses' in the multi-professional pain team: a study of attitudes, beliefs and treatment endorsements. Eur J Pain. 2006;10:13-22.

86. Ponte CD, Johnson-Tribino J. Attitudes and knowledge about pain: an assessment of West Virginia family physicians. Fam Med. 2005;37:477-80.

87. Schrader SL, Nelson ML, Halbritter S, Eidsness L. South Dakota pain surveys: results from 2001. S D J Med. 2005;58:423-31.

88. Le Blon G. As opiniões e as crenças. [citado 22 junho 2006]. Disponível em: http://www.ateus.net/artigos/psicologia/as_opinioes_e_as_crencas.php.

89. Wright LM, Watson WL, Bell JM. Beliefs: many lenses, many explanations. In> _. Beliefs: the heart of healing in families and illness. New York: BasicBooks; 1996. p.19-43. 
90. Beck JS. Terapia cognitiva: teoria e prática. Porto Alegre: Artes Médicas; 1997. p.30.

91. Pimenta CAM, Portnoi AG. Dor e cultura. In: Carvalho MMMJ, organizador. Dor: um estudo multidisciplinar. São Paulo: Summus; 1999. p. 159-73.

92. Lobato O. O problema da dor. In: Mello Filho J. psicossomática hoje. Porto Alegre: Artes Médicas; 1992. p.165-74.

93. Bonica JJ. History of pain concepts and therapies. In: of pain. $2^{\text {nd }}$ ed. Philadelphia: Lea \& Febiger; 1990. p.2-17. The management

94. Teixeira MJ, Marcon RM, Rocha RO, Figueiró JAB. Epidemiologia da dor. In: Teixeira MJ, Figueiró JAB. Dor: epidemiologia, fisiopatologia, avaliação, síndromes dolorosas e tratamento. São Paulo: Moreira Jr; 2001. p. 1-7.

95. Melzak R, Wall PD. Pain mechanisms: a new theory. Science 1965; 50:9719.

96. Pimenta CAM. Atitudes de doentes com dor crônica frente à dor [Tese]. São Paulo: Universidade de São Paulo; 1999.

97. Pimenta CAM, Teixeira MJ. Considerações iniciais sobre a dor no câncer e seu controle. Rev Med São Paulo 1997; 76:3-6.

98. Calil AM, Pimenta CAM. Intensidade da dor e adequação de analgesia. Rev Latin-Am Enferm. 2005; 13:692-9.

99. American Pain Society. Classification of pain. In: __. Pain: current understanding of assessment, management and treatments. [Acesso 5 maio 2005]. Disponível em: http://www.ampainsoc.org/ce/npc/index.htm.

100. Bonica JJ, Ventafridda V, Twycross RG. In: Bonica JJ. The management of pain. $2^{\text {nd }}$ ed. Philadelphia: Lea \& Febiger; 1990. p.400-60.

101. Pimenta CAM. Aspectos culturais, afetivos e terapêuticos relacionados à dor no câncer [tese]. São Paulo (SP): Universidade de São Paulo; 1995.

102. Rosseto EG. Dor recorrente em escolares na cidade de Londrina: prevalência, caracterização e impacto nas atividades diárias. (Dissertação) São Paulo: Escola de enfermagem da Universidade de São Paulo; 2000.

103. Kreling MCGD. Prevalência de dor crônica em adultos trabalhadores. (Dissertação) São Paulo: Escola de Enfermagem da Universidade de São Paulo; 2000.

104. Dellaroza MSG. Prevalência e caracterização da dor crônica em idosos servidores municipais de Londrina-PR [Dissertação]. São Paulo: Escola de Enfermagem da Universidade de São Paulo; 2000. 
105. Loder E, Witkower A, McAlary P, Huhta M, Matarrazzo J. Rehabilitation hospital staff knowledge and attitudes regarding pain. Am J Phys Med Rehabil. 2003; 82:65-8.

106. Pimenta CAM. Dor crônica, terapia cognitiva comportamental e o enfermeiro. Rev Psiquiatr Clin (São Paulo). 2001;28:288-94.

107. Pimenta CAM, Cruz DALM. Crenças em dor crônica: validação do inventário de atitudes frente à dor para a língua portuguesa. Rev Esc Enferm USP. 2006;40(3):prelo.

108. Tait RC, Chibnall JT. Developmental of a brief version of the Survey of Pain Attitudes. Pain 1997; 70:229-35.

109. Castro AB. As clínicas de tratamento de dor no Brasil. In: _. Tratamento da dor no Brasil: evolução histórica. Curitiba: Editora Maio; 1999. p.74-98.

110. Kline P. Na easy guide to factor analysis. London: Routledge; 2000.

111. Bowling A. Measuring disease: a review of disease-specific quality of life measurement scales. Philadelphia: Open University Press; 1995. p.292.

112. Gallagher RM. Planejamento terapêutico em medicina da dor. Clin Med Am North. 1999;83:771-96.

113. Shaw SM. Nursing and supporting patients with chronic pain. Nurs Stand. 2006;20:60-5.

114. Baptista CMA, Ebel R, Fortes S. Grupoterapia e dor crônica. In: Figueiró JAB, Angelotti G, Pimenta CAM. Dor e saúde mental. São Paulo: Atheneu; 2005. cap.17, p.167-79.

115. Figueiró JAB, Angelotti G, Pimenta CAM. Dor e saúde mental. São Paulo: Atheneu; 2005. Prefácio.

116. Jensen MP, Karoly $P$, Huger R. The development and preliminary validation of an instrument to assess patient's attitudes toward pain. J. Psychosomatic Res. 1987; 31(3):393-400. 


\section{ANEXO 1 \\ TERMO DE CONSENTIMENTO PÓS-ESCLARECIDO}

\section{I - DADOS DE IDENTIFICAÇÃO DO SUJEITO DA PESQUISA}

1. NOME:

DOCUMENTO DE IDENTIDADE $\mathrm{N}^{\circ}$ : SEXO:.$M \quad F$

DATA NASCIMENTO:

ENDEREÇO

$\mathrm{N}^{\circ}$ APTO:

BAIRRO: CIDADE

CEP: TELEFONE: DDD

\section{II - DADOS SOBRE A PESQUISA CIENTÍFICA}

1. TÍTULO DO PROTOCOLO DE PESQUISA: Crenças sobre dor crônica entre profissionais da saúde. PESQUISADORA 1: Dayse Maioli Garcia

Profissão: Enfermeira INSCRIÇÃO CONSELHO REGIONAL No: 14660

PESQUISADORA 2: Cibele Andrucioli de Mattos Pimenta

Profissão: Enfermeira INSCRIÇÃO CONSELHO REGIONAL No: 15582

2. AVALIAÇÃO DO RISCO DA PESQUISA:

- SEM RISCO

๑ RISCO MÍNIMO

๑ RISCO MÉDIO

$\square$ RISCO BAIXO $\quad \square$ RISCO MAIOR

(probabilidade de que o indivíduo sofra algum dano como conseqüência imediata ou tardia do estudo)

3. DURAÇÃO DA PESQUISA : 


\section{III - REGISTRO DAS EXPLICAÇÕES DO PESQUISADOR AO PROFISSIONAL DE SAUDE SOBRE A PESQUISA, CONSIGNANDO:}

1. justificativa e os objetivos da pesquisa; 2. procedimentos que serão utilizados e propósitos, incluindo a identificação dos procedimentos; $\mathbf{3}$. desconfortos e riscos esperados; 4 . benefícios que poderão ser obtidos; 5. procedimentos alternativos que possam ser vantajosos para o indivíduo. Estou realizando um trabalho que tem por objetivo identificar as crenças sobre dor crônica em profissionais de saúde que atendem doentes com dor crônica. Para isto, gostaria de contar com a sua participação. Será necessário que você responda a dois questionários, um de caracterização pessoal e outro denominado Inventário de Atitudes frente a Dor para profissionais de saúde. Esse questionário terá perguntas sobre suas crenças em relação à dor crônica não oncológica.O tempo necessário para responder os questionários é em torno de vinte minutos. As informações são confidenciais e utilizadas apenas para fins científicos. Será garantido o anonimato de suas respostas. $O(A)$ senhor(a) gostaria de fazer alguma pergunta?

\section{IV - ESCLARECIMENTOS DADOS PELO PESQUISADOR SOBRE GARANTIAS DO SUJEITO DA PESQUISA:}

1. Acesso, a qualquer tempo, às informações sobre procedimentos, riscos e benefícios relacionados à pesquisa, inclusive para dirimir eventuais dúvidas. SIM

2. Liberdade de retirar seu consentimento a qualquer momento e de deixar de participar do estudo, sem que isto lhe traga prejuízos. SIM

3. Salvaguarda da confidencialidade, sigilo e privacidade. SIM

\section{V - INFORMAÇÕES DE NOMES E TELEFONES DOS RESPONSÁVEIS PELO ACOMPANHAMENTO DA PESQUISA, PARA CONTATO EM CASO DE INTERCORRÊNCIAS CLÍNICAS E REAÇÕES ADVERSAS.}

Dayse Maioli Garcia - celular (11)9614-1004

Cibele Andrucioli de Mattos Pimenta - comercial (11)30667547

\section{VI - OBSERVAÇÕES COMPLEMENTARES:}

A realização desta pesquisa é interesse dos profissionais desta área, visto que não há na literatura, descrição satisfatória desse assunto.

\section{VII - CONSENTIMENTO PÓS-ESCLARECIDO}

Declaro que, após convenientemente esclarecido pelo pesquisador e ter entendido o que me foi explicado, consinto em participar do presente Protocolo de Pesquisa. 
ANEXO 2

\begin{tabular}{|c|c|}
\hline \multicolumn{2}{|c|}{ IDENTIFICAÇÃO PESSOAL } \\
\hline Idade: & Sexo: ( )Feminino ( )Masculino \\
\hline \multirow{2}{*}{\multicolumn{2}{|c|}{$\begin{array}{l}\text { Profissão: } \\
\text { Maior titulação: }\end{array}$}} \\
\hline & \\
\hline \multicolumn{2}{|c|}{ Local de trabalho: } \\
\hline \multicolumn{2}{|c|}{ Ano de graduação: } \\
\hline \multirow{4}{*}{\multicolumn{2}{|c|}{$\begin{array}{l}\text { Com que tipo de doentes você trabalha? } \\
\text { Dor aguda ( )maioria ( ) mediano ( ) poucos doentes } \\
\text { Dor crônica oncológica ( )maioria ( ) mediano ( ) poucos doentes } \\
\text { Dor crônica não oncológica ( )maioria ( ) mediano ( ) poucos doentes }\end{array}$}} \\
\hline & \\
\hline & \\
\hline & \\
\hline \multicolumn{2}{|c|}{ Como você classifica sua experiência com doente com dor crônica? } \\
\hline \multicolumn{2}{|l|}{ ( ) muito experiente } \\
\hline \multicolumn{2}{|l|}{ ( ) mediano experiente } \\
\hline \multicolumn{2}{|l|}{ ( ) pouco experiente } \\
\hline \multicolumn{2}{|l|}{ ( ) nenhuma experiência } \\
\hline \multicolumn{2}{|c|}{ Como você adquiriu conhecimento sobre dor crônica? } \\
\hline \multicolumn{2}{|c|}{ ( ) eventos científicos (congressos, simpósios, palestras) } \\
\hline \multicolumn{2}{|l|}{ ( ) cursos de dor } \\
\hline \multicolumn{2}{|c|}{ ( ) leituras (livros, artigos e periódicos) } \\
\hline \multicolumn{2}{|l|}{ ( ) Outros. Quais? } \\
\hline \multicolumn{2}{|c|}{ Quantos pacientes com dor crônica você estima ter atendido no último mês? } \\
\hline \multicolumn{2}{|l|}{ ( ) entre 1 e 5 doentes } \\
\hline \multicolumn{2}{|l|}{ ( ) entre 6 e 10 doentes } \\
\hline \multicolumn{2}{|l|}{ ( ) entre 11 e 20 doentes } \\
\hline ( ) mais de 21 doentes & \\
\hline
\end{tabular}




\section{ANEXO 3 \\ Inventário de Atitudes Frente à Dor para profissionais de saúde pré-teste}

Considerando que você é profissional de saúde que atua na área de dor crônica, escolha as alternativas que mais se aplicam ao que você acredita sobre DOR CRÔNICA NÃO ONCOLÓGICA.Você acredita que:

\begin{tabular}{|c|c|c|c|c|c|c|}
\hline & & $\begin{array}{l}\text { Totalmente } \\
\text { Falso }\end{array}$ & $\begin{array}{l}\text { Quase } \\
\text { Falso }\end{array}$ & $\begin{array}{l}\text { Nem verdadeiro } \\
\text { Nem Falso }\end{array}$ & $\begin{array}{c}\text { Quase } \\
\text { Verdadeiro }\end{array}$ & $\begin{array}{l}\text { Totalmente } \\
\text { Verdadeiro }\end{array}$ \\
\hline 1 & $\begin{array}{l}\text { Muitas vezes o doente consegue influenciar a } \\
\text { intensidade da dor. }\end{array}$ & 0 & 1 & 2 & 3 & 4 \\
\hline 2 & $\begin{array}{l}\text { Provavelmente sempre se terá que utilizar } \\
\text { medicamentos para tratar dor crônica. }\end{array}$ & 0 & 1 & 2 & 3 & 4 \\
\hline 3 & $\begin{array}{l}\text { Sempre que alguém sente dor a família deve } \\
\text { tratá-lo melhor. }\end{array}$ & 0 & 1 & 2 & 3 & 4 \\
\hline 4 & Não se deve esperar cura médica para a dor. & 0 & 1 & 2 & 3 & 4 \\
\hline 5 & $\begin{array}{l}\text { O maior alívio da dor que se tem é com uso } \\
\text { de medicamentos. }\end{array}$ & 0 & 1 & 2 & 3 & 4 \\
\hline 6 & A ansiedade aumenta a dor. & 0 & 1 & 2 & 3 & 4 \\
\hline 7 & $\begin{array}{l}\text { Sempre que alguém sente dor as pessoas } \\
\text { devem tratá-lo com cuidado e preocupação. }\end{array}$ & 0 & 1 & 2 & 3 & 4 \\
\hline 8 & $\begin{array}{l}\text { Deve-se desistir de buscar a completa } \\
\text { eliminação da dor pelo trabalho da medicina. }\end{array}$ & 0 & 1 & 2 & 3 & 4 \\
\hline 9 & $\begin{array}{l}\text { É responsabilidade dos que amam o doente, } \\
\text { ajudarem-no quando ele sente dor. }\end{array}$ & 0 & 1 & 2 & 3 & 4 \\
\hline 10 & O estresse aumenta a dor. & 0 & 1 & 2 & 3 & 4 \\
\hline 11 & $\begin{array}{l}\text { Exercício e movimento são bons para o } \\
\text { doente com dor. }\end{array}$ & 0 & 1 & 2 & 3 & 4 \\
\hline 12 & $\begin{array}{l}\text { Consegue-se diminuir a dor através da } \\
\text { concentração ou relaxamento. }\end{array}$ & 0 & 1 & 2 & 3 & 4 \\
\hline 13 & $\begin{array}{l}\text { Medicamentos são um dos melhores } \\
\text { tratamentos para a dor crônica. }\end{array}$ & 0 & 1 & 2 & 3 & 4 \\
\hline 14 & $\begin{array}{l}\text { A familia precisa aprender a lidar melhor do } \\
\text { doente quando ele está com dor. }\end{array}$ & 0 & 1 & 2 & 3 & 4 \\
\hline 15 & A depressão aumenta a dor. & 0 & 1 & 2 & 3 & 4 \\
\hline 16 & O exercício pode piorar ainda mais a dor. & 0 & 1 & 2 & 3 & 4 \\
\hline 17 & $\begin{array}{l}\text { Pode-se controlar a dor mudando-se os } \\
\text { pensamentos. }\end{array}$ & 0 & 1 & 2 & 3 & 4 \\
\hline 18 & $\begin{array}{l}\text { Muitas vezes, quando se está com dor, } \\
\text { precisa-se receber mais carinho que se está } \\
\text { recebendo. }\end{array}$ & 0 & 1 & 2 & 3 & 4 \\
\hline 19 & $\begin{array}{l}\text { A pessoa com dor tem algum problema físico } \\
\text { que a impede de fazer muito movimento ou } \\
\text { exercício. }\end{array}$ & 0 & 1 & 2 & 3 & 4 \\
\hline 20 & Pode-se aprender a controlar a dor. & 0 & 1 & 2 & 3 & 4 \\
\hline 21 & A medicina pode curar a dor. & 0 & 1 & 2 & 3 & 4 \\
\hline 22 & $\begin{array}{l}\text { Pode-se, com certeza, aprender a lidar com a } \\
\text { dor. }\end{array}$ & 0 & 1 & 2 & 3 & 4 \\
\hline 23 & $\begin{array}{l}\text { A dor não impede de se levar uma vida } \\
\text { fisicamente ativa. }\end{array}$ & 0 & 1 & 2 & 3 & 4 \\
\hline 24 & A dor física nunca será curada. & 0 & 1 & 2 & 3 & 4 \\
\hline 25 & $\begin{array}{l}\text { Há uma forte ligação entre as emoções e a } \\
\text { intensidade da dor. }\end{array}$ & 0 & 1 & 2 & 3 & 4 \\
\hline 26 & $\begin{array}{l}\text { A pessoa com dor pode fazer quase tudo que } \\
\text { fazia antes de ter dor }\end{array}$ & 0 & 1 & 2 & 3 & 4 \\
\hline 27 & $\begin{array}{l}\text { Se a pessoa com dor não fizer exercícios } \\
\text { regularmente a dor continuará a piorar. }\end{array}$ & 0 & 1 & 2 & 3 & 4 \\
\hline 28 & $\begin{array}{l}\text { A prática de exercícios pode diminuir a } \\
\text { intensidade da dor. }\end{array}$ & 0 & 1 & 2 & 3 & 4 \\
\hline 29 & $\begin{array}{l}\text { Não há procedimento médico que ajude na } \\
\text { dor. }\end{array}$ & 0 & 1 & 2 & 3 & 4 \\
\hline 30 & $\begin{array}{l}\text { A dor impede qualquer pessoa de levar uma } \\
\text { vida ativa. }\end{array}$ & 0 & 1 & 2 & 3 & 4 \\
\hline
\end{tabular}


ANEXO 4

Inventário de Atitudes Frente à Dor para profissionais de saúde

\begin{tabular}{|c|c|c|c|c|c|c|}
\hline & & $\begin{array}{l}\text { Totalmente } \\
\text { Falso } \\
\end{array}$ & $\begin{array}{l}\text { Quase } \\
\text { Falso }\end{array}$ & $\begin{array}{l}\text { Nem verdadeiro } \\
\text { Nem Falso }\end{array}$ & $\begin{array}{c}\text { Quase } \\
\text { Verdadeiro }\end{array}$ & $\begin{array}{l}\text { Totalmente } \\
\text { Verdadeiro } \\
\end{array}$ \\
\hline 1 & $\begin{array}{l}\text { Muitas vezes o doente consegue influenciar a } \\
\text { intensidade da dor. }\end{array}$ & 0 & 1 & 2 & 3 & 4 \\
\hline 2 & $\begin{array}{l}\text { Sempre que alguém sente dor a família deve tratá- } \\
\text { lo melhor. }\end{array}$ & 0 & 1 & 2 & 3 & 4 \\
\hline 3 & A ansiedade aumenta a dor. & 0 & 1 & 2 & 3 & 4 \\
\hline 4 & $\begin{array}{l}\text { Sempre que alguém sente dor as pessoas devem } \\
\text { tratá-lo com cuidado e preocupação. }\end{array}$ & 0 & 1 & 2 & 3 & 4 \\
\hline 5 & $\begin{array}{l}\text { É responsabilidade dos que amam o doente, } \\
\text { ajudarem-no quando ele sente dor. }\end{array}$ & 0 & 1 & 2 & 3 & 4 \\
\hline 6 & O estresse aumenta a dor. & 0 & 1 & 2 & 3 & 4 \\
\hline 7 & $\begin{array}{l}\text { Exercício e movimento são bons para o doente } \\
\text { com dor. }\end{array}$ & 0 & 1 & 2 & 3 & 4 \\
\hline 8 & $\begin{array}{l}\text { Consegue-se diminuir a dor através da } \\
\text { concentração ou relaxamento. }\end{array}$ & 0 & 1 & 2 & 3 & 4 \\
\hline 9 & A depressão aumenta a dor. & 0 & 1 & 2 & 3 & 4 \\
\hline 10 & O exercício pode piorar ainda mais a dor. & 0 & 1 & 2 & 3 & 4 \\
\hline 11 & $\begin{array}{l}\text { Pode-se controlar a dor mudando-se os } \\
\text { pensamentos. }\end{array}$ & 0 & 1 & 2 & 3 & 4 \\
\hline 12 & $\begin{array}{l}\text { Muitas vezes, quando se está com dor, precisa-se } \\
\text { receber mais carinho que se está recebendo. }\end{array}$ & 0 & 1 & 2 & 3 & 4 \\
\hline 13 & Pode-se, com certeza, aprender a lidar com a dor. & 0 & 1 & 2 & 3 & 4 \\
\hline 14 & $\begin{array}{l}\text { A dor não impede de se levar uma vida fisicamente } \\
\text { ativa. }\end{array}$ & 0 & 1 & 2 & 3 & 4 \\
\hline 15 & A dor física nunca será curada. & 0 & 1 & 2 & 3 & 4 \\
\hline 16 & $\begin{array}{l}\text { Há uma forte ligação entre as emoções e a } \\
\text { intensidade da dor. }\end{array}$ & 0 & 1 & 2 & 3 & 4 \\
\hline 17 & $\begin{array}{l}\text { A pessoa com dor pode fazer quase tudo que fazia } \\
\text { antes de ter dor }\end{array}$ & 0 & 1 & 2 & 3 & 4 \\
\hline 18 & $\begin{array}{l}\text { Se a pessoa com dor não fizer exercícios } \\
\text { regularmente a dor continuará a piorar. }\end{array}$ & 0 & 1 & 2 & 3 & 4 \\
\hline 19 & $\begin{array}{l}\text { A prática de exercícios pode diminuir a intensidade } \\
\text { da dor. }\end{array}$ & 0 & 1 & 2 & 3 & 4 \\
\hline 20 & Não há procedimento médico que ajude na dor. & 0 & 1 & 2 & 3 & 4 \\
\hline
\end{tabular}


ANEXO 5

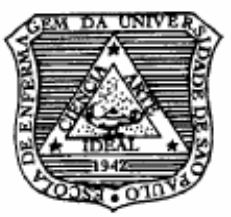

\author{
UNIVERSIDADE DE SÃO PAULO \\ ESCOLA DE ENFERMAGEM \\ Av. Dr. Enéas de Carvalho Aguiar, 419 - CEP 05403-000 \\ Z Fone.: 3066-7548 - Fax: : 280-8213 \\ C.P. 41633 - CEP 05422-970 - e-mail.; edipesq@usp.br
}

São Paulo, 12 de setembro de 2005.

Ilm. ${ }^{a} \mathrm{Sr}^{\mathrm{a}}$

Dayse Maioli Garcia

Ref.: Processo ${ }^{0}$ 462/2005/CEP-EEUSP

Prezada Senhora,

Em atenção à solicitação referente à análise do projeto "CRENÇAS SOBRE DOR CRÔNICA ENTRE PROFISSIONAIS DE SAÚDE”, informamos que o mesmo foi considerado aprovado pelo Comitê de Ética em Pesquisa da Escola de Enfermagem da Universidade de São Paulo (CEP/EEUSP).

Analisado sob o aspecto ético-legal, atende às exigências da Resolução nº 196/96 do Conselho Nacional de Saúde.

Esclarecemos que após o término da pesquisa, os resultados obtidos deverão ser encaminhados ao CEP/EEUSP, para serem anexados ao processo.

Atenciosamente,

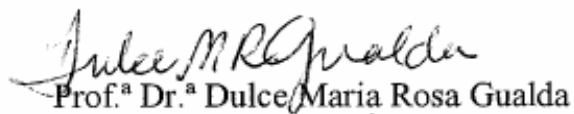

Coordenadora do Comitê de Ética em Pesquisa da

Escola de Enfermagem da Universidade de São Paulo 
ANEXO 6

\begin{tabular}{|c|c|}
\hline MFN: 0530 & PROPES.MST \\
\hline $\begin{array}{l}\text { Num. do Protocolo: } \\
\text { Data de Entrada: } \\
\text { Autor Responsavel: } \\
\text { Autores: }\end{array}$ & $\begin{array}{l}00530200608 \\
14 \text { / } 02 \text { / } 2006 \\
\text { Dayse Maioli Garcia (Garcia DM) } \\
\text { Dayse Maioli Garcia (Garcia DM) } \\
\text { Cibele Andrucioli de Mattos Pimenta (Pimenta CADM) }\end{array}$ \\
\hline $\begin{array}{l}\text { Linha de Pesquisa: } \\
\text { Titulo do Projeto: } \\
\text { Descriçäo: }\end{array}$ & $\begin{array}{l}\text { Humanização e aspectos éticos da assistência à criança e ao adolescente. } \\
\text { Crenças sobre dor crônica entre profissionais de saúde. } \\
\text { O trabalho tem por objetivo identificar as crenças sobre dor crônica em } \\
\text { profissionais de saúde que atendem doentes com dor crônica, através de } \\
\text { questionário, denominado Inventário de Atitudes frente a Dor, para profissionais } \\
\text { de saúde. Esse questionário terá perguntas sobre as crenças dos profissionais de } \\
\text { saúde em relaçäo à dor crônica não oncológica. (DE OUTRA ÁREA) }\end{array}$ \\
\hline $\begin{array}{l}\text { Tipo: } \\
\text { Unidade(s) Executora(s): }\end{array}$ & $\begin{array}{l}\text { Pesquisa teórica } \\
\text { Ambulatório de Neurologia / Dor } \\
\text { Ambulatório de Dor do Departamento de Pediatria }\end{array}$ \\
\hline $\begin{array}{l}\text { Prazo Inicio: } \\
\text { Prazo Termino: } \\
\text { Chefia de Area: } \\
\text { Comissão de Pesquisa: } \\
\text { Relator Comissão: } \\
\text { Tipo: }\end{array}$ & $\begin{array}{l}\text { 01/04/2006 } \\
07 / 04 / 2006 \\
\text { Exeqüivel Silvia Maria de Macedo Barbosa 10/02/2006 } \\
\text { Aprovado Magda Maria Sales Carneiro Sampaio 24/05/2006 } \\
\text { Aprovado Alexander Roberto Precioso 23/05/2006 } \\
\text { Dissertação de Mestrado - Área Técnica }\end{array}$ \\
\hline
\end{tabular}


ANEXO 7

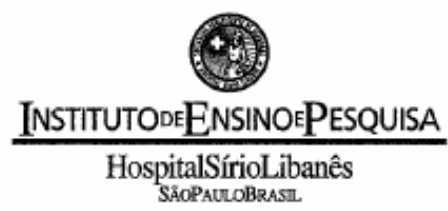

São Paulo, 14 de Setembro de 2005.

Ilma. Enf. Dayse Maioli Garcia

Pesquisadora Responsável

Registro CEPesq: HSL2005/23

Pesquisa: "Crenças sobre dor crônica entre profissionais de saúde".

Prezada Pesquisadora,

O Comitê de Ética em Pesquisa do Hospital Sírio Libanês analisou e APROVOU o protocolo de pesquisa acima citado, na reunião realizada em 14 de setembro de 2005, bem como o Termo de Consentimento Livre e Esclarecido a ser assinado pelo paciente, de acordo com a Resolução CNS 196/96, complementadas pela Resolução 251/97 do Ministério da Saúde.

De acordo com o cumprimento da Resolução 251/97, o Comitê de Ética em Pesquisa (CEPesq), deverá receber relatórios semestrais sobre o andamento do Estudo.

Atenciosamente,

Dr. Orlando Parise Junior

Coordenador do Comitê de Ética em Pesquisa - CEPesq

Sociedade Beneficente Hospital Sírio Libanês

R. Cel. Nicolau dos Santos, 69 Bela Vista São Paulo SP CEP 01308-060 Tel 11 3155-1145/3155-1146 Fax 11 3155-0494 iep@hsl.org.br wwrw.ephsLorg.br 
ANEXO 8

\section{HOSPITAL ALEMÃO \\ OSWALDO CRUZ}

\section{PROTOCOLO DE PESQUISA N. ${ }^{\circ} 015 / 05$ \\ Data de entrada: $19 / 09 / 05$ \\ PARECER do CEP N..$^{\circ} .015 .05$ \\ Data do parecer: $29 / 11 / 05$}

\section{Parecer Consubstanciado}

Título da Pesquisa: "Crenças sobre dor crônica entre profissionais de saúde"

Pesquisador Principal: Enf" Dayse Maioli Garcia

O projeto foi considerado aprovado em 28 de novembro de 2005 , após recebimento e análise das solicitações / esclarecimentos que haviam sido encaminhados à pesquisadora.

(X) APROVADO

( ) APROVADO COM RECOMENDAÇÕES

( ) NÃO APROVADO

( ) COM PENDÊNCIAS - OBS.: a ausência de resposta em 30 dias, acarretará em arquivamento do processo por falta de interesse do pesquisador.

TEMÁTICA ESPECIAL

CONEP

SVS (SECRETARIA DE VIGILÂNCIA SANITÁRIA)
$\operatorname{SIM(~)~NÃO~(X)~}$

$\operatorname{SIM(})$ NÃO (X)

$\operatorname{SIM(~)~NĀO(X)}$

Lembramos aos pesquisadores a necessidade de relatórios semestrais, relatório final e manter o CEP - HAOC informado de toda "alteração" ou "emenda" ao referido projeto, e de todo e qualquer efeito adverso.

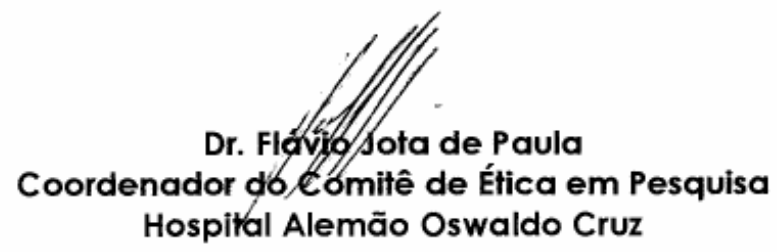




\section{ANEXO 9}

19. Parecer da Comissão de Pesquisa e/ou de Ética do Departamento da FMUSP ou da entidade envolvida.

1- O projeto é relevante e tem planejamento adequado? ( $)$ sim （） não

2- Há restrições quanto a aspectos éticos? （ ) sim (メ) não

3- Há participação direta e explícita de membros do Departamento e/ou Divisão de Neurologia? ( $)$ sim () não

4- Parecer favorável da Comissão de Pesquisa e Ética do Departamento de Neurologia da FMUSP? (メ) sim ( ) não

20. Conselho de Departamegntodia FMUSP

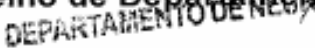

Prof. DR.MLBERTO SCAI:
Chete do Departamento

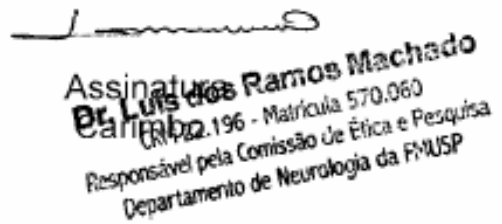

Aprovado em $26 / 09 / 2005$

21. Parecer do Serviço de Verificação de Óbitos da Capital-SVOC, no caso de pesquisas realizadas em peças anatômicas de cadáveres necropsiados naquele Serviço.

Assinatura

Aprovado em

Carimbo

tsc. 


\section{ANEXO 10}

SECRETARIA DE ESTADO DA SAÚDE INSTITUTO DE ASSISTÊNCIA MÉDICA AO SERVIDOR PÚBLICO ESTADUAL Comitê de Ética em Pesquisa - Rua: Pedro de Toledo, $1800-3^{\circ}$ andar - sl. 348 - SP Fones: 5088-8175/ 5088-8747 - FAX: 5088-8175 - E-mail= wpiamsic iq,eoxi.h

\section{CARTA DE APROVAÇÃO}

O Comitê de Ética em Pesquisa aprova sem restrições o Protocolo de Pesquisa, bem como o Termo de Consentimento Livre e Esclarecido registrado e arquivado junto ao CEP/LAMSPE sob o $\mathrm{n}^{\circ} \mathbf{0 8 3} / \mathbf{0 5}$.

Ref.: "Crenças sobre dor crônica entre profissionais de saúde".

Pesquisador responsável: Dayse Maioli Garcia

Serviço: Enfermagem

São Paulo, 31 de janeiro de 2006.

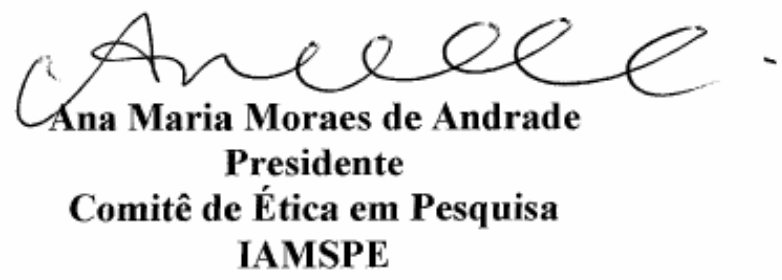




\section{ANEXO 11}

\section{CEMTOO DE TLATAMENTO E' PBSOUISA \\ HOSPIN Do cancen}

Săs paub, 26 de outubro de 2005.

A

Ent. Diryes Maloll Garcia

Ref.: Projato de Pesquisa n. $735 / 05$

"Crences sobre dor cronica em profissionals de saúde"

Prezada Senhora:

Os membros da Comissão de Éttca em Pesqulsa (CEP) do Hospital do Câncer em

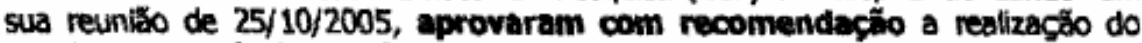
estudo em referencicia, conforme parecer consubstanciado em anexo.

A resposta deverá ser encaminhada à Diretoria Clinica (CEP), 15 dias antes de proxima reunibo.

Atenciosamente,

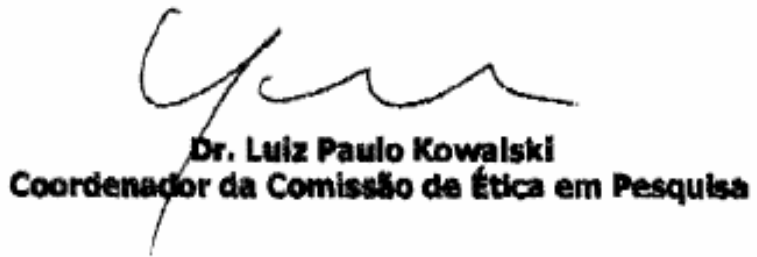

C.S.

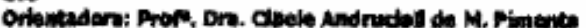

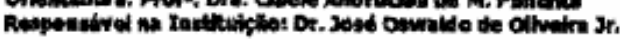



Referências Bibliográficas 103 